\title{
Comentarios en torno a las dos llegadas de Escipión a Numancia: deconstruyendo a Schulten
}

\author{
Comments about Scipio's two \\ arrivals in Numantia: \\ deconstructing Schulten
}

Fernando Morales Hernández

Universidad Complutense de Madrid.

E-mail: fmorales@ucm.es

Orcid ID: https://orcid.org/0000-0002-7756-1848

RECIBIDO: 23 DE MAYO DE 2020 ACEPTADO: 26 DE JUNIO DE 2020

Resumen: Se analizan las interpretaciones que hizo el profesor Adolf Schulten de algunos textos de la Iberiké de Apiano correspondientes a la guerra numantina, y que poco o nada tienen que ver con el relato del historiador alejandrino. Se trata de los pasajes referidos a las dos Ilegadas de Escipión Emiliano a Numancia: el primero tras endurecer y disciplinar al ejército, y el segundo después del periplo por tierras vacceas para iniciar los trabajos de asedio a la ciudad celtíbera. También se aportan nuestros comentarios alternativos.

Palabras Clave: Numancia; Publio Cornelio Escipión Emiliano; Apiano; Iberiké; Adolf Schulten.

\begin{abstract}
Analsys of the interpretations made by Professor Adolf Schulten regarding to some texts of Appian's Iberiké related to Numantia war and that have little or nothing to do with the original work of the Alexandrian historian. These are the episodes referring to the two arrivals of Scipio Aemilianus to Numantia. The first one after hardening and disciplining the army, and the second one after his journey through Vaccaei lands to initiate the siege works of the Celtiberian city. Our alternative comments are also provided.
\end{abstract}

Keywords: Numantia; Publius Cornelius Scipio Aemilianus; Appian; Iberiké; Adolf Schulten. 
Deconstrucción.- 2. f. Fil. y T. lit.: Desmontaje de un concepto o de una construcción intelectual por medio de su análisis, mostrando así contradicciones y ambigüedades!.

E

$\mathrm{N}$ efecto. Desde hace algún tiempo venimos estudiando el tema de la circunvalación escipiónica de Numancia, revisando las teorías de Schulten, leyendo y releyendo los textos de Apiano principalmente, y otras Fuentes, para corregir algunas interpretaciones del profesor alemán que poco o nada tienen que ver con el relato de aquél.

La incorrecta interpretación de los textos de Apiano, que se encuentra en la base misma de sus trabajos, es la clave de sus a veces delirantes postulados y conclusiones, fruto de una imaginación desbordante, llegando al extremo de «forzar» dichos textos para adecuarlos al resultado de sus excavaciones, e incluso a sugerir que Apiano no se había expresado con exactitud.

Las teorías de Schulten en la bibliografía e investigación posteriores han contado con una adhesión casi absoluta sin apenas discusión, por lo que han estado vigentes durante muchísimo tiempo hasta convertirse en verdades prácticamente incuestionables, y auténticos obstáculos para el avance del conocimiento.

A ello también ha contribuido sin duda el hecho de que los materiales de sus excavaciones se encontraran en Alemania, que sus libros fueran escritos y publicados en alemán, y a la perfección de sus axiomas, con el resultado de que apenas tuvieran contestación científica en España ${ }^{2}$, cuyos investigadores poseían escasos conocimientos sobre arqueología militar romana y castrametación. Por el contrario encontró objeciones entre los propios investigadores alemanes, empezando por uno de sus colaboradores, Ernest Fabricius, que cuestionó las cronologías establecidas por Schulten para los campamentos IV y V de Renieblas (1911: 378-382).

Apiano, en su «Historia Romana», nos ha legado un texto extenso sobre la Guerra de Numancia, principal fuente sobre esta cuestión, a la que se ha considerado una copia abreviada de la supuesta monografía que sobre esta guerra escribió Polibio, que supuestamente habría sido testigo directo del asedio y destrucción de Numancia

1 Real Academia Española. Diccionario de la Lengua Española. Edición del Tricentenario. Actualización 2019. https://dle.rae.es/srv/search?m=30\&w=deconstrucción

2 D. Santiago Gómez Santacruz fue Abad de la Colegiata de San Pedro de Soria, y fundador y director del periódico católico El Ideal Numantino. Tras las excavaciones y primeras publicaciones de Schulten, escribió una refutación de las teorías del arqueólogo alemán (Gómez Santacruz, S. (1914): El solar numantino. Refutación de las conclusiones históricas y arqueológicas defendidas por Adolf Schulten, profesor de la Universidad de Erlangen, como resultado de las excavaciones que practicó en Numancia y sus inmediaciones, Madrid, Imprenta de la Revista de Archivos, Bibliotecas y Museos), aunque más con el corazón que con la cabeza, es decir, más con pasión patriótica que con argumentos arqueológicos de los que carecía, como él mismo reconocía (Gómez Santacruz, S. (1947): La meseta numantina en la Historia. Biblioteca Pública de Soria. (Estudio inédito) págs. 28, 31, 109, etc. 
(Cuntz, 1902: 56, seguido por Schulten ${ }^{3}$ (1905: 83; 1927: 1, 7 y 8), hipótesis ambas admitidas ciegamente por la bibliografía posterior (Taracena, 1941: 68; Bosch y Aguado, 1955: 165; Pédech, 1964: 524, 561-562; Capalvo, 1996: 25-28; Blázquez, 1999: 68-69; Luik, 2005: 77; Jimeno et al., 2002: 91; Jimeno, 2006: 179; Dobson, 2008: 42; Gómez Espelosín, 2009: 237; Sánchez-Moreno, 2010: 81). Hoy en día, y en contra del sentir de Schulten, está totalmente descartada la presencia de Polibio en la toma de Numancia junto a Escipión (Dudas en Werner, 1878: 41, y en Walbank4, 1948: 160; Díaz Tejera, 1972: 44; Sancho Royo, 1973: 25-26; Marín, 2012: 456; Morillo et al., 2017: 188).

Así mismo, se ha demostrado que la tradicionalmente admitida dependencia de la crónica de Apiano sobre la guerra numantina de Polibio no resulta sostenible. Nada avala, excepto la cita aislada en carta de Cicerón a Lucilio (Ad fam. 5, 12, 2), que Polibio escribiera un opúsculo sobre la caída de Numancia (Sancho Royo, 1973: 27-33; 1976: passim; Pérez Vilatela, 2000: 31; García Moreno, 2002: 133, nota 23, interesante la propuesta de I. Hahn). Apiano pudo utilizar para la composición del relato del asedio de Numancia otras fuentes bien informadas y no suficientemente valoradas, como el historiador Rutilio Rufo (Norden, 1920: 436-437; Richardson, 1986: 194), que según comenta Apiano (Iber. 88) sirvió como Tribuno con Escipión y escribió sobre estos

3 Cuntz, 1902: «Polybius scheine den Scipio im Jahre 134 nach Spanien begleitet zu haben. Das war bisher eine Vermutung, jetzt haben wir die Gewifsheit. Beide Grofshaten seines Freundes, die Eroberung von Cartago wie die von Numantia sah Polybius mit eigenen Augen».

Schulten, 1905: «Polybius machte die beiden letzten Jahre des Krieges im Gefolge Scipios mit, und beschrieb ihn als Nachtrag zu dem mit dem J. 146 endenden Hauptwerke in einer besonderen Schrift, die nur einmal, von Cicero (ad fam 5, 12,2) erwähnt wird. Diese Schrift erzälhte nicht etwa nur die bieden letzten, vom Verfasser selbst mitgemachten Kriegsjahre, sondern den ganzen Krieg 144-133 meinen, wie es Florus $(1,34)$ und Appian thun».

Schulten, 1927: «In dem jüngsten der drei Lager auf dem die numantinische Ebene beherrschenden Hügel Castillejo hat der Zerstörer von Karthago die Belagerung von Numantia geleitet, begleitet von seinm Mentor Polybios, von Marius, Rutilius Rufus, C. Gracchus, Lucilius». «Da nun aber Polibios die Belagerung von Numantia als Augenzeuge beschrieben hat, so halte ich an meiner Ansicht, daB Appian auf Polibios zurükgehe, fest». «Vermittelt wurde dieser Bericht des Polibios dem Appian wohl durch Poseidonios». «Die Schrift des Polybios über den numantinischen Krieg, bekanntlich ein selbständiger und selbständig publizierten Nachtrag zu seinem Hauptwerk, wird nur einmal erwähnt, von Cicero (ad fam, 5, 12, 2)».

${ }^{4}$ Werner, 1878: «Num Polybius cum Scipione profectus sit ad bellum numantinum, cum omnino nihil sit traditum memoriae, diiudicari non potest; verissimile est cum non interfuisse bello propter nimis profectam aetatem».

Walbank, 1948: «But whether, as is so often asserted, he was present, as an old man of seventy, in Scipio's camp at Numantia, remains uncertain». Sin embargo, ambos admiten, incluso con certeza, un opúsculo sobre la guerra de Numancia escrito al final de su vida, entre 133 y 130/129 a. C.

5 Norden, 1920: «In der "Iberiké" des Appianus ist die letzte Epoche des Numantinischen Krieges mit einer Lebendigkeit und Anschaulichkeit beschrieben, der sich nicht viel Ebenbürtiges aus Antiker Historiographie an die Seite Stellen läBt: überall merkt man hier die Hand eines an den Ereignissen selbst Beteiligten, der seine Aufzeichnungen späterhin schriftstellerisch ausgearbeitef hatte; kein Zweifel, daB es Rutilius Rufus war, dessen Name inmitten der Erzählung als Feldzugsteilnehmer genannt ist (1): der Reichtum des topographischen und ethnographischen Materials ist bemerkenswert». 
hechos; Sempronio Aselio, el analista, también Tribuno bajo el mando de Escipión (Gelio, II, XIII, 3) ${ }^{6}$; el poeta C. Lucilio, amigo personal de Escipión al que acompaño a Numancia, o el historiador C. Fannio, entre otros (Astin, 1967: 4; Sancho Royo, 1973: 34-40; Goukowsky, 1997: XLI: García Moreno, 2002: 133, nota 23; Dobson, 2008: 42).

Siguiendo a Sancho Royo y a Díaz Tejera, Pérez Vilatela resume la cuestión en esta frase: «Es incluso perfectamente sostenible que la guerra numantina que historió Polibio fuese la de 154 y años siguientes y no la de 134-133 y por tanto, que Apiano no le siguiese» (2000: 23).

Aunque Apiano escribe su «Historia Romana» durante la primera mitad del siglo II d. C., en un contexto social, político e ideológico diferente del que existía en la Roma de Escipión y Polibio, muchos autores coinciden en que su obra parece fiable en general como resultado de la utilización de fuentes bien informadas (Astin, 1967: 4; Díaz Tejera, 2000: 1072; Gómez Espelosín, 1993: 26-30; Goukowsky, 1997: XXXIII-XLIII; Dobson, 2008: 41-43). Sin embargo, todavía hay quien cuestiona la fiabilidad del relato de Apiano (Jimeno, 2002: 173-174; 2004: 245).

Otros muchos autores clásicos como Polibio, Diodoro, Livio, Plutarco, Plinio, Frontino, Polieno, Floro, Valerio Máximo, etc, también hablan de la Guerra de Numancia, pero lo que nos ha llegado de ellos son citas aisladas, pequeños retazos de esta historia, aunque en muchos casos aporten preciosos e interesantes detalles. Apiano, por el contrario, nos ofrece una historia completa de esta guerra, con sus causas, su inicio, desarrollo y terminación. Y aquí reside precisamente la importancia de su relato.

A pesar de tan extensa narración, y del razonable grado de certidumbre, somos conscientes de que en la obra de Apiano resalta la pobreza de detalles y la escasez de información (Dobson, 2008: 42). Aun teniendo en cuenta estas deficiencias, estamos de acuerdo con Schulten cuando afirma que «el relato de Apiano figura entre las más sugestivas y exactas relaciones que poseemos de una guerra de la Antigüedad» (1945: 54).

Los textos que nos van a servir de hilo conductor durante todo el tiempo corresponden a la «Iberiké» o Historia de Iberia, libro sexto de la obra Historia Romana de Apiano, en traducción de Antonio Sancho Royo (1980).

Comenzamos nuestro trabajo en el año 135 a. C., y más concretamente en el otoño de este año, cuando las tropas romanas de la Citerior encargadas de llevar la guerra contra la ciudad de Numancia, ahora al mando de Calpurnio Pisón, ponen rumbo hacia la Carpetania donde instalan sus cuartes de invierno.

6 Gelio, II, XIII, 3: «Is Aselio sub P. Scipione Africano tribunus militum ad Numantiam fuit resque eas quibus ipse interfuit conscripsit». 
AP. Iber. 83.- Elegido general contra ellos Calpurnio Pisón no realizó ningún intento contra Numancia, sino que hizo una incursión contra el territorio de Palantia y, tras haberlo devastado un poco, pasó el resto de su mandato en sus cuarteles de invierno en Carpetania.

Según la versión de Apiano, Calpurnio Pisón no atacó Numancia, y posiblemente ni se dirigió a su territorio, ya que su acción se orientó contra los vacceos. Sin embargo, otras Fuentes aseguran que fue derrotado por los numantinos ${ }^{7}$.

Posteriormente, en este mismo párrafo Apiano sitúa claramente las tropas romanas invernando en Carpetania, durante todo el mandato que le restaba a Calpurnio Pisón, es decir, hasta el momento en que éste debía entregar el mando a su sucesor. Este hecho aparece tan claramente explicitado en Apiano que nadie lo cuestiona (Schulten, 1905, 74; 1914: 365; 1945, 134; Simon, 1962: 169; Capalbo, 1996: 180; Luik, 2005, 76).

Carpetania, el país de los carpetanos, era un territorio relativamente grande situado en el centro de la península Ibérica. Como veremos a continuación, fue incorporado muy tempranamente a la órbita de influencia romana como consecuencia de su situación estratégica para el avance romano.

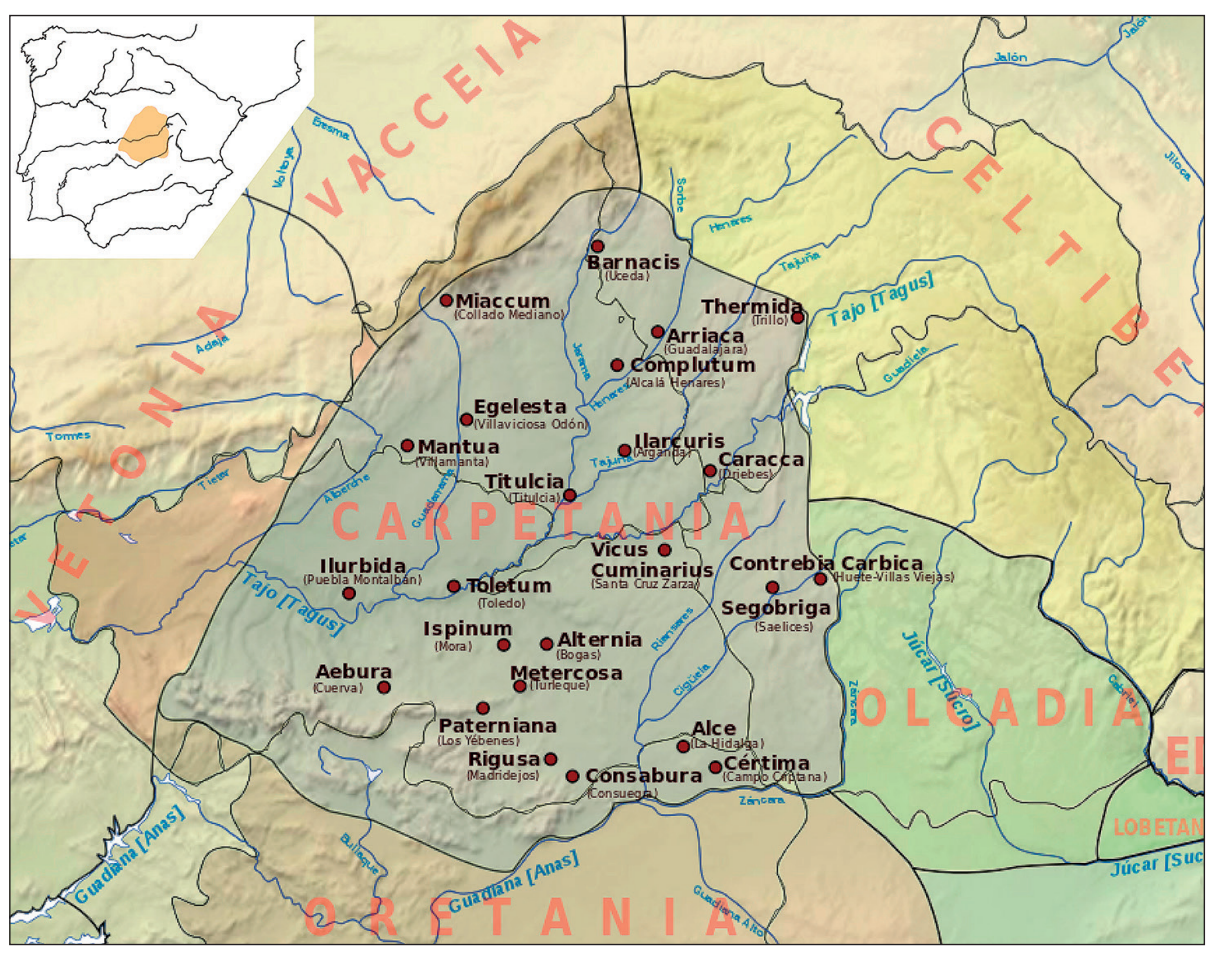

Figura 1

Mapa de Carpetania con sus principales ciudades. https://es.wikipedia.org/wiki/Carpetania

7 Obsequens 26: «Ser. Flacco Q. Calpurnio coss. (...) in Numantia res male gestae, exercitus Romanus oppressus». Schulten interpreta que Obsequens confundió vacceos y numantinos (1937: 59). 
Los primeros contactos con los romanos hay que remontarlos al año 193 a. C. y se deben al cónsul M. Fulvio Nobilior quien un año después consiguió tomar Toletum, una de las principales ciudades carpetanas. Los éxitos de L. Quintio Crispino y C. Calpurnio Pisón en 186-185 a. C. y posteriormente de Q. Fulvio Flaco en 181 a. C. pusieron las bases para que en 179 a. C. el pretor T. Sempronio Graco consiguiera el sometimiento definitivo de Carpetania y su integración en el ámbito romano. Con ello se pretendía proteger los ricos territorios de la Bética estableciendo una amplia frontera defensiva con base en el río Tajo. (González-Conde Puente, 1987: 27-30).

Apiano no menciona ningún detalle sobre en qué parte de la Carpetania estaban los cuarteles de invierno de Calpurnio Pisón. No obstante, hay razones para pensar que pudieron establecerse en la zona sur del territorio. Así, desde un punto de vista estratégico, el Tajo marcaba esa frontera defensiva a la que aludíamos más arriba. Era un territorio pacificado e integrado en la órbita romana; se encontraba relativamente alejado de la zona conflictiva de los celtíberos y con una amplia región al norte del Tajo que servía de «colchón» ante posibles ataques enemigos. Y a la vez no estaba tan alejada del teatro de operaciones del Duero como otras zonas utilizadas tradicionalmente para la invernada, como la Bética o la costa levantina. Y también por razones climáticas, ya que los inviernos en esta zona son más suaves que los del norte de Carpetania.

Además, en esta zona meridional se encontraban algunas de las principales ciudades Carpetanas como Toletum, Consabura, Aebura, Cértima, Segóbriga,... en cuyas cercanías pudieron establecerse estos campamentos romanos de invierno.

\section{AP. Iber. 84.- De esta manera Escipión, cónsul por segunda vez, se apresuró contra Numancia.}

En Roma estaban cansados de esta guerra larga y difícil, por lo que de nuevo eligieron cónsul a Publio Cornelio Escipión Emiliano, el conquistador de Cartago, en el convencimiento de que sólo él, un Escipión, y además hijo de Emilio Paulo, sería capaz de vencer a los numantinos. Para ello hubo que derogar temporalmente la ley que prohibía su reelección.

Schulten nos dice que Escipión fue nombrado cónsul el 1 enero de 134 a. C. (1914: 368; 1945: 134). En efecto, a partir del año 154 a. C. todas las magistraturas de Roma dejaron de ser nombradas el 15 de marzo para adelantarse al 1 de enero, como consecuencia de la campaña de Q. Fulvio Nobilior contra Segeda (Ap. 45).

En el relato se dice que Escipión «se apresuró contra Numancia», quizá indicando más que el inicio del viaje (ya que un poco más adelante nos dice Apiano que él con algunos se lanzó hacia Iberia, señalando, ahora sí, su partida de Roma) los preparativos y gestiones para su campaña contra Numancia, es decir, recabar financiación (que no le dieron), reclutar ese pequeño contingente de parientes, amigos y voluntarios que le iban a acompañar, solicitar ayuda a todos sus importantes clientes y amistades extranjeras, etc. 
Aunque ningún texto antiguo menciona nada al respecto, supone Schulten que el mes de enero pudo haberlo dedicado a los asuntos consulares y armar al pequeño cuerpo militar, y que a principios de febrero pudo haber emprendido el viaje desde Roma hacia Hispania. Inicialmente, el investigador alemán pensó que Escipión hizo este viaje por mar, zarpando a principios de $\operatorname{abril}^{8}$ (1905: 75); sin embargo, posteriormente se retracta afirmando que el viaje lo «realizó todo por tierra como era costumbre», llegando a Tarraco en Abril (1914: 368; 1945: 134). Esta fecha es aceptada por Simón sin ningún comentario adicional (1962: 176) así como por García Bellido (1969: cap. V).

En nuestra opinión, algunas afirmaciones son cuestionables. Así, un mes, enero, es poco tiempo para que Escipión realizara todos los preparativos que requería una campaña tan complicada, por lo que el inicio del viaje a principios de febrero no nos parece viable. Quizá una fecha en torno a mediados de marzo fuera más apropiada, aunque no pasa de ser una mera conjetura. Tampoco estamos de acuerdo en que el viaje se realizara por tierra. Al menos todo. Sin embargo, sí es posible que la fecha de llegada a Tarraco fuera dentro del mes de abril, aunque en nuestra opinión debió ser muy a principios de mes, mientras que Schulten no se pronuncia, pero comenta que cuando llegó ya había comenzado la primavera hace algún tiempo (ver nota 22).

Capalvo supone que Escipión «posiblemente estaba ya en la península en marzo de 134», aunque sin aportar ningún fundamento para esta atribución. A partir de aquí, y considerando la cita de Veleyo Patérculo9 según la cual la toma de Numancia se produjo a los 15 meses de la llegada de Escipión a la península, considera que la caída de la ciudad quedaría situada aproximadamente a fines de la primavera de 133 a. C. (1996: 195).

Por su parte, Jimeno y Chaín (2017: 239), siguiendo a Capalvo, opinan que Escipión «pudo llegar a la península ya en marzo de 134 a. C.», al igual que Sopeña (2013: 568); sin embargo, la rendición de Numancia, ocurrida al año y tres meses de su llegada, la llevan, como Schulten, al verano del 133 a. C. (Jimeno, 2006: 179; Jimeno y Chaín, 2017: 246). Cierto que no tenemos ningún testimonio en las Fuentes, y por tanto ninguna certeza, sobre el momento de la caída de Numancia. Schulten supone que se produjo en julio o agosto del 133 a. C. (Schulten, 1937: 84; 1945: 225) que posteriormente refina a finales de julio o principios de agosto apoyándose en varias referencias como la muerte de Tiberio Graco, los 15 meses citados por Veleyo, así como el regreso de Escipión a Roma y las elecciones consulares de noviembre (Schulten, 1927: 56). Pero algunas de estas reseñas tienen escasa precisión cronológica y otras son totalmente subjetivas. Por nuestra parte, y en función de la llegada de Escipión a Tarraco que hemos propuesto anteriormente, la toma de Numancia pudo producirse entre finales de junio y principios de julio del 133 a. C., es decir, un mes antes de las fechas propuestas por Schulten.

\footnotetext{
8 «Sobald das Meer offen war, also etwa, Anfang April 134, in See gestochen sein».

9 Veleyo, 2, 4, 2: «Publio Escipión Africano Emiliano, el que arrasó Cartago, después de tantas derrotas sufridas ante Numancia, hecho cónsul de nuevo y enviado a España, respondió en esta provincia a la fortuna y al valor demostrado en África, y al cabo de un año y tres meses de haber llegado, Numancia, cercada de fortificaciones, fue destruida y arrasada».
} 
A todos ellos, que en total eran unos cuatro mil, los puso bajo el mando de su sobrino Buteón y él, con unos pocos, se adelantó hacia Iberia para unirse al ejército, pues se había enterado que estaba lleno de ociosidad, discordias y lujo...

En este pasaje, continuación del anterior, Apiano, siempre parco en detalles, relata cómo Escipión, ante las noticias que le habían llegado referentes al estado en que se encontraba el ejército, se adelanta al resto del contingente para hacerse cargo de las tropas.

Nada se dice de cuándo inició el viaje; si lo hizo por tierra, qué camino siguió; si fue por mar, dónde embarcó; cuánto duró el trayecto o cuándo llegó a Tarraco; dónde estaba el ejército; etc. Y tampoco otras Fuentes aclaran ninguno de estos aspectos, por lo que para intentar responderlos hemos de recurrir, en primer lugar, a los propios textos de Apiano, y después a la comparación de lo que era habitual hacer en otras campañas anteriores con destino en Iberia. También hay que tener en cuenta que las Fuentes en muy contadas ocasiones recogen información de este tipo, a no ser que se trate de un dato relevante dentro del relato.

Schulten hace cuentas, sobre la base de experiencias anteriores, de los días que se pudo tardar en llegar de Roma a Tarraco (1914: 296-297). Pero ya hemos dicho que no estamos de acuerdo con él en que Escipión realizara su viaje a Tarraco por tierra. Al menos en su totalidad. Veamos.

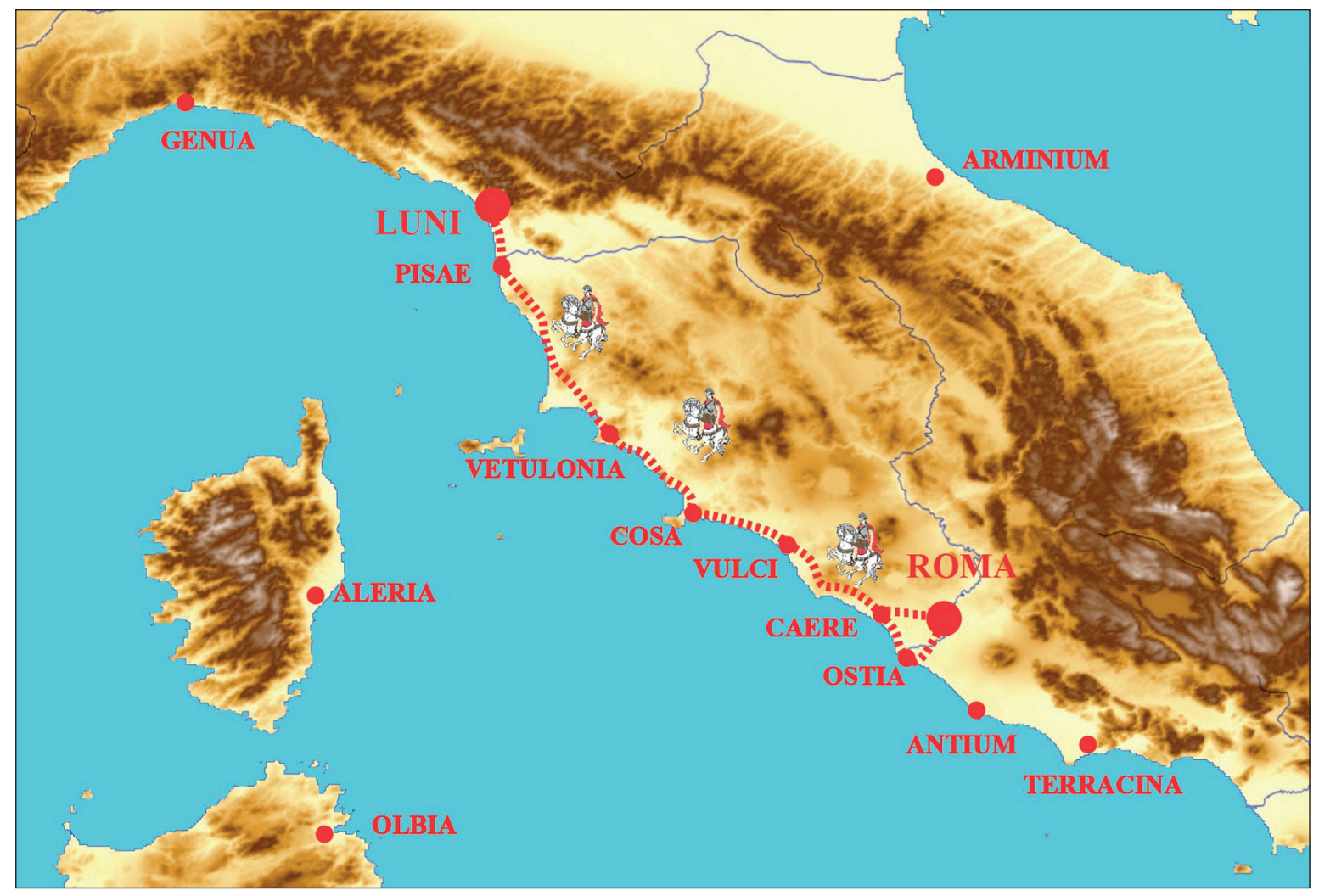

Figura 2

Mapa con el posible itinerario de Escipión desde Roma a los puertos de Pisae o Luni (dibujo C. Tabernero/Areco Arqueología) 
Roma no tenía un puerto adecuado para el embarque de tropas ni para el comercio (y no lo tuvo hasta época imperial), por lo que los romanos utilizaron otros puertos, por motivos estratégicos, para embarcar las expediciones militares que tenían como destino las guerras contra los pueblos indígenas sublevados en Hispania.

Uno de estos puertos utilizados desde muy temprano fue el de Luni (Golfo de Spezia), en Liguria, al norte de Italia. Este puerto fue utilizado por motivos estratégicos antes incluso de fundarse como colonia en 177 a. C. (Raffelini, 2002: 731 y $743-$ 745; Rossignani et al. 2002: 763). Así, las fuentes escritas, en concreto Livio $^{10}$, dice que el año 195 a. C. el cónsul M. Porcio Catón concentró la flota en el puerto de Luni desde el que zarpó hacia el puerto de Pireneo (portus Veneris) actual Port Vendrés, en el sur Francia. Y algunos años después, en 186 a. C., el pretor C. Calpurnio Pisón también salió de Luni con destino a Hispania como sucesor del cónsul de la Ulterior Cayo Atinio, vencedor a los lusitanos, pero muerto en el sitio de Asta. De estos acontecimientos tenemos igualmente la referencia de Livio ${ }^{11}$. Es decir, el puerto de Luni deviene para los romanos una base militar de uso sistemático para las expediciones militares contra los pueblos indígenas sublevados en Hispania (Wilsdorf, 1878: 72; Cunt, 1902: 58; Raffelini, 2002: 743).

De igual manera, el Portus Pisanus, en la Toscana, fue otra cabeza de puente de gran valor estratégico y militar para llevar rápidamente nuevos contingentes militares a Hispania (Raffelini, 2002: 743-744; Pasquinucci et al., 2002: 769; Pasquinucci and Menchelli, 2017: 324 y 328

También en 137 a. C. el cónsul T. Hostilio Mancino realizó por mar parte del viaje a Hispania para hacerse cargo de los asuntos numantinos. Nada menciona Apiano al respecto, que se centra en los enfrentamientos con Numancia (Ap. 80), pero sí otras Fuentes. Plutarco, en sus «Vidas Paralelas», cuenta que T. Sempronio Graco, que acompañaba a Mancino en esta expedición, al pasar por la Toscana en su viaje a Hispania, concibió la idea de la reforma agraria ${ }^{12}$. Es decir, que hacía el viaje por tierra hacia algún lugar más al norte de la Toscana. Y este lugar era sin duda un puerto, pues

${ }^{10}$ Livio XXXIV, 8, 4: «Una vez derogada la ley Opia, el cónsul Marco Poncio partió inmediatamente de la Ciudad y con veinticinco buques de guerra, cinco de los cuales pertenecían a los aliados, zarpó del puerto de Luni donde había recibido el ejército órdenes de concentrarse. Había mandado publicar un edicto a lo largo de toda la costa para que se reuniesen naves de toda clase en Luni y a partir de alli dejó órdenes para que le siguieran hasta el puerto de Pireneo».

${ }^{11}$ Livio XXXIX, 21, 1-5: «Cuando se leyó la carta que comunicaba su muerte, el Senado fue de la opinión de que se debía enviar un correo al pretor Cayo Calpurnio, en el puerto de Luni, e informarle de que el Senado le aconsejaba apresurar su partida, pues aquella provincia no podía quedar sin un administrador. El correo llegó a Luni en cuatro días, pero Calpurnio había partido unos días antes».

${ }_{12}$ Plutarco: «Pero su hermano Cayo dijo en un escrito que al hacer Tiberio su viaje a España por la Toscana, viendo la despoblación del país, y los labradores y pastores eran esclavos advenedizos y bárbaros entonces concibió ya la primera idea de una providencia, que fue para ellos el manantial de infinitos males». (Plutarco. Trad. de D. Antonio Ranz Romanillos.Vidas de los Hombres Ilustres. Las Vidas Paralelas. Tomo IV. Imprenta Nacional, 1822, p. 346). 
Livio $^{13}$ menciona que Mancino se embarcó hacia Hispania. Y no sólo esto, sino que Valerio Máximo ${ }^{14}$ cita el puerto de Hércules (actual Mónaco) como el punto de embarque, a donde había llegado por tierra. Y también Obsequens ${ }^{15}$ se refiere a este puerto como el lugar en el que se embarcó con dirección a Numancia. Y alude al puerto de Génova como la segunda opción del embarque.

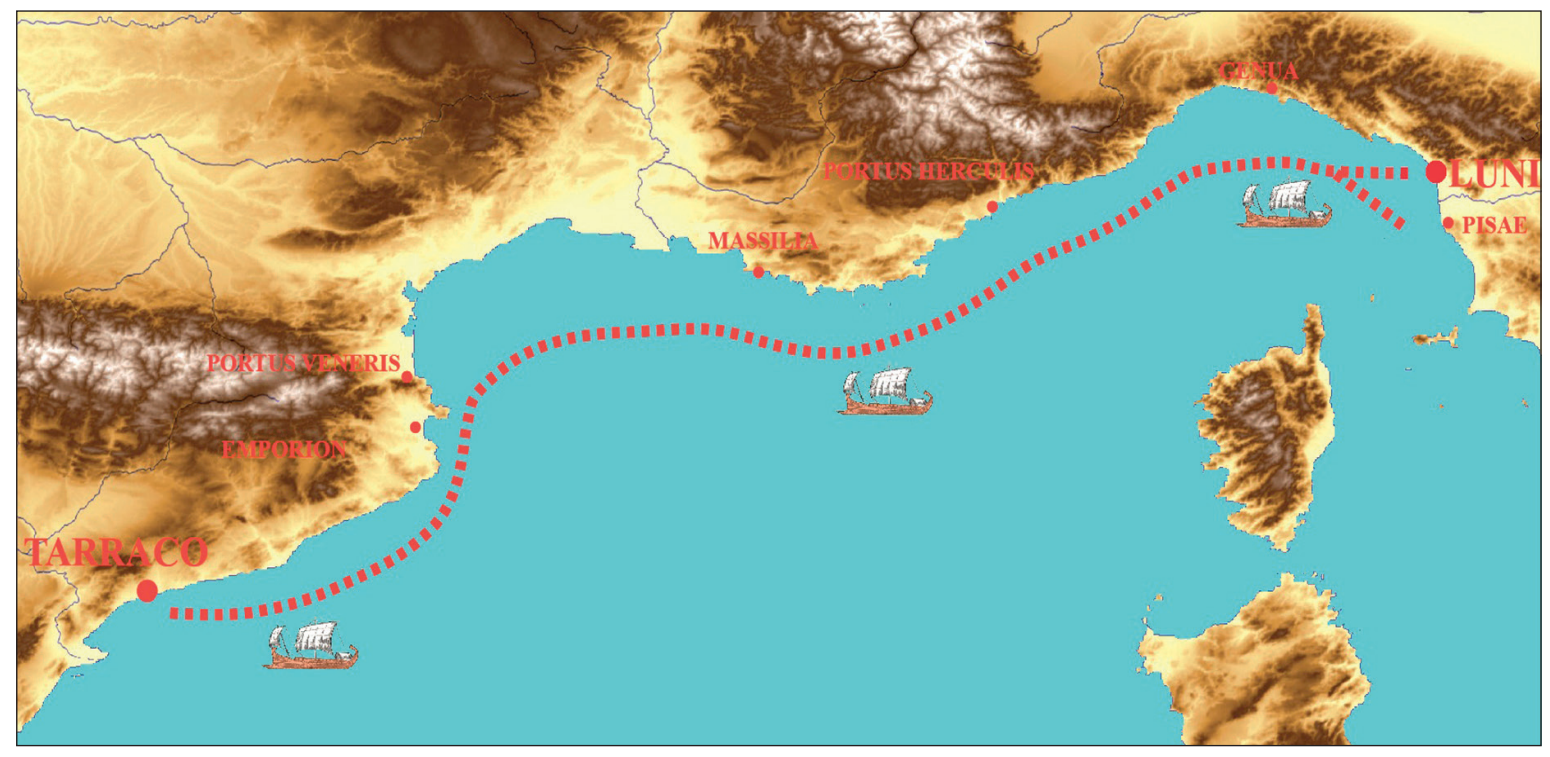

Figura 3

Mapa con el posible trayecto de Escipión en barco desde Pisae o Luni a Tarraco (dibujo C. Tabernero/Areco Arqueología)

En consecuencia, y a pesar de su primera impresión (1905: 75), no parece que sea correcta la afirmación de Schulten de que Escipión «realizó el viaje de Roma a Tarraco por tierra como era costumbre» (1914: 368; 1945: 134), sino que lo habitual parecen ser los viajes por mar siguiendo la costa, navegación costera, en la que una de sus formas es el cabotaje, más lenta pero más segura que los viajes por altamar (Pédech, 1964: 557; Arnaud, 2005: 107 y ss.), aprovechando las corrientes marinas costeras del Mediterráneo noroccidental (Lacombe et Tchernia, 1972: 31-33; Millot, 1989: 501, Figura 1), y en especial cuando se tenía prisa en llegar a algún lugar (Pastor y Pastor, 2012: 69 y 92) por lo que habría que reconsiderar la importancia estratégica de todos estos puertos en el expansionismo romano hacia el noroeste y las expediciones militares hacia Galia e Hispania (Pasquinucci et al., 2002: 770).

\footnotetext{
${ }^{13}$ Livio, Periocas, 55: «Más tarde, al embarcarse para su viaje a España...».

${ }^{14}$ Valerio Máximo 1, 6, 7: «Al embarcarse en el puerto de Hércules, a donde había llegado por tierra...». «Aterrorizado por ella, torció el rumbo y marchó hacia Génova; y subiendo aquí en un esquife...».

${ }^{15}$ Obsequens, p. 50: «Al embarcarse el cónsul Hostilio Mancino en el puerto de Hércules, en dirección a Numancia... Habiendo ido a Génova se embarcó de nuevo...».
} 
¿Qué tiempo pudieron emplear Escipión y sus acompañantes en llegar a Tarraco? Apiano dice que «se apresuró contra Numancia» y que «se adelantó hacia Iberia», dando a entender la prisa y la urgencia con las que Escipión deseaba ponerse al frente del ejército, especialmente tras enterarse del lamentable estado en el que se encontraba.

Es posible que el viaje por tierra, unos $410 \mathrm{~km}^{16}$ (Cunzt, 1902: 23), lo hicieran a caballo por la ruta de la costa, la más corta, hasta alguno de las puertos del norte, como Pisae, o quizá más posiblemente Luni, tradicional puerto de embarque de las tropas hacia Iberia. En esta empresa debieron emplear unos 7 u 8 días considerando el espacio que recorre un caballo en un día ${ }^{17}$ (Pastor y Pastor, 2012: 69 y 92; Gozalbes y González, 2012: 350 y nota 35).

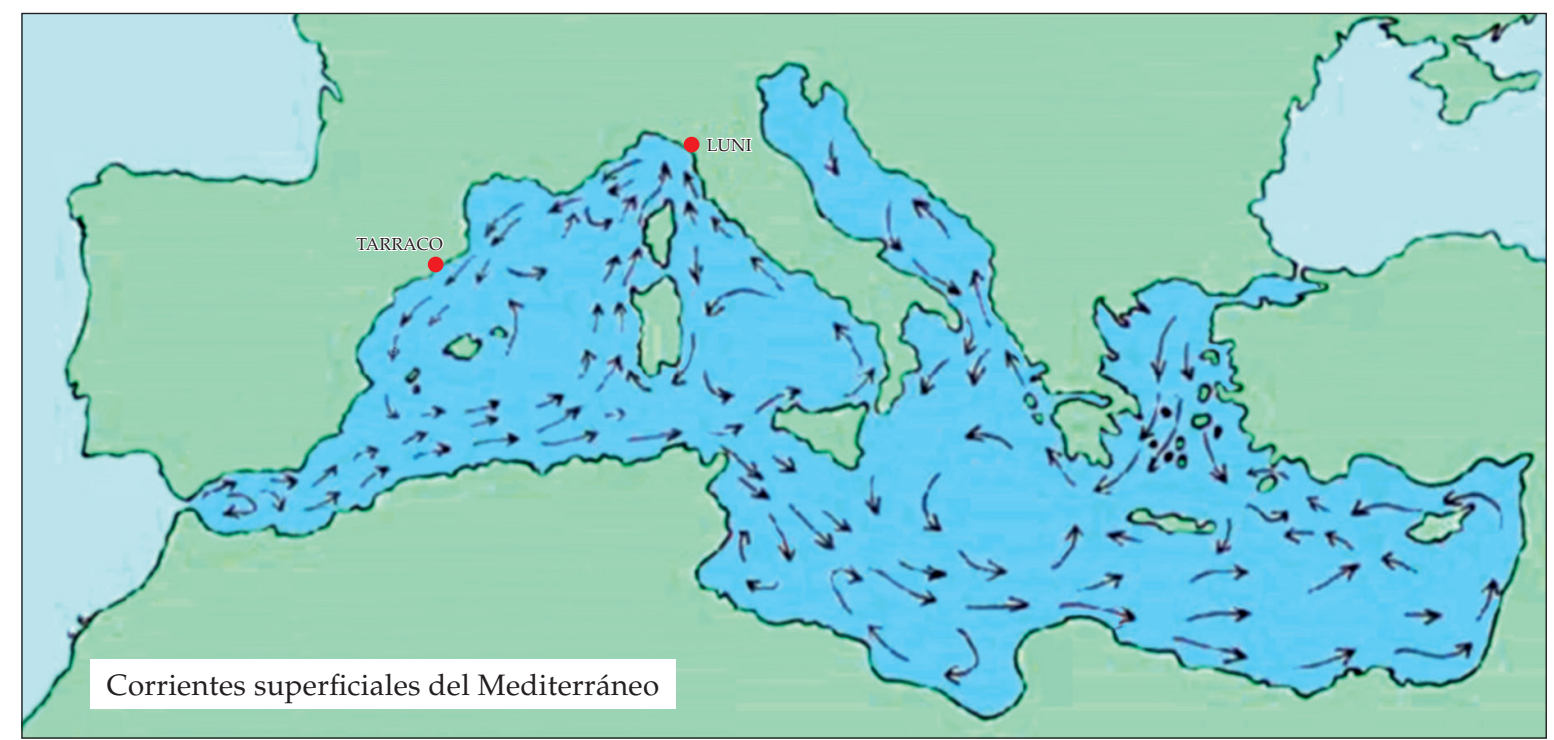

Figura 4

Mapa de las corrientes marinas superficiales del Mediterráneo.

http:/ / cambioclimaticoenergia.blogspot.com/2011/01/las-corrientes-del-mediterraneo.html

Tras embarcarse, el viaje por mar hasta Tarraco mediante navegación de cabotaje, de unos $1000 \mathrm{~km}$, pudo durar en torno a 7 u 8 días de acuerdo con los nudos/hora (millas/día) que podía recorrer un determinado tipo de barco (Arnaud, 2005: 70-74;

${ }^{16}$ Polibio en XXXIV, 11, 3, da la distancia de 2500 estadios por la costa entre Luni y Ostia, unos $463 \mathrm{~km}$, cifra al parecer excesiva, ya que en la realidad se limita a unos $280 \mathrm{~km}$. Por otro lado, Hultsch, con base en el texto de Polibio, relata 1330 estadios, unos $246 \mathrm{~km}$, por la costa entre Ostia y Luni, distancia un poco pequeña para el trayecto, y que sólo se correspondería con el tramo Luni-Cosa (Ansedonia).

${ }^{17}$ Hemos encontrado pocas referencias en las Fuentes para establecer paralelos; algunas cifras son exageradas, dada la necesidad de descanso del caballo, y se refieren a casos excepcionales. La realidad es que un caballo normal recorre unos $7 \mathrm{~km} / \mathrm{h}$ yendo al paso, unos $14 \mathrm{~km} / \mathrm{h}$ si lo hace al trote y en torno a $25 \mathrm{~km} / \mathrm{h}$ si es al galope. Cuando se trata de largas distancias se emplea el paso/trote, recorriendo cada día unos 50/60 km en jornadas de unas 8 horas. 
González y Medina, 2012: 262, con más referencias ${ }^{18}$; Livio XXXVII, 7, 1; Avieno ${ }^{19} \mathrm{O}$. M. 563-565). Según esta argumentación, el trayecto total Roma-Luni/Pisae-Tarraco le debió costar a Escipión unos 15 ó 16 días, por lo que pudo llegar a Tarraco en los primeros días de abril. Tenía entonces 50 años (Wilsdorf, 1878: 106; Schulten, 1937: 61; Blázquez, 1999: 69).

Schulten supone que Escipión encontró el ejército esperándole en Tarraco (1914: 368; 1937: 62 y 63; 1945: 134). De hecho cree que el ejército se habría trasladado a Tarragona esperando su llegada ${ }^{20}$. No aclara cuándo se produjo el desplazamiento, pero da a entender que al llegar Escipión ya llevaba al menos un tiempo allí21 puesto que incluso habla de la estancia en primavera ${ }^{22}$. Bosch y Aguado siguen a Schulten en este punto (1955: 158).

En defensa de esta supuesta venida de las tropas a Tarraco, Schulten esgrime el caso de Fulvio Flaco en 179 a. C. cuando desde Celtiberia marchó con el ejército a Tarraco para entregarlo a su sucesor Tiberio Sempronio Graco. Pero no se trató de un simple relevo del mando en Tarraco, como Schulten pretende hacernos creer, tomándolo como paradigma del caso escipiónico. El motivo principal de que Fulvio

${ }^{18}$ Plinio Nat. 19. 3: «Mas, ¿en qué parte de la vida no le topamos? O ¿qué maravilla hay mayor que haya hierba que junte a Egipto con Italia en tanta manera que Galerio navegase desde el foso de Mesina a Alejandría en siete días, y Babilio en seis, ambos a dos adelantados? Y en el estío pasado, Valerio Mariano, senador praetorio, desde Puzol, en nueve, con muy próspero y sosegado viaje».

Plinio, Nat. 19. 4: «iQue haya hierba que lleve a Cadiz, que está cabo las columnas de Hércules, en siete días a Hostia y en cuatro a la España Citerior, a la provincia Narbonense en tres y en dos a África! Lo cual también aconteció con buen tiempo y sosegado a Cayo Flavio, embajador de Vibio Crispo, procónsul de vida osada y llena de maldades. Se siembran cosas para recibir los vientos y las tempestades».

${ }^{19}$ Livio: «Al cierre del año (210 a. C.) llegó a Roma Cayo Lelio, treinta y cuatro días después de salir de Tarragona». Esta demora ya fue cuestionada por Pedech (1964: 557, nota 247), y sólo se explica por ser una navegación en contra de las corrientes marinas y del viento en el Mediterráneo, o por ser una navegación de cabotaje con escalas nocturnas puerto a puerto. Avieno afirma que desde las Columnas de Hércules hasta la costa de los Pirineos se empleaban siete días de navegación: «sed in Pyrenen ab columnis Herculis Atlanticoque gurgite et confinio Zephyridis orae cursus est celeri rati septem dierum».

20 (1937: 62): «Es de suponer que la tropa había marchado a Tarraco a fin de esperar al nuevo jefe». (1937: 63): «Escipión debió encontrar la tropa en Tarraco». (1945: 134): «El ejército había invernado en la Carpetania (Castilla la Nueva), pero seguramente fue concentrado en Tarragona, que en todo tiempo fue la base de los romanos».

${ }^{21}$ (1937: 62): «Por fin llegó con el invierno del 135 el ansiado descanso, pero el agradable cuartel invernal en la rica Carpetania y más aún la estancia en la lujosa ciudad de Tarragona, fueron casi más dañinos para la moral de aquellas tropas que las penalidades anteriores». (1945: 135): «El invierno pasado en Carpetania (Castilla la Nueva) y en la costa de levante, debía haber aumentado tal desorganización, ya que en las ciudades de la costa había entonces bastante lujo».

22 (1914: 368): «Es muß von da aus im Frühjahre 134 nach Tarraco geführt worden sein, um hier den neuen Feldherrn zu erwarten», y lo ratifica posteriormente en (1914: 368, nota 3): «Die angenehmen Winterquartiere in dem reichen Karpetanien und vollends der Frühling in Tarraco waren für die Disziplin eines solchen Heeres fast schlimmer als die früheren Strapazen». 
Flaco acudiera a Tarraco (motivo que Schulten calla, pero que se encuentra también en Livio) es que el propio Tiberio Sempronio Graco le había ordenado que debía llevar su ejército a Tarragona, donde tenía la intención de licenciar a los soldados veteranos, incorporar refuerzos a las distintas unidades y, en consecuencia, reorganizar todo el ejército (Livio 40, 39).

Pero además de la orden expresa de Sempronio Graco, en este caso concreto las circunstancias aconsejaban este desplazamiento: en primer lugar se trataba de un relevo de soldados, ya que un buen número de veteranos debían ser licenciados y embarcados hacia Italia. En segundo lugar esta reducción de los efectivos del ejército desaconsejaba permanecer en territorio enemigo con fuerzas tan mermadas. Y en tercer lugar, pero quizá el más importante, por cuestiones climatológicas: todos los cónsules que hacían campañas en tierras celtíberas, llegado el momento, se retiraban a pasar el invierno a lugares más cálidos. Bástenos recordar aquí las desgraciadas estancias invernales frente a Numancia de Q. Fulvio Nobilior (Ap. 47) y Q. Pompeyo Aulo (Ap. 78) y las calamidades que pasaron por causa la nieve y el frío. Y la invernada de Escipión Emiliano no debió ser mejor que las citadas, aunque en este caso no se diga nada al respecto (Ap. 89 y ss).

En respuesta a Schulten, y a la vez en defensa de nuestra teoría referente a que es el nuevo cónsul el que se incorpora al ejército, esgrimimos el caso de Emilio Lépido (Ap. 80), quién, tras el desastre de Hostilio Mancino, fue enviado a Iberia para hacerse cargo del ejército cuando Mancino fue llamado a Roma para ser sometido a juicio.

Una vez firmados los pactos, el ejército quedó libre, y podía haber marchado a Tarraco a esperar al nuevo general; sin embargo, el ejército de Mancino permanecía en las proximidades de Numancia; aquí se incorporó Lépido, que inactivo y cansado de esperar marchó contra los vacceos.

Schulten también trata de apuntalar la estancia del ejército en Tarraco esgrimiendo la cantidad de prostitutas que rondaba el campamento, iihasta 2000 fueron expulsadas!! (Livio, per. 57). Esta escena, en su opinión, sólo puede explicarse por el hecho de que se tratara de una gran ciudad, especialmente una ciudad portuaria, como era Tarraco, ciudades donde tanto ayer como hoy son sede de todos los vicios (1914: 368, nota 3). Y el texto de Polieno (8, 16, 2-4) abunda en ello al comentar que Escipión las envió a una ciudad que estaba en fiestas, lo que le sirve de argumento a Schulten para relacionar esa ciudad con Tarraco, ya que el campamento debía estar cerca de la ciudad (1937: 67-68). Y el lujo de los baños calientes citados por Apiano (Ap. 85) es otro argumento que apunta a la proximidad de una ciudad, ya que los caldarios apenas estuvieron presentes en los campamentos (1914: 368 nota 3). 
Sin embargo, estos argumentos referentes a Tarraco y a las putas y los baños ya fueron rebatidos por Simon ${ }^{23}$ (1962: 176-177 nota 85) y cuestionados mucho antes por Viereck y Roos (1939: 127).

Por tanto, toda esta argumentación de Schulten sobre el traslado del ejército a Tarraco no sólo es discutible, sino incluso rechazable, ya que anteriormente (Ap. 83) habíamos dejado establecido que el ejército de Calpurnio Pisón se encontraba en los cuarteles de invierno de Carpetania todo lo que le restaba de mandato, es decir, hasta que su sucesor llegase y se hiciese cargo de las tropas. Y Apiano así lo aclara posteriormente (Ap. 84) al decir que Escipión se adelantó para unirse al ejército.

Ya hemos visto cómo Schulten cree que el campamento estaba cerca de Tarraco, que Escipión se incorporó a él, y que la «limpieza» del campamento la realizó allí mismo. Pero si mantenemos, según los textos de Apiano, que el campamento seguía instalado en Carpetania cuando Escipión llegó a Tarraco, ¿qué ruta empleó para incorporarse al campamento?

Escipión y su séquito debieron tomar la ruta que siguiendo la costa mediterránea baja hacia el levante y el sur peninsular, un antiguo camino indígena conocido como vía Hercúlea y posteriormente como vía Augusta en homenaje a su impulsor. A la altura de la desembocadura del río Júcar, donde se encuentra la ciudad indígena de Sicana $/$ Sucro $^{24}$, debió tomar algún viejo camino indígena que remonta el curso del río hasta el interior peninsular, cerca ya de Carpetania (Pérez et al., 2010: 22-23; Aranegui, 2015: 24). Este itinerario fue el que posiblemente realizó Quinto Fulvio Flaco en 181 a. C. desde Tarraco hasta la ciudad de Aebura, (actual Cuerva) en Carpetania (Schulten, 1922: kärtchen 1: Marschlinie «Flaccus 181»), y que igualmente ha sido sugerido recientemente por Salinas (1989: 72).

\footnotetext{
${ }^{23}$ «Zum Unterschied von Klima und Vegetation: SCHULTEN NUM. I 169. SCHULTEN (NUM. I 368) nimmt an, daß das Heer nach dem Winter in Karpetanien Scipio entgegengezogen sei zur Übernahme in Tarraco. Dafür spreche u. a. (a. O. Anm. 3) die gewöhnliche Übung, die Menge der Dirnen (Hafenstadt!) und der Luxus warmer Bäder. Dieser, von VIERECK-ROOS (Appian-Ausgabe zu Iber. 366) schon bezweifelten Annahme, kann ich nicht zustimmen. Bezeugt ist für unsere Jahrzehnte kein einziges Winterlager des diesseitigen Heeres in einer Hafenstadt (zu verrmuten für Popillius 139/138 in Carthago Nova, s. oben S. 143). Die Bäder braucht man sich ja wohl nicht zu luxuriös vorzusrellen; Dirnen abet pflegen einem Heer überallhin zu folgen, und sei es in die abgelegenste Gegend. Offensichtlich hatte der "Troß"sich im Lager selbst angesiedelt, wie die verschiedenen Zeugnisse über Ausweisungen besagen. Schließlich gewinnt man auch den Eindruck, daß es Scipio mit Mißständen zu tun hatte, die sich seit langem, mindestens seit Monaten, eingefressen hatten; bei SCHULTENS Ansicht bliebe aber nur wenig Zeit zwischen dem Eintreffen des Heeres in Tarraco und Scipios Ankunt».

${ }^{24}$ Se ha propuesto situar la ciudad de Sucro en varios lugares próximos al río Júcar, aunque los más acertados la localizan en Cullera (Chofre, 2002: 258-259) o más posiblemente en Albalat de la Ribera (Schulten, 1937: 209-210; Montalbán, 2017: 22), ya que la vía Hercúlea pasa por esta villa constituyendo además un vado sobre el río Júcar, pues sólo allí era fácilmente vadeable. En Cullera se encontraría el Portus Sucrone, es decir, el puerto de la ciudad de Sucro, a unos $15 \mathrm{~km}$ de distancia.
} 
Y es la ruta que probablemente siguió Lúculo en 151 a. C. en su campaña contra los vacceos, a los que atacó desde Carpetania cruzando el Tajo cerca de Toledo ${ }^{25}$ (Simon, 1962: 46; Pérez Vilatela, 2000: 24). Conviene recordar ahora que acompañando a L. Licinio Lúculo, y en calidad de Tribuno, venía el joven P. Cornelio Escipión Emiliano, por lo que este itinerario ya le era conocido.

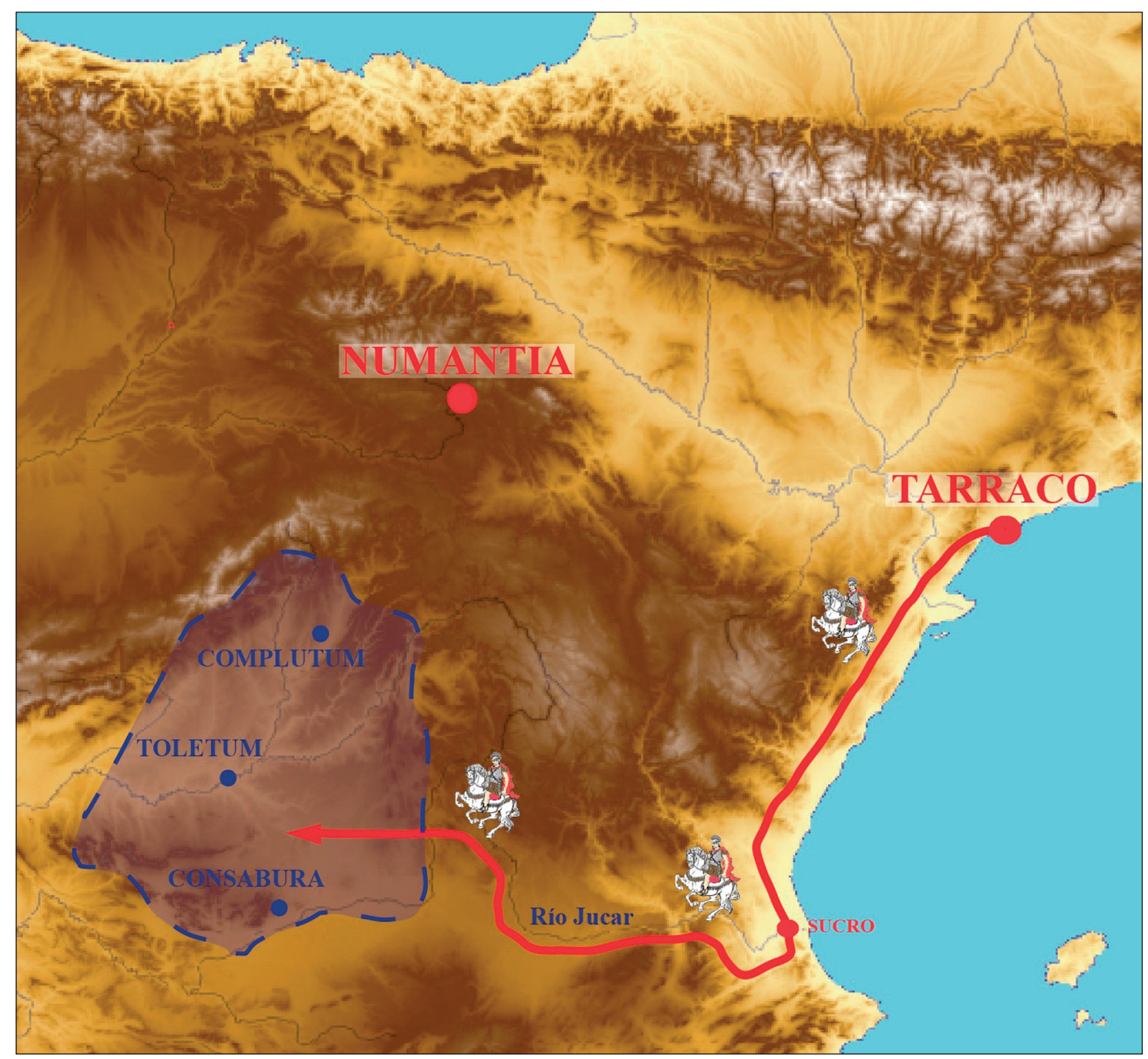

Figura 5

Mapa con el posible trayecto de Escipión desde Tarraco a la zona sur de Carpetania siguiendo la ruta Hercúlea y remontando el curso de río Júcar (dibujo C. Tabernero/Areco Arqueología)

${ }^{25}$ Simon: «Als Lucullus mit seinem so mühsam zusammengebrachten Heer in Spanien, Wahrscheinlich in Tarraco». «Er zog an der Küste entlang nach Süden und dann durch das Tal des Jucar auf die neukastilische Hochebene».

Pérez Vilatela: «Lúculo se encontraría en Tarraco con la Guerra celtibérica acabada, gracias a la habilidad de Marcelo. Marcharía por la costa mediterránea hacia el sur y penetraría en Castilla la Nueva (Carpetania) por el valle del Jucar. Luego atravesaría el Tajo y llegaría ante Cauca». 
El trayecto entre Tarraco y el río Júcar supone 1480 estadios (Polibio XXXIV, 11, 3, en Cunzt, 1902: 25) es decir, unos 285 km. El itinerario remontando el curso del río Júcar entre Sucro y algún punto del sur de Carpetania (Consuegra o Toledo, por ejemplo, ya que desconocemos la ubicación de los cuarteles de invierno), representa en torno a $300 \mathrm{~km}$ más, que en total suponen unos 580-600 km, en lo que habría invertido otros 11 ó 12 días adicionales en salvarlos hasta llegar al campamento de Calpurnio Pisón, es decir, mediado el mes de abril.

AP. Iber. 85.- Nada más llegar, expulsó a todos los mercaderes y prostitutas, así como a los adivinos y sacrificadores, a quienes los soldados atemorizados a causa de las derrotas consultaban continuamente.

Les prohibió llevar en el futuro cualquier objeto superfluo,

Ordenó también que fueran vendidos todos los carros y la totalidad de los objetos innecesarios que contuvieran y las bestias de tiro...

A nadie le fue autorizado tener utensilios para su vida cotidiana, exceptuando un asador, una marmita de bronce y una sola taza.

Les limitó la alimentación a carne hervida y asada.

Prohibió que tuvieran camas...

Impidió también que cabalgaran sobre mulas cuando iban de marcha...

Tuvieron que lavarse y untarse con aceite por si solos...

De esta forma, los reintegro a la disciplina a todos en conjunto y también los acostumbró a que lo respetaran y temieran...

Aquí Apiano nos describe todo un abanico de medidas disciplinarias que Escipión introdujo en el campamento para reconducir la situación de una tropa descarriada, ociosa e indolente y devolverla a la disciplina, el trabajo y el respeto. Algunas de ellas bajo el efecto de su ejemplo personal ${ }^{26}$.

Poca discusión existe en este capítulo, con excepción de que según Schulten todas estas disposiciones tuvieron lugar en el campamento de Tarraco, mientras que nosotros pensamos que fue en los cuarteles de Carpetania (Morales, 2004: 251).

AP. Iber. 86.- Pero con todo, ni aun así se atrevió a entablar combate hasta que los ejercitó con muchos trabajos. Así que, recorriendo a diario todas las Ilanuras más cercanas, construía y demolía a continuación un campamento tras otro, cavaba las zanjas más profundas y las volvía a llenar, edificaba grandes muros y los echaba

\footnotetext{
${ }^{26}$ Apiano 85: «...y él fue el primero en descansar sobre un lecho de hierba». Polieno 8, 16, 2-4: «... por vestiduras usar una capa céltica, ciñéndose él mismo el primero una piel negra; los oficiales lo veían echado sobre un lecho de pajas».
} 
abajo otra vez, inspeccionándolo todo en persona desde la aurora hasta el atardecer. Las marchas... las llevaba a cabo siempre en formación cuadrada y sin que estuviera permitido a ninguno cambiar el lugar de la formación que le había sido asignado.

Si acampaba al aire libre, los que habían formado la vanguardia durante el día debían colocarse en torno al campamento después de la marcha y un cuerpo de jinetes recorrer los alrededores. Los demás, por su parte, realizaban las tareas encomendadas a cada uno, unos cavaban trincheras, otros levantaban las tiendas de campaña, y estaba fijado y medido el tiempo de realización de todos estos menesteres.

Además de las medidas descritas anteriormente y que entrarían fundamentalmente dentro del ámbito «doméstico», estableció otras de tipo «profesional» encaminadas igualmente a restablecer la disciplina militar, pero estas segundas destinadas al fortalecimiento del cuerpo y también del espíritu militar; a la resistencia física y mental; a reintegrar el valor y la propia confianza; a sobreponerse a las adversidades; a la organización y al reparto de tareas, y también al respeto a las órdenes, a los mandos y al cumplimiento del deber.

Llama la atención, sin embargo, que ni Apiano ni otras Fuentes citen dentro de estos ejercicios algo tan propio de un ejército como son los entrenamientos para el combate, la lucha cuerpo a cuerpo, prácticas con armas arrojadizas y puntería, movimientos de unidades en una batalla, maniobras de ataque y retirada, etc. ¿Es que acaso Escipión confiaba tan poco en sus tropas como para arriesgar un enfrentamiento directo con los numantinos, para dar una batalla que resolviera a su favor esta guerra? De hecho, Apiano dice textualmente que «A pesar de que los numantinos salían con frecuencia en son de batalla y le provocaban al combate, los desdeñaba, ya que consideraba que era más conveniente no trabar combate con unos hombres que luchaban con desesperación, sino conquistarlos por hambre después de haberlos sitiado» (Ap. 90).

Teniendo en cuenta las numerosas derrotas de que había sido objeto el ejército romano ante Numancia, especialmente las recientes de Hostilio Mancino, y de los informes que habría recibido de sus oficiales veteranos de campañas anteriores, ¿es posible que Escipión tuviera ya decidido que el único modo de acabar con los numantinos era someterlos a un férreo asedio y rendirlos por hambre? Recordemos aquí que la toma de Cartago en la primavera de 146 a. C., sometida durante dos años a un blando cerco en manos de generales inútiles, sólo se resolvió tras hacerse cargo de la campaña Escipión Emiliano, quien limpió el ejército de todo lo indeseable, cortó los suministros mediante una incursión por los alrededores, como después haría en Numancia, y sometió a la ciudad durante un año a un asedio asfixiante, tanto por tierra como por mar, con el resultado que conocemos, y que le valió el título de «Africanus Minor». Es muy posible que Escipión, con los antecedentes descritos y su propia experiencia, tuviera decidido desde el principio lo que pensaba hacer, y desde que llegó al campamento en Carpetania todas sus decisiones y esfuerzos los encaminara a los trabajos de asedio. 
Esta misma impresión parece haberla tenido Schulten, quien ve en estos trabajos «los preparativos para la circunvalación de Numancia, a la que Escipión estaba ya resuelto de antemano» (1937: 68; 1945: 137), y, siguiendo a este, también Bosch y Aguado (1955: 162 y 166). En este sentido, también Luik considera que Escipión debió estimar que la fuerza de combate de sus tropas no era especialmente alta ${ }^{27}$ (2005: 78).

Capalvo se pregunta por qué si el cerco de Numancia era el plan original de Escipión, Apiano ha esperado a que se inicien los trabajos de asedio para comentarlo (1996: 189). Cree que la respuesta está en Orosio (Hist. 5, 7, 5-8) quien dice que tras el verano y el invierno Escipión trabó batalla con los numantinos siendo el resultado incierto, o incluso negativo según Frontino $(2,8,7)$, lo que le decidió a cercar la ciudad. Sin embargo, en respuesta a Capalvo se puede alegar que el comentario de Apiano en este momento, cuando se inicia el cerco, puede deberse precisamente a que es ahora cuando Escipión está llevando a cabo lo que siempre había pensado, rendir la ciudad por hambre mediante su asedio. Y el saqueo de los alrededores de la ciudad, más que para provocar al combate a los numantinos, pudo tener como objetivo algo tan simple como el propio abastecimiento, razonamiento que comparte el propio Capalbo (1996: 190, nota 1074), y que Apiano nos cuenta que hizo Escipión en tierras vacceas: «...segando todo, y recogiendo para su propio abastecimiento lo útil,» (Ap. 87).

Y los comentarios de Orosio y Frontino referentes a un choque con los de $\mathrm{Nu}$ mancia contradicen la versión de Apiano que expresamente dice que «Ni siquiera atacaba a los enemigos» (Ap. 87) y que «A pesar de que los numantinos salían con frecuencia en son de batalla y le provocaban al combate, los desdeñaba» (Ap. 90).

En consecuencia, vemos que ante Numancia Escipión cambia de estrategia en la forma de enfrentarse al enemigo; abandona las viejas e inútiles tácticas que habían seguido sus predecesores de ataques y enfrentamientos directos, e introduce la novedad de hacer todo lo contrario que ellos: disciplina y endurece las tropas; no sitúa avanzadas en lugares fortificados; no ataca a los enemigos y desprecia las provocaciones; observa el curso de la guerra; $y$, finalmente, recurre al asedio para rendirlos. Sin duda, todas y cada una de estas iniciativas obedecen a un plan diseñado de antemano, quizá incluso antes de partir hacia Hispania.

Volviendo al inicio, hemos visto como Schulten sitúa la tropa de Calpurnio Pisón en Tarraco. A partir de la llegada de Escipión, el sabio alemán considera que todo el ejército se traslada a los llanos de Urgel y el Ebro inferior, región de Lérida, donde cree que se desarrollan las maniobras de adiestramiento y endurecimiento descritas por Apiano, camino ya hacia tierras vacceas por Pancorbo (1937: 69 y 71; Bosch y Aguado, 1955: 163).

\footnotetext{
${ }^{27}$ «Anscheinend schätzte er die Kampfkraft seiner Truppen auch jetzt noch nicht als besonders hoch ein».
} 
Schulten piensa que es aquí, en el Ebro inferior, donde Escipión tuvo dudas sobre qué camino seguir para llegar a tierras vacceas, y donde muchos le aconsejaban el camino más corto que pasaba junto a Numancia, pero él eligió el más largo. Este camino más corto piensa Schulten que es el que partiendo del Ebro en Balsio pasa por Turiaso y Augustobriga y llega a Numancia (1905: 74; 1914: 372; 1937: 70-71) o el que remonta el valle del río Queiles desde Tudela (Cascantum - Cascante) hasta entrar en la meseta cerca de Numancia (1945: 139). El camino más largo, y el que cree que eligió Escipión, es el de Pancorbo. Recientemente Sopeña recoge y acepta la ruta BalsioTuriaso-Augustobriga-Numantia (2017: 170-171).

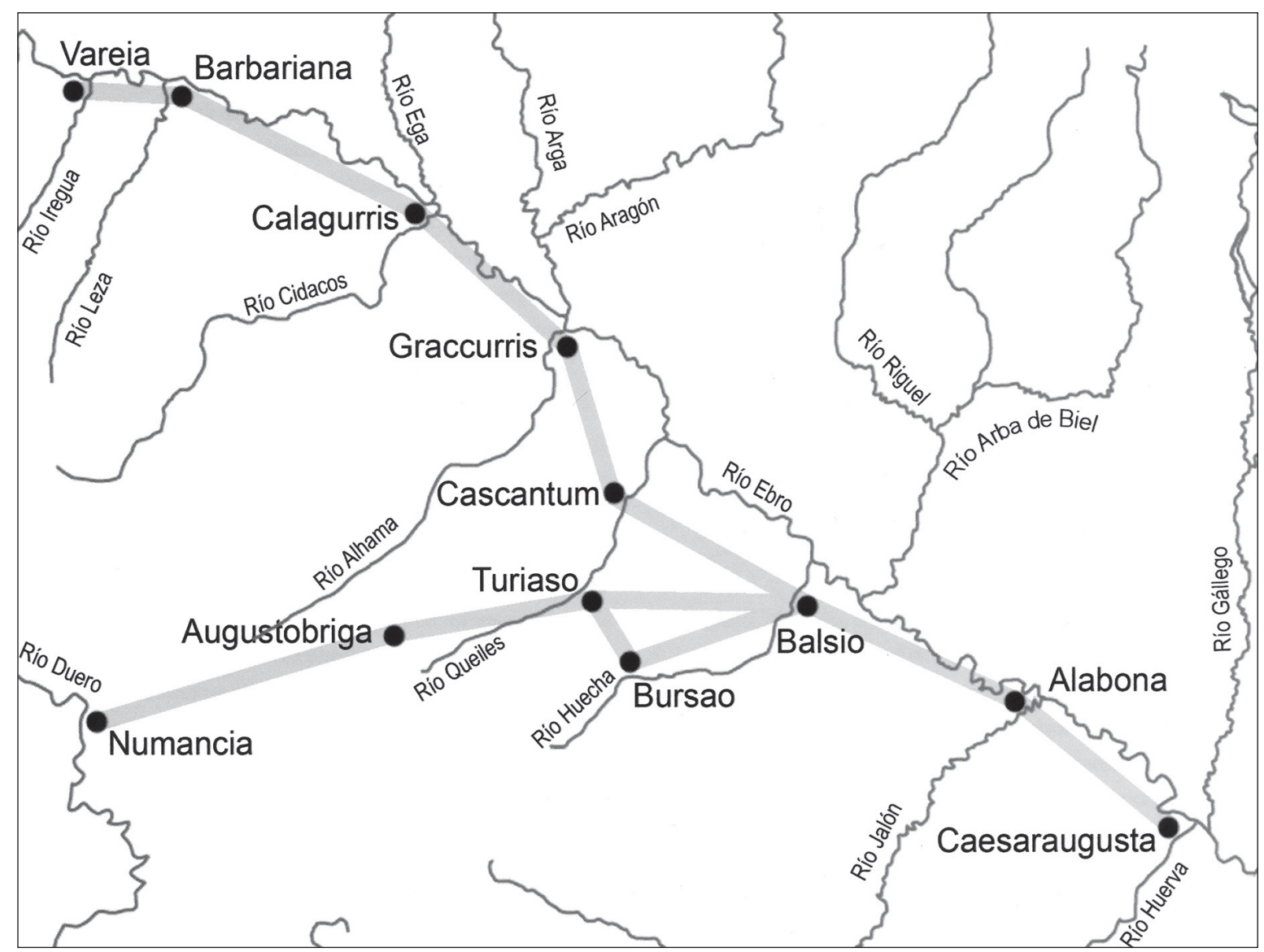

Figura 6

Mapa con el trayecto del Ebro al Duero desestimado por Escipión, según Schulten, en su viaje hacia tierras vacceas (Sopeña, 2017: 170)

Y siguiendo a Schulten, también Jimeno y Chaín piensan que la campiña donde se realizaron estos trabajos es el valle del Ebro, zona ya controlada por Roma. Pero a partir de aquí se desvinculan de Schulten y de su «ruta larga» hacia tierras vacceas y se pasan al relato de Apiano, según el cual Escipión «trasladó su campamento a las cercanías de los numantinos», en una mezcla Schulten/Apiano en la que Escipión estaba en el Ebro (Schulten) pero se acerca a Numancia (Apiano), sin duda por el camino corto que llega al Duero y a Numancia, pero que no acepta Schulten (Jimeno y Chaín, 2017: 239). 
Al parecer, este mismo esquema fue ya propuesto por Fabricius (1911: 379) y posteriormente por García Bellido, quien dice que probablemente el ejército se concentró en Tarraco, pero luego, sin mencionar el valle del Ebro, hace partir a Escipión a tierras vacceas desde Numancia, con una fracción de la tropa, pues piensa que el resto del ejército se quedó en el campamento ocupado ya en levantar el cerco (1969: cap. VI).

Como ya hemos dicho anteriormente, creemos que todos estos trabajos se llevaron a cabo en las amplias llanuras de Carpetania, al sur del Tajo, en los alrededores de los cuarteles de invierno, y teniendo a éstos como base. De esta misma opinión es Capalvo, quien considera que aunque no hay datos seguros para deducir el lugar donde se realizaron estas maniobras, lo más probable es que se realizaran en los cuarteles de Carpetania (1996: 183). Y también la Carpetania era una zona controlada por Roma.

¿Cuánto tiempo pudieron durar estos ejercicios? Nada dice Apiano sobre el particular, sólo una pequeña referencia al momento de su finalización «cuando calculo que el ejército estaba presto... trasladó su campamento a las cercanías de los numantinos» (Iber. 87). Estas maniobras de entrenamiento pudieron durar todo un mes, es decir, hasta mediados de mayo.

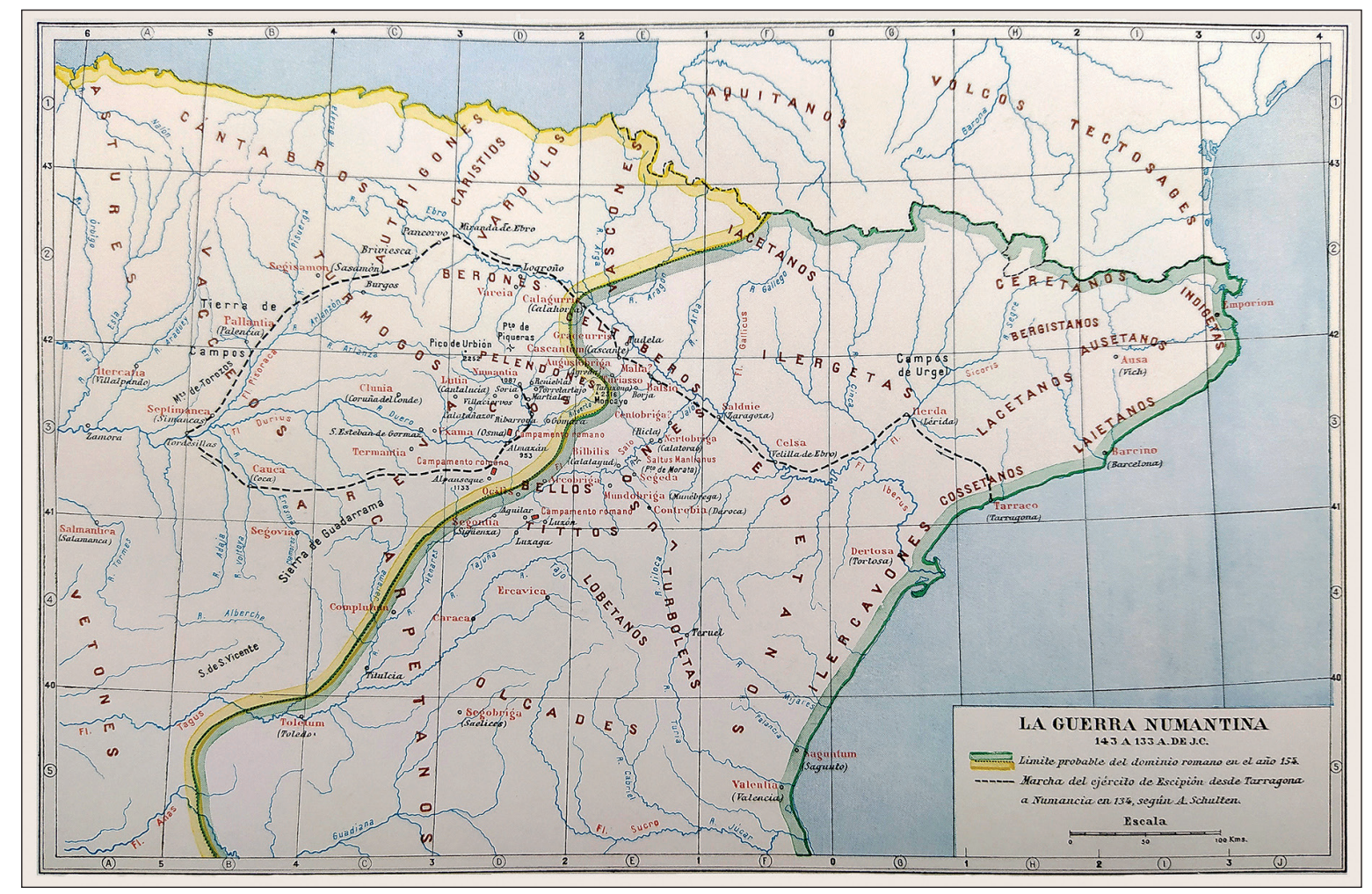

Figura 7

Mapa con el itinerario de Escipión desde Tarragona a Numancia en 134 a. C., según Schulten (Bosch y Aguado, 1955: 152) 
AP. Iber. 87.- Cuando calculó que el ejército estaba presto, obediente a él y capaz de soportar el trabajo, trasladó su campamento a las cercanías de los numantinos.

Pero no estableció, como algunos, avanzadillas en puestos de guardia fortificados ni dividió por ningún concepto a su ejército,...

No llevó a cabo tampoco ningún intento contra aquellos, pues todavía estudiaba la naturaleza de la guerra, su momento favorable y cuáles serían los planes de los numantinos.

Este párrafo de Apiano referente al acercamiento de Escipión a Numancia es posiblemente uno de los textos más controvertidos en la interpretación que hace Schulten de los textos del alejandrino.

Tras entrenar, endurecer y disciplinar a su ejército, Escipión calculó que ya estaba preparado para enfrentarse a los numantinos, o al menos «para un determinado tipo de enfrentamiento», como hemos visto anteriormente.

Schulten considera que tras el entrenamiento en el Ebro inferior (llanos de Urgel y región de Lérida), Escipión traslada su campamento cerca de Numancia, tal y como dice Apiano, pero entiende por «cercanías» la región del Ebro Medio que está separada de Numancia por la sierra que divide el valle del Ebro de la Meseta castellana, es decir, la zona de Gallúr-Mallén (1937: 70). Interpreta que es en esta zona del Ebro donde siega el trigo todavía verde, y que cronológicamente sitúa «antes de junio de 134 a. C.», ya que en esa región el trigo está maduro a principios de junio (1937: 71). De nuevo Jimeno y Chaín hacen suyas aquí las tesis de Schulten diciendo que esta acción podría ser quizá en mayo (2017: 240).

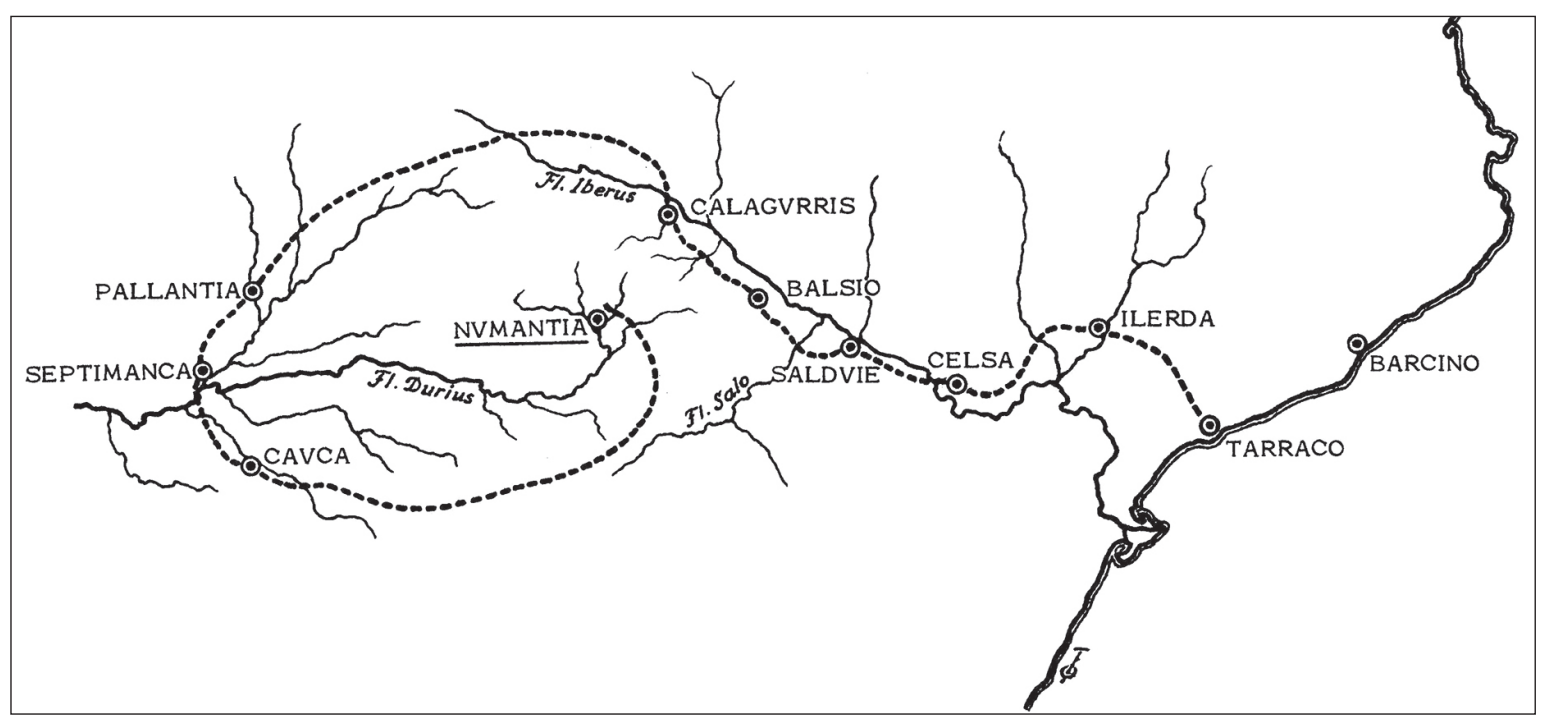

Figura 8

Mapa con el itinerario de Escipión al país de los vacceos, según Schulten

(Ortego, 1975: 37; 1985: 144) 
No estamos de acuerdo con la interpretación que hace Schulten del texto de Apiano, pues según éste Escipión se trasladó a las cercanías de los numantinos. Por tanto, el campamento de Escipión debía estar relativamente cerca de Numancia, ya que Apiano dice a continuación que «No llevó a cabo tampoco ningún intento contra aquellos, pues todavía estudiaba la naturaleza de la guerra, su momento favorable y cuáles serían los planes de los numantinos», es decir, circunstancias que exigen una cierta proximidad.

Schulten cree que desde la zona de Gallúr-Mallén donde se encontraba, Escipión tomó el camino que remonta el río llegando al Alto Ebro, y a través del desfiladero de Pancorbo entró en la meseta castellana hasta el territorio vacceo, donde el ejército romano segó el trigo ya maduro, por lo que calcula que debía ser finales de julio del 134 a. C., momento de la cosecha allí (1937: 71), recogiendo lo útil para su aprovechamiento y quemando el resto. Bosch y Aguado siguen a Schulten (1955: 164), y recientemente Sopeña, en una paráfrasis de la propuesta de Schulten, recoge este mismo itinerario, aunque el regreso de Escipión desde Cauca lo hace pasar por la celtíbera Segovia para tomar el camino natural que posteriormente se convertiría en la Cañada Soriana Occidental (Sopeña, 2013: 568-571; 2017: 170-171).

Y también Salinas piensa, como Schulten, que Escipión llevó el ejército al Ebro para su adiestramiento, pero receloso de las tribus no quiso entrar en Celtiberia, sino que prefirió dar un rodeo por Pancorbo (1986: 18).

Continuando con los postulados de Schulten, a través de Pancorbo llegó Escipión a tierras de Palantia, considerándola la actual Palencia (a orillas del río Carrión), en cuyas cercanías se encontraba la llanura de Coplanio donde los vacceos le tendieron una emboscada. Sin embargo, Schulten comete aquí un error (reproducido posteriormente por otros autores), ya que hay dos Palantias: ésta Palantia de Apiano se corresponde con la actual localidad de Palenzuela, entre Palencia y Burgos, donde existe un importante yacimiento vacceo (González González, 1990: 36-37, 68-71, 81 y 94).

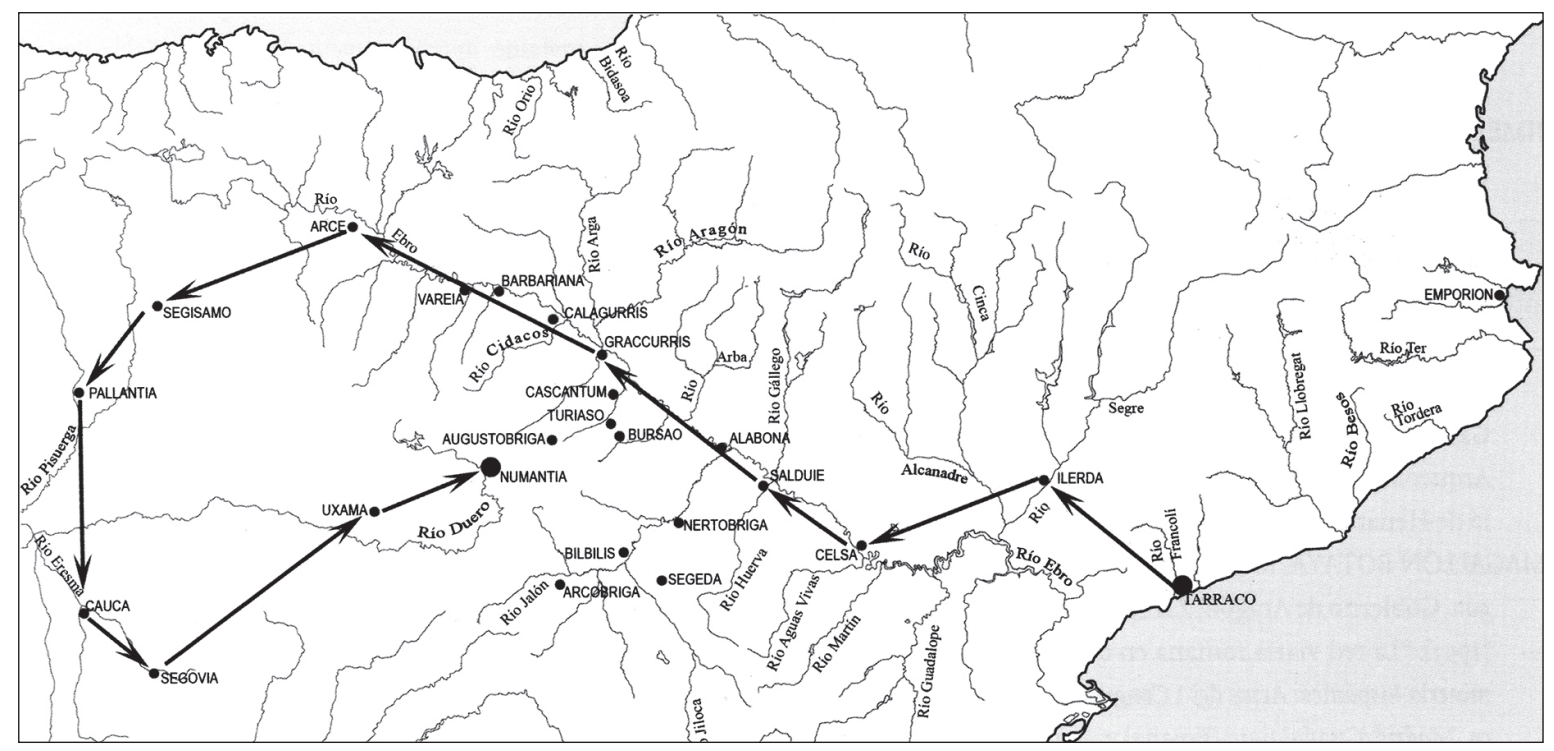

Figura 9

Mapa con la ruta de Escipión remontando el Ebro hasta Arce (Miranda de Ebro) y su periplo por tierras vacceas, según Schulten (Sopeña, 2017: 170) 
Desde aquí, Schulten hace continuar a Escipión bajando por el valle del Pisuerga hacia cerca de la actual Simancas, por donde cruzó el río Duero. Remontando el Eresma llegó a la ciudad de Cauca (1937: 72), citada por Apiano, anunciándoles que podían regresar sin miedo a sus hogares, ya que al llegar el ejército romano los caucenses habrían huido de la ciudad recordando la masacre de Lúculo, con quien había servido el propio Escipión algunos años antes (Ap. 51-52). Desde Cauca Escipión se dirigió a Numancia para pasar el invierno. Jimeno parece compartir este recorrido al afirmar que Escipión accede a Numancia desde territorio caucense para establecer su cerco a esta ciudad (2011: 234).

Schulten no menciona el itinerario que pudo seguir Escipión entre Cauca y Numantia. Únicamente dice que «pasó al norte de la ciudad y continuó por el Duero arriba camino de Numancia». También menciona que en su regreso cayó en una emboscada en un barranco, que supone puede tratarse de una de las muchas hoces que van de la sierra de Guadarrama al Duero, con lo que está indicando que la ruta iba al oeste de la ciudad de Segovia (1945: 141), es decir, al pie de la meseta, al sur del Duero (1937: 74).

Sin embargo, y a pesar de toda esta interpretación subjetiva que hace de los textos de Apiano para sacar adelante sus conclusiones prefijadas, Schulten tuvo inicialmente dudas sobre dónde se unió Escipión al ejército. Y su primera opción fue pensar que el ejército permanecía en el Tajo y que fue Escipión quien se incorporó a él ${ }^{28}$ (1905: 74).

Pero luego lo reconsidera y ve que esta suposición no está de acuerdo con lo que escribe Apiano en el capítulo 87, puesto que si el ejército estaba en Tarraco la marcha lógica hacia el país de los vacceos es remontando el Ebro con dos alternativas: una hacia el Duero, y otra por las montañas, de las que Escipión, en contra de todos, elije la más larga pero más segura. Y en esta ruta la primera ciudad que se cita es Palantia.

Y también esgrime, apoyando su ruta por el Ebro, que si el camino hacia los vacceos hubiera partido de Carpetania la primera ciudad que se habría encontrado Escipión habría sido Cauca, por lo que el itinerario desde Carpetania no es posible.

Sin embargo, todos estos argumentos son muy discutibles desde el momento en que Apiano dice que cuando le pareció a Escipión que el ejército estaba preparado se trasladó cerca de los numantinos (Ap. 87); que sufrió una emboscada en una aldea (de los alrededores de Numancia), y ya al final del capítulo Apiano relata que salió del campamento hasta las tierras de los vacceos.

Tampoco Capalvo está de acuerdo con Schulten, pues interpreta que Apiano es muy claro es este sentido: la palabra griega $\dot{\alpha} \gamma \chi o \tilde{v}$ significa «junto», «al lado de», lo que implica que las tropas estaban acampadas en las proximidades de Numancia. Además, la «observación», en griego $\pi \varepsilon \rho l \sigma \kappa o \pi \tilde{\omega} v$, de todo lo relativo a la guerra y a los numantinos no debía dejar duda sobre la cercanía a Numancia (1996: 184).

\footnotetext{
${ }^{28}$ «Man könnte zunächst annehmen, dass das Hear am Tajo geblieben und von ihm aufgesucht worden sei».
} 
En relación con estas hipótesis de Schulten, que nada tienen que ver con el texto de Apiano, el propio Capalvo nos presenta un interesante pasaje de Giménez Soler en el que este autor critica la interpretación de Schulten de hacer remontar a las legiones romanas todo el valle del Ebro hasta Miranda para entrar en Castilla iipor los desfiladeros de Pancorbo!!, por lo que comenta que «no ve la finalidad que se propuso Schulten al establecer marcha tan fuera de la geografía, tan contraria a los buenos usos militares y tan contradictoria con los planes tácticos de Escipión» (Giménez, 1921: 31-32).

Por nuestra parte, ajustándonos a los textos de Apiano, presentamos una alternativa a las hipótesis de Schulten basada en varios acontecimientos que han quedado perfectamente asentados y que no admiten discusión. Pero también es cierto que en base a estos mismos acontecimientos Schulten dedujo una serie de hipótesis que como dice Capalvo nada tienen que ver con el texto de Apiano.

- Los cuarteles de invierno de Calpurnio Pisón estaban en Carpetania.

- Escipión, con unos pocos, se adelantó hacia Iberia para unirse al ejército.

- Trasladó su campamento a las cercanías de los numantinos.

- Y se dirigió a continuación al territorio de los vacceos.

Hemos aceptado que Escipión pudo haber llegado en barco a Tarraco en los primeros días de abril de 134 a. C. También hemos propuesto un posible itinerario por el que se incorporó al ejército en Carpetania, quizás a mediados de abril. Tras entrenar y disciplinar el ejército en las llanuras de Carpetania, a mediados de mayo Escipión decidió acercarse a su objetivo: Numancia.

Partiendo de la zona sur de Carpetania (Consábura/Toletum) ya que desconocemos dónde estaban los cuarteles de invierno, Escipión cruzó el Tajo quizá por la zona de Toledo, como antes lo hiciera con su comandante Licinio Lúculo en 151 a. C. Desde aquí seguiría por el camino indígena (que después se convertiría en la vía XXV del Itinerario de Antonino Emerita-Caesaraugustam) que remonta el Tajo hasta Titulcia (Titulcia), y por los valles del río Jarama y después del río Henares pasa por las ciudades carpetanas de Complutum (Alcalá de Henares) y Arriaca (Guadalajara) para entrar en territorio celtíbero por la ciudad de Caesada (Espinosa de Henares?). El camino sigue el río Henares por la celtíbera Segontia (Sigüenza) hasta enlazar con la cabecera del río Jalón al otro lado de la Sierra Ministra, cerca de la actual Medinaceli ¿Occilis? ${ }^{29}$.

\footnotetext{
${ }^{29}$ La tradicionalmente aceptada reducción Occilis = Medinaceli parece que no puede mantenerse en función de los últimos estudios. (FATÁS CABEZA, G. (1985): «Una tésera cortonense». En: Melena, J. L. (Edit), Symbolae Ludovico Mitxelena Septuagenario Oblatae, Vol. 1, Veleia anejo n. 1, Vitoria; PASTOR EIXARCH, J. M. (1996): «Sobre la identificación de Segontia con Medinaceli y la localización junto a ella de un posible "castra". Celtiberia, 90, Centro de Estudios Sorianos (CSIC)», Soria; BURILLO MOZOTA, F. (1998): Los Celtíberos. Etnias y Estados. Barcelona; GÓMEZ FRAILE, J. Mª (2001): Los celtas en los valles altos del Duero y del Ebro. Alcalá de Henares; PASTOR EIXARCH, J. M. (2014): «Segontia, la que ahora llaman comúnmente Medinaceli (Rodrigo Ximénez de Rada, 1170-1247)». En: Chordá, M. y Burillo, F. (Coord), VII Simposio sobre los celtíberos. Nuevos Hallazgos, Nuevas Interpretaciones, Daroca, 103-112.
} 
Abandonando aquí este camino y tomando dirección norte, Escipión pudo llegar a Numancia en un viaje de cuatro jornadas por Almazán y Ribarroya, donde existen campamentos romanos, intuyendo la posibilidad de otro más en las proximidades de Adradas (Schulten, 1945: 62-63), que podría confirmarse por los recientes hallazgos realizados en esta localidad (Revilla, 1985: 16-18). Taracena, que parece aceptar este camino entre Medinaceli y Almazán en tiempos de la conquista, lo desestima para época imperial al no existir en esta línea ruinas romanas (1934: 274).

El tiempo que se puede estimar para el trayecto de Carpetania a Numancia depende del punto de partida. En el caso de que los cuarteles de invierno hubieran estado próximos a Toletum el viaje hasta Numancia, de unos $390 \mathrm{~km}$, habría durado unos 13/15 días, que se incrementarían en dos jornadas más si las legiones hubieran salido de los alrededores de Consabura, es decir, una marcha de entre 15 y 17 días, por lo que Escipión pudo haber llegado a Numancia en los primeros días de junio del año 134 a. C. (Morales, 2009a: 86), fecha que vendría respaldada por el comentario de Apiano 87 cuando dice que «segó el trigo todavía verde».

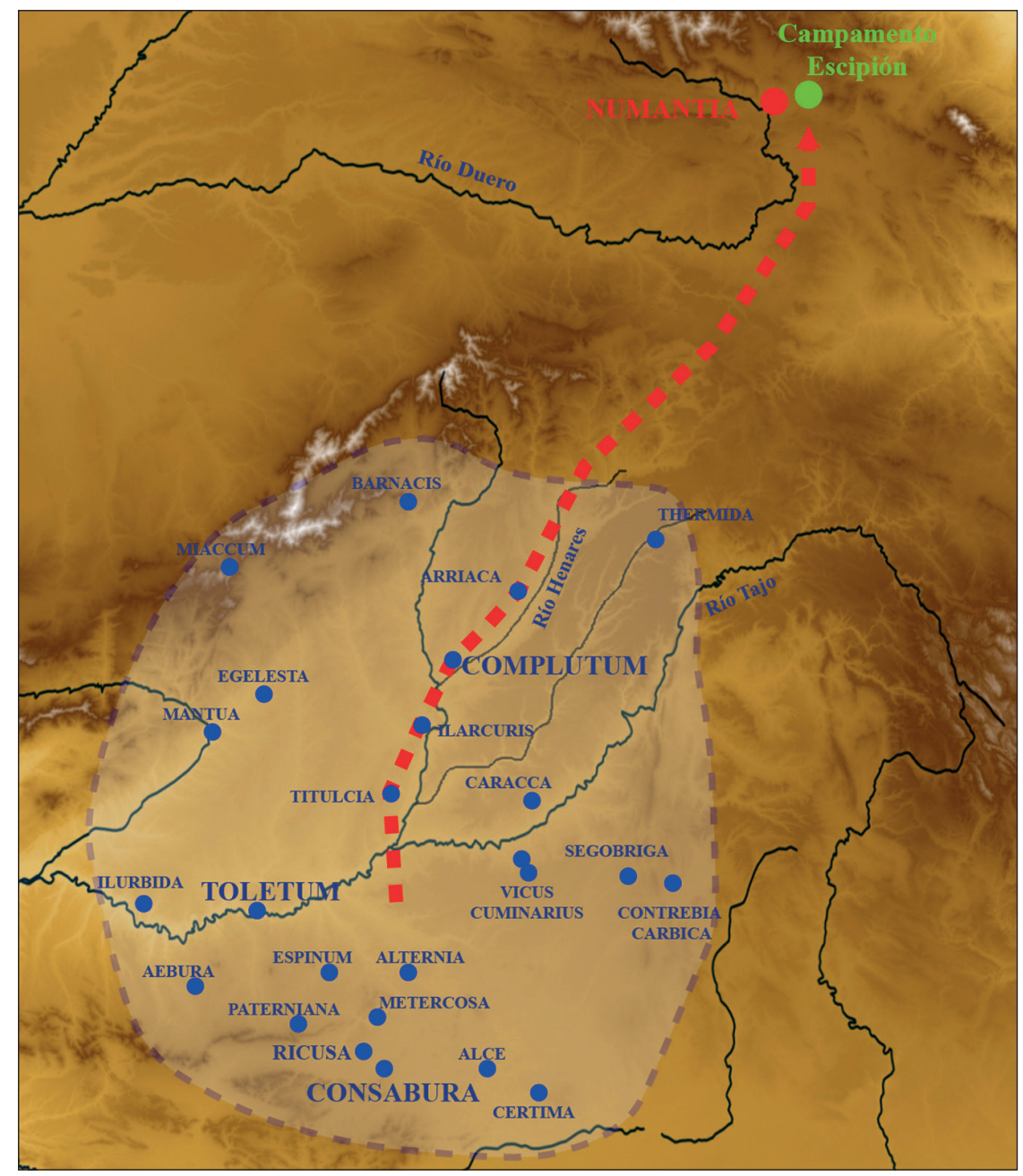

Figura 10

Mapa con el posible itinerario de Escipión desde el sur de Carpetania donde había entrenado al ejército hasta territorio numantino (dibujo C. Tabernero/Areco Arqueología) 
Nada dice Apiano, ni otras Fuentes, sobre dónde se instaló Escipión al llegar a territorio numantino, únicamente que «en las cercanías» de Numancia. Actualmente ha sido probada la ubicación de su campamento en el «Talayón» o «Gran Atalaya» de Renieblas. Sin embargo, en este cerro Schulten descubrió y excavó los restos de 5 campamentos a los que atribuyó diferentes cronologías: campamentos I y II de 195/194 a. C.; campamento III de 153 a. C. y campamentos IV y V de 75/74 a. C., a pesar de lo cual ninguna de ellas coincidía con el periodo escipiónico.

Fabricius, uno de los colaboradores de Schulten, cuestionó desde el principio las fechas atribuidas a los Campamentos IV y V de Renieblas, que éste colocaba, como se ha dicho, en época sertoriana, pero que aquél prefería interpretarlos como dos sucesivos establecimientos de Escipión, el más antiguo, el campamento IV, un castra aestiva levantado durante el primer acercamiento a Numancia, es decir, este que Apiano sitúa «en las cercanías» de la ciudad. El segundo, campamento V del que ya hablaremos, debía corresponder al hiberna al que regresó Escipión Emiliano después de la expedición vaccea, es decir, en el otoño de 134 a. C. (1911: 378-382).

La razón principal de la hipótesis de Fabricius es que difícilmente podía haber habido una circunstancia histórica distinta al propio asedio de Numancia que justificase un campamento tan grande y tan bien equipado como el V de Renieblas, donde se iniciaron los preparativos del asedio y desde donde Escipión podía observar Numancia. Muchos años después, la revisión del material numismático hallado en las excavaciones del Talayón llevó a Hildebrandt a la misma conclusión, fechándolo en 135/130 a. C. (1979: 238-271).

Tras la publicación de Hildebrandt, Jimeno considera, por la asociación de monedas y ánforas CCNN, que el campamento de Escipión puede ser el campamento V de Renieblas (Jimeno y Martín, 1985: 186 y 188), y aunque posteriormente sigue manteniendo la ocupación escipiónica del campamento V (2006: 180) recientemente parece retractarse de su atribución inicial (Jimeno y Chaín, 2017: 241).

Sanmartí aceptó la cronología escipiónica de Hildebrandt para el campamento V (1985: 150 y nota 20; 1992: 419 y 428), que ha sido empleada después como fósil director para datar diverso material arqueológico presente en Renieblas (Romero, 1990: 258, nota 8 y 287; Sanmartí y Principal, 1997: 38).

Aunque sin definir un lugar concreto, también Capalbo acepta que el campamento estaba junto a Numancia, una sólida base de operaciones desde donde se habrían realizado las acciones de saqueo del entorno primero y la expedición hacia los vacceos después. Y cree probable, como también lo hiciera García Bellido (1969: cap. VI), que Escipión no llevara todo su ejército contra los vacceos (de ahí las dificultades encontradas en los campos palantinos), sino que una parte debió quedarse guardando el campamento, las provisiones y el material de asedio, además de mantener la presión sobre la ciudad (Capalbo 1996: 185). Por el contrario, García Bellido piensa (ignorando a Apiano) que el grueso del ejército que se quedó como guarnición del campamento estaba ya ocupado «en las obras circunvalatorias de Numancia que estaban entonces - primavera y verano del año 134- en plena actividad» (1969: cap. VI). 
Sin embargo, estas opiniones contradicen el relato de Apiano, quien dice expresamente que Escipión no dividió por ningún concepto a su ejército.

Desde nuestros primeros trabajos sobre el cerco de Numancia hemos considerado que el primer campamento de Escipión, que podríamos definir como el de verano, habríamos de buscarlo en la Gran Atalaya de Renieblas (Morales, 2000: 239; 2004: 252 y 256). Hallazgos posteriores no solo nos han reafirmado en esta creencia, sino que nos han llevado a insinuar que el campamento de Escipión podría ser una reocupación del campamento III de Renieblas atribuido al consúl Fulvio Nobilior en 153 a. C. (Gómez-Pantoja y Morales, 2008: 51) y recientemente a confirmar esta atribución (Morales y Morillo: en prensa).

Acampado cerca de Numancia Escipión estableció una serie de medidas preventivas para evitar desde el comienzo que algún descalabro le hiciera despreciable y objeto de burla a ojos de los enemigos. Así, no estableció avanzadillas en puestos de guardia fortificados, no dividió por ningún concepto a su ejército, ni llevó a cabo ningún ataque contra los numantinos, pues, haciendo gala de su proverbial prudencia y buen juicio, estudiaba la naturaleza de la guerra, su momento favorable y cuáles serían los planes de los numantinos.

Recorrió, en busca de forraje, toda la zona situada detrás del campamento y segó el trigo todavía verde. Cuando hubo segado todos estos campos, se hizo preciso marchar hacia adelante. Había un atajo que pasaba junto a Numancia en dirección a la llanura y muchos le aconsejaban que lo tomara. Manifestó, sin embargo, que temía el retorno, pues los enemigos estarían, entonces, descargados y tendrían a su ciudad como base desde donde atacar y a la que poder retirarse. Y añadió: «en cambio los nuestros retornarán cargados, como es natural en una expedición que viene de recoger trigo, y exhaustos, y llevarán animales de carga, carros y vituallas. El combate será muy difícil y desigual; arrostraremos un gran peligro, si somos vencidos, y sin embargo, en caso de vencer, no obtendremos una gloria grande ni provechosa. Es ilógico exponerse al peligro por un resultado pequeño... Después de haber dicho esto, ordenó a sus oficiales que hicieran la ruta por el camino más largo».

Además, con objeto de privar a los de Numancia de provisiones y a la vez acarrear suministros en su propio beneficio, dice Apiano que recorría los campos que había detrás del campamento segando el trigo todavía verde. Esto, como ya hemos señalado, podría suceder a primeros de junio (Morales 2009a: 86). Cuando acabó de segar estos campos, Escipión quiso avanzar hacia otros, pero el camino pasaba cerca de Numancia, por lo que era arriesgado tomarlo ya que al regreso los numantinos podían atacarle desde la ciudad.

Partiendo, como parece probado, de que Escipión instaló su campamento en la gran Atalaya de Renieblas, teniendo en frente a Numancia, los campos que había detrás deben corresponder a los llanos de parte del Campillo de Buitrago (Pedraza, Almajano, Canos, La Aldehuela de Periañez y Arancón). Cuando quiso avanzar hacia otros, cuyo camino pasaba cerca de Numancia, pueden tratarse de las llanuras que 
hay a ambos lados del río Tera, al oeste de Garray, Tardesillas y Chavaler, a los que se accede sin necesidad de cruzar el río Duero.

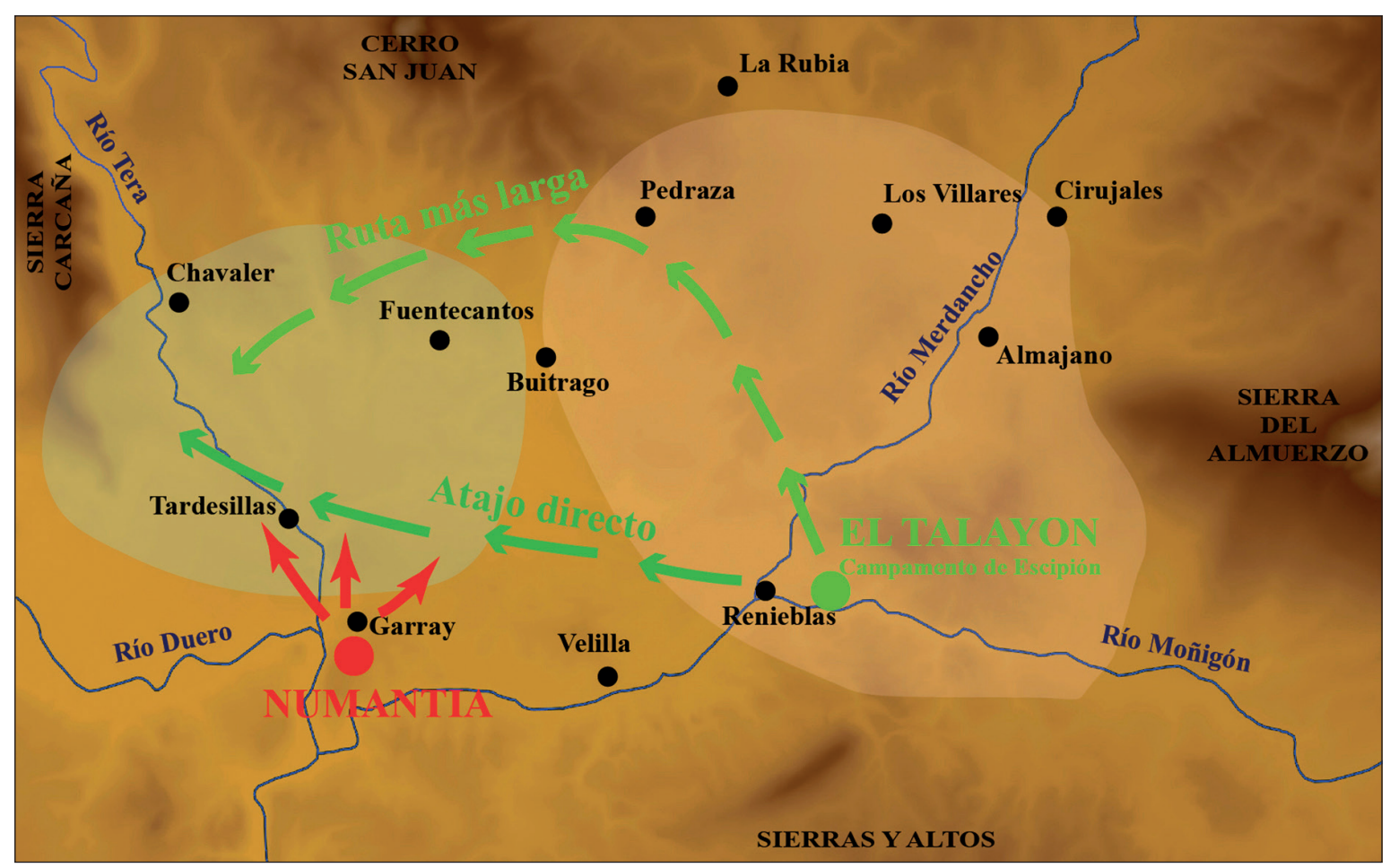

Figura 11

Mapa de los alrededores de Numancia, con el campamento de Escipión en «El Talayón» de Renieblas y las zonas donde pudo segar el trigo detrás y delante del campamento (dibujo C. Tabernero/Areco Arqueología)

Acompañó, entonces, a la expedición hasta el límite del campamento y se dirigió a continuación al territorio de los vacceos, de donde los numantinos compraban sus provisiones, segando todo lo que encontraba y reuniendo todo lo que era útil para su alimentación, mientras que lo sobrante lo amontonaba en pilas y le prendía fuego.

Hemos visto que Escipión había establecido su campamento en el «Talayón» o Gran Atalaya de Renieblas, en las cercanías de Numancia. La salida hacia tierras vacceas pudo haberse producido poco antes de mediados del mes de julio. Nos interesa ahora determinar el posible itinerario que pudo seguir el general romano hacia el territorio de los vacceos.

Considera Taracena que las vías romanas de época imperial seguirían en gran parte trazados anteriores, «marcados por el tráfico secular de la población indígena» (193435: 259), es decir, que aprovecharon viejos caminos indígenas preexistentes (Sánchez Verdú, 2016: 139); sin embargo, y en contra de esta difundida creencia, actualmente se sabe que los romanos trazaron sus vías, comerciales o militares, con otros criterios (las vías romanas comunicaban ciudades romanas, principalmente, romanizadas o ex novo, «vías rápidas» aunque, con el tiempo, en su recorrido fueran surgiendo otros 
establecimientos) y proyectadas y construidas con criterios de ingeniería (trazados rectilíneos, estructuras complejas, aporte de materiales, nivelaciones, obras constructivas, etc, (Moreno Gallo, S/AÑO; 2006; 2010a; 2010b: 14). Pero esta red de calzadas, salvo excepciones, no fue una creación nueva de los romanos. Algunos caminos indígenas de origen ancestral, y posiblemente ganadero, se convertirían en auténticas vías, aunque generalmente de nivel secundario, que seguían cursos fluviales «y que dibujan una retícula mucho más rica de trayectorias» (Alfaro, 2001: 218-225; García Martín, 2001: 14).

Sin embargo, aquí no nos interesan las vías romanas ni sus productos derivados, sino los caminos y vías naturales prerromanas que pudieron haber sido frecuentados por la población indígena como vías pecuarias y de comunicación anteriores a la conquista romana, y de las que presumiblemente se sirvió Escipión en su periplo vacceo.

En este sentido, parece probado que los valles fluviales, especialmente la red fluvial mayor, fueron espacios de asentamiento y de armazón del poblamiento, y por tanto «corredores naturales que encauzan la circulación y comunicación regional» (Sacristán et al., 1995: 352-353), y también, de manera genérica, vías pecuarias y cañadas ovinas, como ocurre en territorio vacceo, especialmente durante la primera y segunda Edad del Hierro, de economía predominantemente ganadera, y de las que se sirvieron los romanos como rutas de penetración (Sierra y San Miguel, 1995: 391-398).

Schulten por su parte consideraba que «los caminos naturales de penetración en la meseta y la red de comunicaciones comarcales durante los siglos II y I antes de J. C, demostrarían un perfecto conocimiento de la topografía del Duero por parte del mando romano» (1914: 299-214).

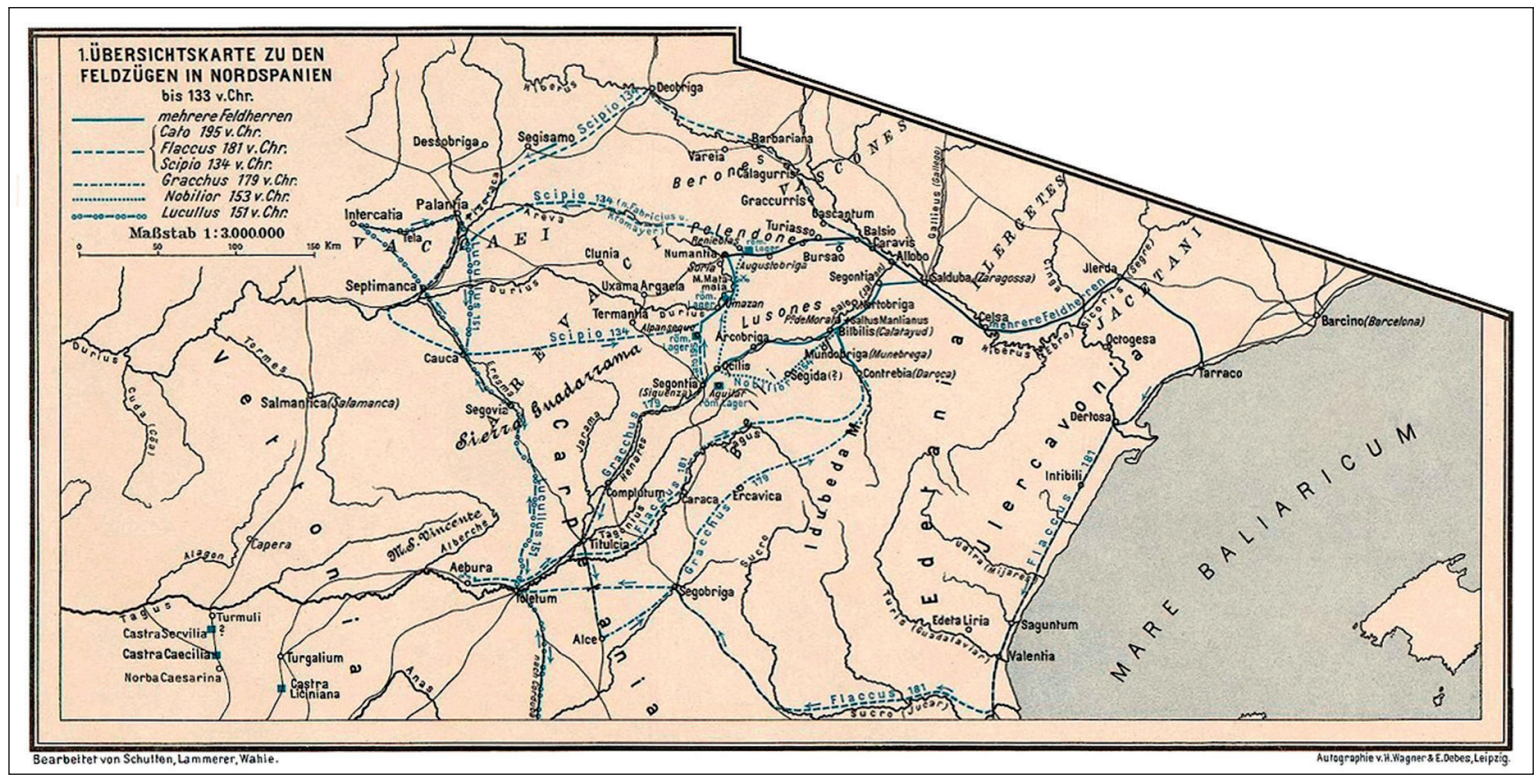

Figura 12

Mapa con el itinerario de Escipión al país de los vacceos, por el Ebro según Schulten (Scipio 134), y por el río Arlanza (Areva) según Fabricius y Kromayer (Scipio 134 n. Fabricius u. Kromayer)

(Schulten, 1922: Blatt. 12. 1) 
La ruta de Escipión desde su campamento en la Gran Atalaya de Renieblas hacia el territorio vacceo podría haber seguido el camino natural que remonta el curso del río Duero, un posible camino celtibérico con inicio en Numancia.

Taracena denomina a este camino «Vía Municipal del Alto Duero» (1934-5: 274275), un camino prerromano que se revela en primer lugar por la presencia del castro celtíbero de La Virgen del Castillo de El Royo ${ }^{30}$, que, aquí sí, los romanos convirtieron en Vía Augusta y que viene marcada también por la villa romana de Tardesillas (Morales, 1995: 257-258), las 2 inscripciones romanas de Dombellas, las 3 de Santervás de la Sierra, y la de Langosto (Jimeno, 1980: 79-80, 125-129 y 88-89), así como por la inscripción romana rupestre de Vinuesa, en la que consta como constructor un magistrado municipal, el duunviro L. Lucretius Densus (Jimeno, 1980: 164-165). El camino seguiría por los lugares de Covaleda y Duruelo de la Sierra para entrar en tierras burgalesas y enlazar con la cabecera y valle del río Arlanza. En la provincia de Burgos ${ }^{31}$ la ruta continúa por Regumiel de la Sierra, siguiendo el curso del río Zumiel que desagua en el río Arlanza en la localidad de Quintanar de la Sierra, donde se localiza el castro de «La Cerca» ${ }^{32}$.

Acompañando el curso del Arlanza la vía sigue por Palacios de la Sierra y Salas de los Infantes donde se descubren sendos castros prerromanos, «El Castillo» $\mathrm{y}$ «El Castro» respectivamente ${ }^{33}$, y por los lugares de Barbadillo del Mercado y Hortigüela en cuyos términos existen restos romanos. Y en Covarrubias se encuentra el yacimiento de «La Muela» ${ }^{34}$. Es decir, el curso del río Arlanza es una reconocida vía natural de comunicación que sigue su curso hasta que confluye con el río Arlanzón cerca de Palantia-Palenzuela (Abasolo y García, 1980: 149).

De forma aproximada, esta ruta de Escipión por los ríos Duero-Arlanza (al que llaman Areva), ya fue imaginada por Fabricius y Kromayer para acceder a territorio vacceo (Schulten, 1922: 61-61 y Kärtchen 1: Marschlinie «Scipio 134 nach Fabricius und Kromayer»).

${ }^{30}$ Este castro ya fue reconocido y excavado por Taracena (1929: 6-7; 1941: 145-146) y posteriormente por Eiroa, quien reconoce una ocupación en el Hierro I, con fecha radiocarbónica de 530 a. C. y una fase celtibérica con inicio hacia el 320 a. C., y su final con las guerras celtibéricas. (Eiroa 1984-85: 147-148 y 202; Romero 1991: 94-101).

${ }^{31}$ Queremos hacer constar nuestro agradecimiento a D ${ }^{\text {a }}$ Cristina Echeverría Zarranz, arqueóloga territorial del Servicio Territorial de Cultura, Delegación Territorial de la Junta de Castilla y León en Burgos, por facilitarnos el acceso a la plataforma PEME Catálogo de Yacimientos de la JCyL de Burgos.

32 Únicamente se habla de un «poblamiento prerromano castreño», pero la descripción de los hallazgos nos revela un típico castro de la Primera Edad del Hierro, de los siglo VI a IV a. C. (Abasolo y García 1980: 78-79; Sacristán y Ruiz 1985: 191).

${ }^{33}$ La atribución del yacimiento de Palacios al Hierro I no es segura y únicamente está basada en lo estratégico del lugar (Abasolo y García 1980: 76). No obstante, en el PEME Catálogo de Yacimientos de la JCyL su atribución cultural es Hierro II. En Salas, por el contrario, está perfectamente documentada la existencia de «El Castro», de la Primera Edad del Hierro con continuidad en época celtibérica (Abasolo y García 1980: 82; PEME Catálogo de Yacimientos de la JCyL).

${ }^{34}$ La Muela es un castro con ocupaciones durante el Hierro I con continuidad en época celtibérica (Sacristán y Ruiz 1985: 187; Sacristán 1998:13). 


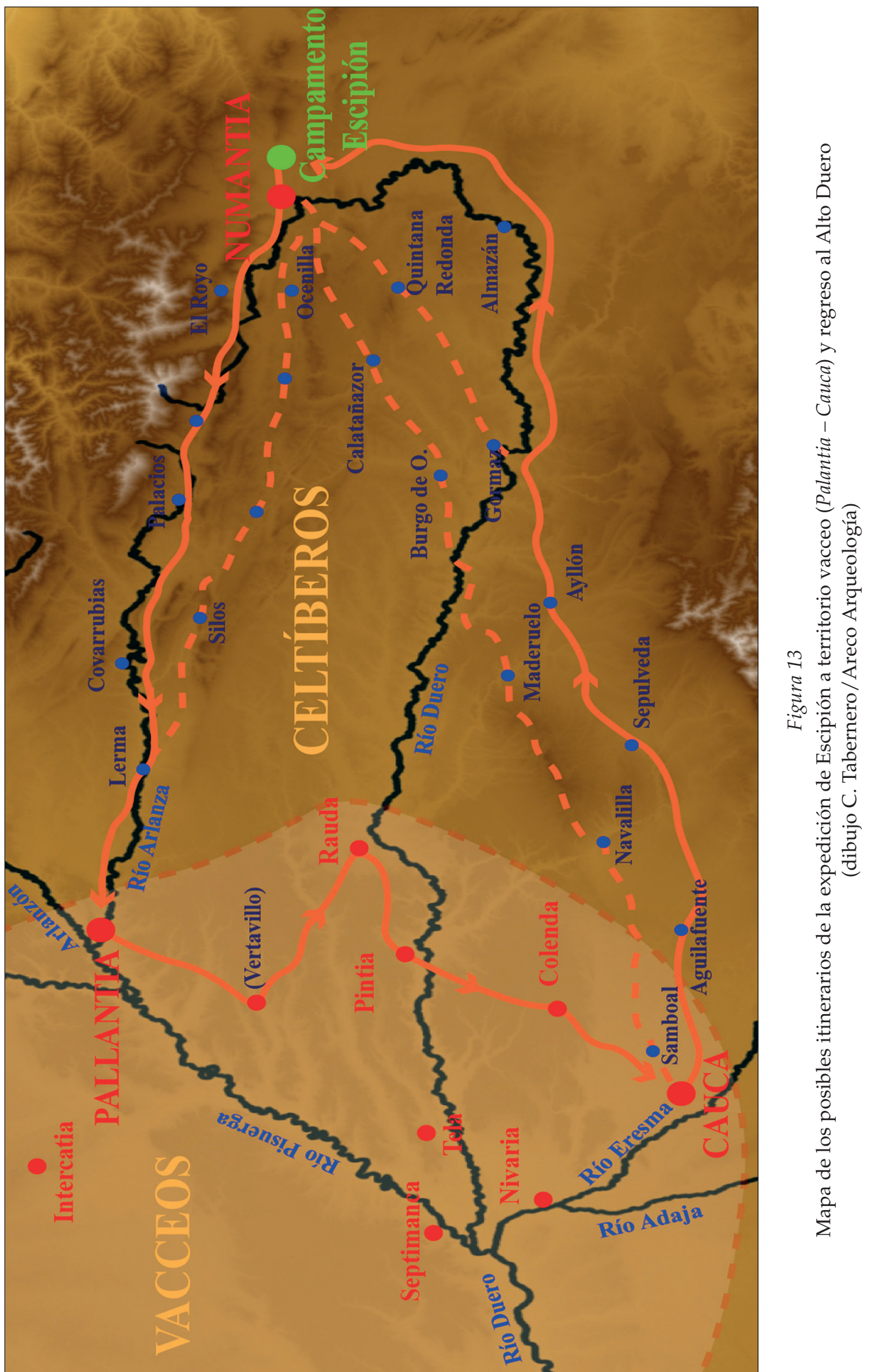


Otra posible ruta, alternativa al Duero-Arlanza, es la que partiendo igualmente de Numancia corre al norte y a los mismos pies de la Sierra de Cabrejas, coincidiendo grosso modo con el trazado de la actual carretera nacional N-234 hacia la provincia de Burgos. En ella se encuentran los castros celtíberos de «Los Castillejos» de Oceni$11 a^{35}$, y «El Pico» de Cabrejas del Pinar ${ }^{36}$. Seguiría por los lugares de Navaleno y San Leonardo de Yagüe para continuar en la provincia de Burgos, siguiendo el curso de la N-234 que corre paralelo al río Lobos por Hontoria y Navas del Pinar, con sendos castros prerromanos ${ }^{37}$, y por La Gallega, para desviarse poco después hacia Carazo, con restos romanos, y entrar en el valle del río Mataviejas, y a través de su estrecho desfiladero llegar a Santo Domingo de Silos, con varios asentamientos prerromanos ${ }^{38}$. Desde aquí seguiría por la carretera provincial BU-901 y BU-900, en cuya ruta se encuentra Solarana con el poblado de «El Castro» ${ }^{39}$ hasta Lerma, donde enlaza con la anteriormente citada ruta del río Arlanza (Abasolo y García, 1980: 151).

Estas dos rutas que corren paralelas gran parte de su trazado tienen, además, reconocidas vías transversales que las unen ofreciendo varios itinerarios alternativos; así, desde Hontoria del Pinar y La Gallega, siguiendo la carreta N-234 se llega al valle del Arlanza en Salas de los Infantes, para continuar por el valle hacia Barbadillo del Mercado (Abasolo y García, 1980: 151), y un poco más adelante otro enlace sería el que desde Santo Domingo de Silos lleva a San Pedro de Arlanza (Abasolo y García, 1980: 151) o Covarrubias, ambos ya en la vía del Arlanza.

En esta empresa Escipión pudo emplear unos 7 días de marcha continuada. Pero desconocemos por dónde y cómo realizó el viaje, si efectuó paradas de forrajeo y avituallamiento, etc, por lo que no podemos estar seguros del tiempo empleado en llegar a Palantia o el momento en que alcanzó los alrededores de la ciudad.

${ }^{35}$ Taracena, que realizó excavaciones en el castro, lo fecha entre la segunda mitad del siglo III a. C. y las guerras numantinas, siendo abandonado entre los años 153 y 133 a. C. (Taracena 1932: 51; 1941: 122-124).

${ }^{36}$ Con idéntica cronología que el castro de Ocenilla (Taracena 1941: 45; Romero 1991: 61-63).

${ }^{37}$ En Hontoria del Pinar se encuentran los yacimientos de «El Castro», un poblado celtibérico con una posible ocupación anterior (Abasolo y García 1980: 48-49) y «El Castillejo», un castro del Primer Hierro (PEME Catálogo de Yacimientos de la JCyL). En Navas del Pinar se localiza el castro «Pico de Navas», que por la descripción se trata de un castro de la Primera Edad del Hierro (Abasolo y García 1980: 51-52; Sacristán y Ruiz 1985: 187).

${ }^{38}$ Nos referimos a los castros de «El Picacho» del Hierro I (Abasolo y García 1980: 87; Sacristán y Ruiz 1985: 195); «Peña de Nuestra Señora» también del Primer Hierro (Abasolo y García 1980: 88) y el conocido de «La Yecla», con ocupación del Hierro I y también en época celtibérica (Abasolo y García 1980: 89-93). A estos habría que añadir, por su proximidad a Santo Domingo de Silos, el castro de «Pico Castro», en Hortezuelos, con ocupaciones durante el Primer Hierro y en época celtibérica (Abasolo y García 1980: 94-95).

${ }^{39}$ Es un asentamiento en altura con ocupación continuada durante la primera y segunda Edad del Hierro (Osaba 1964: 266; Sacristán y Ruiz 1985: 188, 195 y 210; Sacristán 1998: 5, 13 y 53). 
Al final del capítulo Apiano refiere que Escipión se dirige a territorio vacceo donde los numantinos compraban los alimentos, segándolo todo, guardando lo útil y quemando el resto. ¿Es posible que antes de llegar a Palantia Escipión ya viniera haciendo esto? Porque Palantia se encuentra en el límite del territorio vacceo con los arévacos y Apiano comenta este proceder antes de llegar a la ciudad vaccea. Si esto hubiera sido así, estas acciones de siega, acopio y quema se habrían producido en territorio celtíbero.

\begin{abstract}
AP. Iber. 88.- En una cierta llanura de Palantia, Ilamada Coplanio, los palentinos habían ocultado un grueso contingente de tropas en las estribaciones boscosas de las montañas $y$, con otros, atacaron abiertamente a los romanos mientras recogían el trigo. Escipión ordenó a Rutilio Rufo, historiador de estos sucesos y, a la sazón, tribuno militar, que tomase cuatro cuerpos de caballería y pusiera en retirada a los asaltantes.
\end{abstract}

Apiano apenas da detalles del desarrollo de la expedición. Escipión pudo haber iniciado la devastación del territorio por otras ciudades vacceas antes de ir a Palantia. Aunque no es probable. Ya hemos comentado que estas acciones de saqueo posiblemente se venían produciendo antes de llegar a tierras palantinas. El hecho de que Apiano cite esta ciudad puede deberse simplemente a que en sus alrededores se produjeron ciertos acontecimientos dignos de ser reseñados dentro de una campaña monótona y aburrida y con poco digno de subrayar.

Por otro lado, no parece lógico que Escipión iniciara sus acciones en el centro del territorio vacceo (lo que implica que habría seguido la ruta del río Duero por Rauda, Pintia y Tela), luego habría subido a Palantia para bajar después a Cauca. Sin embargo, también es posible que en los calculados planes de Escipión las acciones contra los vacceos comenzaran por Palantia: él ya la conocía puesto que había acompañado a L. Licinio Lúculo en el cerco a la ciudad en 151 a. C. y quizá «le tuviera ganas», o que por ser la principal ciudad de los vacceos, o al menos una de las más importantes, el efecto psicológico disuasorio que pudiera producir en las otras ciudades el hecho de ver como arrasaba impunemente los campos palantinos, así conviniera a la mentalidad del cónsul.

Ya hemos mencionado anteriormente el error de Schulten en la identificación de la Palantia de Apiano. Y es que hay dos Palantias: la actual Palencia (en la orilla del río Carrión), ciudad romana y sin apenas restos indígenas, y Palenzuela (a orillas del río Arlanza), a mitad de camino entre Palencia y Burgos, una importante ciudad vaccea muy rica y famosa por el valor de sus habitantes (AP. Iber. 55), no romanizada, asentada sobre un suave promontorio con una extensión de unas 60 has y que sin duda se corresponde con la Palantia citada por Apiano (González González, 1990: 36-37, 68-71, 81 y 94). Quizá por ser la principal ciudad de los vacceos ya había sido anteriormente objetivo de los ataques de L. Lúculo (151 a. C.), E. Lépido (137 a. C.) y C. Calpurnio Pisón (135 a. C.). 
Escipión ya conocía la ciudad de Palantia de la fracasada campaña con Lúculo. Sin embargo, la intención de Escipión en este caso no era atacar la ciudad, sino únicamente allegar provisiones, segar el trigo ya maduro y el forraje y quemar el resto con la doble intención, que ya hemos comentado anteriormente, de por un lado aprovisionar a sus tropas y por otro desabastecer al enemigo. Según el texto de Apiano, la iniciativa del hostigamiento corresponde a los palentinos que tratan de evitar el robo de los romanos, y a los que atraen hacia una emboscada que finalmente logra salvar el propio Escipión.

Aunque el relato de Apiano menciona únicamente a Palantia, y en el regreso a Cauca, resulta difícil aceptar el itinerario que propone Schulten siguiendo el curso del Pisuerga (donde cita la ciudad de Septimanca, actual Simancas) y el del Adaja-Eresma (en el que pudo pasar por la ciudad de Nivaria, actual Matapozuelos); vemos que en este recorrido aparecen pocas ciudades, si, como narra Apiano, el propósito de Escipión era desabastecer a los vacceos de trigo con el que ayudar a los numantinos. Sin embargo, no creemos que Escipion se aventurara mucho más al oeste en territorio vacceo como para avanzar hasta Intercatia (Paredes de Nava) o Amallobriga (Tiedra). E incluso ni a Septimanca y Nivaria. Antes bien, somos de la opinión de que la acción de Escipión se limitó a la zona más oriental del territorio vacceo, y por tanto a aquellas ciudades que pudieran tener más relación comercial con la zona celtíbera. Entonces, ¿pudo haberse acercado a otras ciudades en el curso del Duero como Rauda (Roa de Duero) o Pintia (Padilla de Duero), o de más al sur como Colenda (Cuellar), antes de dirigirse a Cauca?

También es posible aceptar la ruta propuesta por Schulten si consideramos que las acciones de saqueo del trigo y la quema de campos en algunos lugares, así como el «paseo disuasivo» del ejército romano por territorio vacceo, pudo servir de advertencia para desanimar al resto de ciudades de prestar ayuda a los numantinos. Además, desde esta ruta pudo haber enviado destacamentos a los poblados y ciudades próximas con el doble objetivo arriba expuesto. Sin embargo, en contra de esta propuesta está el comentario de Apiano del capítulo 87 de lo reacio que se mostraba Escipión a la hora de dividir su ejército, y de las consecuencias negativas cuando no siguió este criterio (emboscada de Rutilio Rufo en Coplanio; emboscada en la aldea cerca de Numancia). Por tanto, desechamos ambos planteamientos.

Nada se dice sobre el tiempo que pudo emplear Escipión en esta empresa, pero no debió ser poco, ya que estaba entretenido en los trabajos de siega y quema de los campos de aquellos lugares por los que pasaba, y que debieron retrasar bastante su avance.

Cuando estaba levantando el campamento y emprendía la retirada, se interponía un río difícil de atravesar y cenagoso, y junto a él, le esperaban emboscados los enemigos. Escipión, al enterarse, se desvió de la ruta y tomó otra más larga y menos propicia para las emboscadas, haciendo de noche el viaje a causa del calor y la sed, y cavando pozos, la mayoría de los cuales resultaron ser de agua amarga. Logró salvar a sus hombres con extrema dificultad, pero algunos de los caballos y bestias de carga murieron de sed. 
Relata Apiano que una vez que Escipión consiguió salvar a Rutilio Rufo de la emboscada en la que había caído con los cuatro cuerpos de caballería, y puso a salvo los jinetes en la llanura, levantó su campamento y emprendió la retirada. Estos acontecimientos se desarrollaron en la llanura de Coplanio, junto a Palantia, por lo que el campamento al que se refiere ahora Apiano debe corresponder al campamento que debió levantar Escipión cuando llegó ante la ciudad para segar los campo de trigo de los palantinos y quemar lo que no podía llevarse. Y también dice que emprendía la retirada, lo que debemos interpretar como el alejamiento de las tierras palantinas una vez conseguidos sus objetivos, para proseguir con su campaña contra otras ciudades vacceas.

Sin embargo, al poco de iniciar la marcha se encontró con un río difícil de atravesar y cenagoso, donde le esperaban emboscados los enemigos, sin duda palantinos, los mismos que le tendieron la emboscada de la llanura de Coplanio. El río debía encontrarse cerca de Palantia, por lo que quizá fuera el Arlanza, y era «difícil de atravesar» $\mathrm{y}$ «cenagoso». Al ser fangoso descartamos que llevara algún agua, lo que es lógico tratándose de los meses de julio y agosto, y quizá la dificultad para atravesarlo radicara también en su anchura, circunstancias ambas, que sumadas a la emboscada de los enemigos junto al río, impidieron que el ejército lo atravesara, por lo que Escipión «se desvió de la ruta».

Entonces, ¿cuál era la ruta prevista? El alejandrino no ofrece ninguna información adicional. Únicamente aclara que su prudencia le aconsejó tomar otro camino menos propicio a las emboscadas, aunque más largo.

En este párrafo Apiano nos aporta una información de gran interés a la hora de desmontar la teórica ruta sugerida por Schulten que hace bajar a Escipión por los cursos del río Pisuerga y luego del Adaja-Eresma hasta Cauca: el hecho de que tuviera que viajar de noche a causa del calor y la sed, y que precisara de cavar pozos. Si Escipión hubiera seguido la ruta junto a los ríos Pisuerga y después Adaja-Eresma no habría tenido problemas de abastecimiento de agua y por tanto no habría necesitado cavar pozos para buscarla. Este comentario de Apiano indica que desde Palantia, para evitar las emboscadas, Escipión se aventuró por una zona árida y con muy escasos recursos hídricos. Una comarca con estas características la encontramos entre los cursos de los ríos Arlanza y Duero, los Montes del Cerrato ${ }^{40}$, una región de páramos calcáreos con pequeños arroyos pero sin cursos importantes de agua (con excepción del río Esgueva) y que en esta época del año podrían estar secos a causa del calor. Esta posibilidad ya fue apuntada por Castro cuando comenta que (Escipión) «se ve obligado a internarse en los montes del Cerrato por donde, pasando gran sed y calamidades, pudo alcanzar el Duero» (Castro, 1977: 98).

\footnotetext{
${ }^{40}$ Ficha resumen de los formularios oficiales de la Red Natura 2000. Febrero 2005. ES4140053 Montes del Cerrato. Descripción del lugar. Otras características: Paisaje árido y orográficamente accidentado, en el que a la vez dominan los extensos, planos y horizontales páramos, de cuyos cerrales y cuestas se desgarran cerros, tesos, alcores, lomas y barrancas, testigos de sus valles de origen erosivo y sedimentario. http://rednatura.jcyl.es/natura2000/LIC/Formularios\%20oficiales/PDF\%20LIC\%20resumen/ ES4140053.pdf
} 
Apiano también dice que la mayoría de estos pozos resultaron ser de agua amarga ( $\pi \imath \kappa \rho \grave{\alpha}=$ amargo, acre, penetrante). El subsuelo de los montes del Cerrato presenta índices geotérmicos que tanto en la antigüedad como ahora hacen aprovechables sus aguas para baños termales (Baños de Cerrato) (Rosa y Mosso, 2004: 120; Molto, 1992: 214). Pero lo más importante es que las aguas de este subsuelo son sulfatadas sódicas ${ }^{41}$, es decir, con alto contenido en azufre, ácidas, ligeramente saladas y sabor desagradable, y aunque hoy se saben medicinales, su olor característico a huevos podridos no las hacen apetecibles en modo alguno. Esto explicaría por qué las aguas de los pozos que abrió Escipión eran «amargas».

Parece entonces posible que desde Palantia Escipión desviara su ruta y tomara otra más larga, atravesando estos páramos del Cerrato. Quizá pasara por el importante oppidum vacceo que existió bajo el actual Vertavillo del Cerrato ${ }^{42}$ (Abarquero y Palomino, 2006), distante unos $40 \mathrm{~km}$, y desde aquí se encaminara hacia Rauda, una importante ciudad vaccea de unas 19 has de extensión, para lo que tuvo que cubrir un espacio de otros $40 \mathrm{~km}$ a vuelo de pájaro, algunos más sobre el terreno que, en las condiciones que describe Apiano, pudieron haber sido cuatro o cinco jornadas de viaje. Desde aquí pudo haber descendido por el curso del Duero hasta Pintia (Padilla de Duero), otra gran ciudad vaccea de 25 has de extensión, y a tan sólo $22 \mathrm{~km}$ en línea recta de Rauda.

Desde Pintia, y sin adentrarse más en tierras vacceas, Escipión pudo marchar a la ciudad de Colenda (actual Cuellar), distante unos $27 \mathrm{~km}$ en línea recta, pero por un páramo seco y sin apenas arroyos que lo rieguen, y desde aquí dirigirse a Cauca (actual Coca), a unos $28 \mathrm{~km}$ de la anterior, y desde donde Apiano dice que Escipión inició el regreso a tierras numantinas.

Aunque Apiano no da ningún dato temporal, más arriba hemos dejado dicho que Escipión pudo haber iniciado el viaje a tierras vacceas poco antes de mediados del mes de julio del año 134 a. C., y que el trayecto hasta Palantia, de haberlo hecho seguido, habría durado unos 7 u 8 días, por lo que pudo presentarse ante la ciudad hacia mediados de mes o poco después. Sobre el resto de la marcha hasta llegar a Cauca poco se puede decir, ya que desconocemos la ruta exacta, qué ciudades visitó, el tiempo que pudo permanecer acampado frente a cada ciudad mientras segaba y quemaba los campos, cómo pudo afectar el calor y la sed a los desplazamientos, incluso los nocturnos, etc, pero podemos suponer que emplearía el resto del mes de julio y buena parte o todo el mes de agosto.

\footnotetext{
${ }^{41}$ https://es.wikipedia.org/wiki/El_Cerrato

42 Se trata de un yacimiento de unas 25/30 has de extensión, una auténtica civitas vaccea no identificada cuya cronología está centrada en el siglo II a. C., y que no se encuentra supeditada espacialmente a ningún núcleo conocido. Se ajusta al modelo de población vacceo, encontrándose rodeado de otras grandes civitates del centro de la cuenca de Duero, entre las que se encontraría, aunque fuera del grupo que se acomodan a la red fluvial mayor.
} 
Y ya que Apiano menciona además de la sed el tema del calor, actualmente la climatología en estas tierras palentinas del Cerrato, con una altitud media de unos 750-800 msnm (Alcalde, 1997: 13), se caracteriza por un clima mediterráneo frío, continentalizado, con escasas precipitaciones, inviernos largos y fríos y veranos cortos y no excesivamente cálidos ${ }^{43}$, pero que en ocasiones pueden llegar a máximas cercanas a los $40^{\circ} \mathrm{C}$. (Morales y Ortega, 2000: 165-166), y con un período seco bien marcado en los meses de julio y agosto. Y abundando en el asunto, en época romana, aproximadamente entre el 200 a. C. y el 150 d. C., en la Europa Occidental se produjo lo que se conoce como «Periodo Cálido Romano» u «Óptimo Climático Romano», una época de clima cálido, agudizado en los veranos, con altos niveles de insolación, húmedo y estable (López et al., 2009: 341; Sánchez-López et al., 2016: 143).

\begin{tabular}{|c|c|c|c|c|c|c|c|c|c|c|c|c|c|}
\hline \multicolumn{14}{|c|}{ Parámetros climáticos promedio de Palencia en el periodo 1981-2010 } \\
\hline Mes & Ene. & Feb. & Mar. & Abr. & May. & Jun. & Jul. & Ago. & Sep. & Oct. & Nov. & Dic. & Anual \\
\hline Temp. máx. abs. $\left({ }^{\circ} \mathrm{C}\right)$ & 17.8 & 23.6 & 24.8 & 30.6 & 34 & 38.4 & 40 & 39.6 & 37.8 & 30.2 & 24 & 20.2 & 40 \\
\hline Temp. máx. media $\left({ }^{\circ} \mathrm{C}\right)$ & 8 & 10 & 14 & 15 & 19 & 25 & 28 & 29 & 24 & 18 & 12 & 8 & 17.5 \\
\hline Temp. media $\left({ }^{\circ} \mathrm{C}\right)$ & 3.4 & 5.0 & 8.0 & 10.2 & 13.9 & 18.2 & 21.9 & 20.6 & 17.1 & 12.2 & 7.1 & 4.3 & 11.6 \\
\hline Temp. mín. media $\left({ }^{\circ} \mathrm{C}\right)$ & -1 & 0 & 2 & 3 & 6 & 10 & 12 & 12 & 10 & 7 & 2 & -1 & 5.5 \\
\hline Temp. mín. abs. $\left({ }^{\circ} \mathrm{C}\right)$ & -15 & -11 & -12 & -6 & -5 & -1 & 2 & 2 & 0 & -5 & -8 & -13 & -15 \\
\hline Precipitación total (mm) & 40.4 & 28.6 & 25.1 & 38.6 & 44.6 & 28.7 & 16.3 & 17.9 & 23.1 & 45.6 & 46.1 & 43.4 & 489 \\
\hline Días de lluvias ( $\geq 1 \mathrm{~mm}$ ) & 8 & 7 & 7 & 9 & 9 & 5 & 3 & 3 & 4 & 8 & 8 & 9 & 80 \\
\hline Días de nevadas ( $\geq 1 \mathrm{~mm}$ ) & 2 & 2 & 1 & 0 & 0 & 0 & 0 & 0 & 0 & 0 & 0 & 2 & 7 \\
\hline
\end{tabular}

Figura 14

AEMET: Atlas agroclimático de Castilla y León. Junta de Castilla y León, Consejería de Agricultura y Ganadería. Datos para el periodo 1981-2010 en Palencia. (http:/ /atlas.itacyl.es/descarga)

\begin{abstract}
AP. Iber. 89.- Mientras atravesaba el territorio de los cauceos, cuyo tratado había violado Lúculo, les hizo saber por medio de un heraldo que podían regresar sin peligro a sus hogares. Y prosiguió hasta el territorio de Numancia para pasar el invierno. Allí se le unió también, procedente de África, Yugurta, el nieto de Masinissa, con doce elefantes y los arqueros y honderos que habitualmente le acompañaban en la guerra.
\end{abstract}

El hecho de que Escipion les anunciara que podían regresar sin miedo a la ciudad, no sería óbice para que segara los campos caucenses y recogiera provisiones tal y como era el propósito de su viaje.

Nada aclara Apiano sobre qué hizo Escipión una vez que atravesó el territorio caucense. Si nos ceñimos escrupulosamente al texto del alejandrino comprobamos que desde Cauca tomo algún camino en dirección al Alto Duero y a Numancia. Schulten no menciona ninguna ruta concreta, únicamente que «pasó al norte de la ciudad y continuó por el Duero arriba camino de Numania» (1945: 141). No así Sopeña, que sin ningún argumento lleva el itinerario de vuelta por Segovia y desde aquí a Uxama y a Numantia (2017: Figura 2; ver en este mismo artículo).

\footnotetext{
${ }^{43}$ https://es.weatherspark.com/y/35858/Clima-promedio-en-Palencia-España-durante-todo-el-año
} 
Desde Cauca-Coca hay dos posibles rutas directas hacia Numancia no muy distantes entre sí y que corren paralelas en su trazado ${ }^{44}$ :

La primera de ellas correría aproximadamente por la actual carretera provincial SG-332 por Navas de Oro y Navalmanzano, donde se convierte en la provincial SG222; por Fuentepelayo, con un poblado del Primer Hierro ${ }^{45}$; Valdesimonte ${ }^{46}$; Sepulveda, con dos asentamientos prerromanos ${ }^{47}$, y Ayllón, con varios poblados prerromanos ${ }^{48}$. Desde aquí existen varias alternativas para acceder al Alto Duero ${ }^{49}$ y a Numancia:

- Por San Esteban de Gormaz y El Burgo de Osma a Numancia (Renieblas) ${ }^{50}$.

- Por Gormaz y Quintana Redonda a Numancia (Renieblas) ${ }^{51}$.

${ }^{44}$ Queremos hacer constar nuestro agradecimiento a D. Luciano Municio González, arqueólogo territorial del Servicio Territorial de Cultura, Delegación Territorial de la Junta de Castilla y León en Segovia, por facilitarnos el acceso a la plataforma PEME Catálogo de Yacimientos de la JCyL de Segovia.

${ }^{45}$ El castro es conocido como «San Juan» (Arribas, 1984).

${ }^{46}$ Con un posible castro con materiales del Hierro I conocido como «San Benito». (PEME Catálogo de Yacimientos de la JCyL).

${ }^{47}$ En Sepúlveda se encuentran los castros de «San Julián», un espolón sobre el río Duratón, con ocupaciones durante el Primer y Segundo Hierro, según constataron las prospecciones de Arias Funez, J. en 1992, y el cerro «El Otero», con un poblado de época celtibérica, prospectado por Caballero, J.et al., ITAR, en 1993. (PEME Catálogo de Yacimientos de la JCyL).

${ }^{48}$ Nos referimos a los lugares de «Castillo de Ayllón», «Rosablas» $\mathrm{y}$ «Santo Domingo», todos ellos con niveles del Primer y Segundo Hierro (Zamora, 1993: 5-22; STRATO, 2011).

${ }^{49}$ Queremos hacer constar nuestro agradecimiento a Da . Elena Heras Fernández, arqueólogo territorial del Servicio Territorial de Cultura, Delegación Territorial de la Junta de Castilla y León en Soria, por facilitarnos el acceso a la plataforma PEME Catálogo de Yacimientos de la JCyL de Soria.

${ }^{50}$ En este camino se encuentran poblados prerromanos en Aldea de San Esteban en el lugar de «El Picotillo II», con restos celtibéricos (PEME Catálogo de Yacimientos de la JCyL); en San Esteban de Gormaz, donde existen poblados celtibéricos en «Castro Moros»y «El Tablazo», y en «Las Veletas» un poblado con necrópolis con restos del Primer y Segundo Hierro (PEME Catálogo de Yacimientos de la JCyL); en El Burgo de Osma la ciudad celtíbera de Uxama (Taracena, 1941: 125-134); en Calatañazor los asentamientos celtíberos de «Los Castejones» y «El Molino» (Pascual, 1991: 32-54 y 55-58); en Villaciervos el castro de «San Cristóbal» correspondiente al Primer Hierro (Pascual, 1991: 254256); en Carbonera de Frentes se encuentra el castro celtíbero de «Cerro Ontalvilla» (Morales, 1995: 47) y en Golmayo los castros de «Castillejo»y «Las Rabaneras», ambos con ocupaciones durante el Primer y Segundo Hierro (Morales, 1995: 192-199 y 200-202). Es la ruta más probable.

${ }^{51}$ En esta ruta alternativa existen restos prerromanos en los municipios de Gormaz, con los asentamientos de «Fuentes Grandes», fechado en época celtibérica (Ortego, 1969: 46-55; García Merino 1973: 52-56; 1975: 311); el «Cerro del Castillo», con ocupaciones del Hierro I y Hierro II (Taracena, 1941: 84; Ortego, 1972: 79 y 85-86; García Merino, 1975: 304 y 321-322; Zozaya, 1989: 107-108); y la conocida necrópolis celtibérica de «La Requijada» (Cabré, 1917: t. 3, 37-86; Taracena, 1941: 84; García Merino, 1973: 36-43); en Quintanas de Gormaz se encuentra la necrópolis celtibérica de «El Picón» o «Los Navajos» (Cabré, 1917: t. 3, 87; Taracena, 1941: 138; García Merino, 1973: 43-48); en Osonilla se encuentra el asentamiento celtibérico de «El Malacate» y la necrópolis celtibérica de «Los Villares», quizá correspondiente al citado poblado (Pascual, 1991: 142-143 y 144-147); en Quintana Redonda existe un poblado de «El Ero», fechado en el Primer Hierro (Pascual, 1991: 154-157); y finalmente, en Los Llamosos se localizan restos celtíberos en el sitio de «La Garcimona» (Pascual, 1991: 119-122). 
- Sin cruzar el Duero, y remontando el río, por Recuerda, Hortezuela y Almazán a Numancia (Renieblas) ${ }^{52}$.

El otro itinerario de vuelta, algo más al norte pero paralelo al anterior, correría por Samboal ${ }^{53}$ y Gomezserracín ${ }^{54}$, donde existen poblados de la Primera Edad del Hierro, y por Castroserracín y Maderuelo ${ }^{55}$ entraría en la provincia de Soria por la ruta de San Esteban de Gormaz y El Burgo de Osma (Uxama) ya comentada.

En el regreso desde Cauca, de unos 230-260 km según el trayecto elegido, Escipión pudo haber empleado unos 10 u 11 días de marcha, por lo que la llegada al territorio de Numancia pudo haberse producido muy a finales de agosto o quizá principios de septiembre (Morales, 2009a: 86).

Schulten estima que la llegada de Escipión a la región de Numancia debió producirse «antes de octubre» (1905: 76; 1914: 374) para posteriormente precisar que sería «a principios de septiembre» (1927: 14-15; 1945: 141-142), criterio que recogen otros autores (Bosch y Aguado, 1955: 167; Simon, 1962: 184; Luik, 2005: 78; Jimeno, 2005: 242; Jimeno y Chaín, 2017: 240).

¿Dónde instaló Escipión, en esta segunda llegada ante Numancia, lo que sería su campamento de invierno?

Schulten no acepta la existencia de un campamento cerca de Numancia anterior a las obras del cerco. Él supuso que Escipión, para invernar, se situó ya «muy cerca» de Numancia, estableciendo los dos campamentos provisionales de Castillejo y Peña Redonda (1927: 16-17; 1937: 74). Pero no debió ser así, ya que Apiano dice que, no mucho

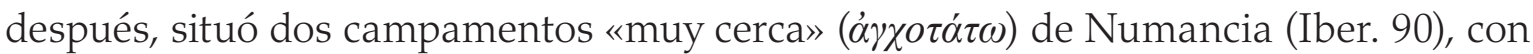
lo que está indicando que antes de situarse «muy cerca» sólo estaba «cerca» (⿳亠㐅八 $\gamma \chi o v)$ (Ib 87 y 89), y desde esa posición se dedicaba a saquear y devastar los alrededores.

Se ha sugerido que en la segunda llegada a tierras numantinas Escipión ocupó de nuevo la Gran Atalaya de Renieblas, pero que ahora construyó un campamento de

52 Documentando este posible camino encontramos restos prerromanos en Rebollo de Duero en el sugestivo paraje de «La Buitrera», con ocupaciones durante el Hierro I y la etapa celtibérica (Revilla, 1985: 230-239); en Ciadueña se localizan asentamientos celtibéricos en los lugares de «Cuesta de la Torre», «Las Eras» y «Los Prados» (Revilla, 1985: 166-168, 169-171, y 172), y en Almazán quedan posibles restos celtíberos en «El Cinto», y seguros en «La Corona», «Los Chopazos» y «La Muela» (Revilla, 1985: 26, 26-34, 35-60, 97-112).

${ }^{53}$ En este municipio existen restos de un poblado del Hierro I en «Los Pantanos» (PEME Catálogo de Yacimientos de la JCyL).

${ }^{54}$ Con tres poblados de la Primera Edad del Hierro en los parajes de «Las Llosas», «Los Pradillos» y «El Ternerillo» (PEME Catálogo de Yacimientos de la JCyL).

${ }^{55}$ Junto al «Pantano de Linares» se han realizados hallazgos sueltos correspondientes al Hierro I (PEME Catálogo de Yacimientos de la JCyL). 
invierno, el campamento V (Fabricius, 1911: 378-382; Sanmartí, 1992: 418-420), aunque esta cronología está en entredicho (Luik, 1997; 2002; Salvatore, 1996; Gómez-Pantoja y Morales, 2002; Dobson, 2008; Dobson y Morales, 2008). También se han aportado otras alternativas fundadas en los restos constructivos (Dobson, 2008: 188 ss, y 387).

En nuestra opinión, Escipión se instaló en el mismo campamento que había ocupado a principios del verano de 134 a. C., antes de partir a territorio vacceo, es decir, que volvió a reocupar el antiguo campamento de Nobilior como campamento de retaguardia, pero al que añadió un anexo para dar cabida a una parte de su gigantesco ejército (Morales y Morillo: en prensa).

Desde su campamento en la Gran Atalaya de Renieblas, Escipión debió dedicar todo el mes de septiembre no sólo a saquear y devastar los alrededores, sino también a tantear a los numantinos.

\section{Escipión, entregado al saqueo y a la devastación constante de las zonas de alre- dedor, le pasó inadvertida una emboscada en una aldea... pero no persiguió a los que huían, sino que se retiró al campamento tras haber sufrido pocas bajas ambas partes.}

Otro suceso en el que tampoco estamos de acuerdo con Schulten es el referente a la emboscada que sufrió Escipión junto a una aldea rodeada por una laguna y una garganta. Schulten sitúa este acontecimiento en el regreso de Cauca a Numantia, en una región al pie de la meseta, al sur del Duero. Cree que el campamento fortificado al que se retira Escipión tras salvar la emboscada era un campamento de marcha, ya que el propio Schulten dice que Escipión permaneció en él poco tiempo, y que, además, aquí llegó Yugurta con doce elefantes, arqueros y honderos (1937: 74).

Pero esta interpretación es rebatible, ya que el relato de Apiano es muy claro: «(Escipión) prosiguió hasta el territorio de Numancia para pasar el invierno. Allí se le unió también, procedente de África, Yugurta,...». Es más lógico que Yugurta se incorporara a un campamento estable como escribe Apiano, a que se uniera a la expedición en un campamento de marcha que se movía continuamente como pretende Schulten. Y es en territorio numantino donde sucede la emboscada de la aldea, por lo que el campamento al que se retira Escipión es el campamento que tiene en las proximidades de Numancia, es decir, el de La Gran Atalaya de Renieblas.

Y en cuanto al episodio de la aldea, tampoco estamos de acuerdo con Capalbo cuando considera que esta empalizada no es la de un campamento, sino la empalizada de la aldea, ya que, dice, Apiano no menciona campamento alguno (Capalvo, 1996, 188). No tiene sentido que una vez que el grueso del ejército salió de la aldea y puso en fuga a los enemigos, Escipión volviera a refugiarse de nuevo a la aldea como pretende Capalvo. Por tanto, la empalizada $(\chi \dot{\alpha} \rho \alpha \xi)$ a la que se retira Escipión es la de su campamento; aquí se pone de manifiesto, una vez más, el sentido práctico y la prudencia 
de Escipión. Por otro lado, todas las traducciones que hemos consultado referentes a este incidente de la aldea consideran que se trata de su campamento (Remacle: chapitre XIV, 89; Schweigewser, 1852: 177; Saavedra, 1879: 94; White, 1979: 281; Sancho, 1980: 179; Gómez, 1993: 116; Richardson, 2000: 95; Goukowsky, 2003: 83). Excepto Schulten, más confuso, que traduce «se replegó dentro de la estacada» (1937: 296), aunque quizá refiriéndose también al campamento.

\begin{abstract}
AP. Iber. 90.- No mucho después, estableció dos campamentos muy próximos a Numancia y puso al frente de uno de ellos a su hermano Máximo, en tanto que él en persona se encargaba del otro. A los numantinos, que con frecuencia salían fuera de la ciudad en orden de combate y le provocaban a la lucha, no les hacía caso alguno porque consideraba más conveniente cercarlos y reducirlos por hambre que entablar un combate con hombres que luchaban en situación desesperada. Y después de establecer siete fuertes en torno a la ciudad (comenzó) el asedio...
\end{abstract}

Schulten parte de los textos de Apiano (1905: 63) e inicialmente acepta que el asedio a Numancia estuvo formado por 2 campamentos y 7 fuertes, estableciendo una clara diferencia entre ambos términos. A partir de ese mismo momento intenta encontrarles acomodo en un mapa topográfico de los alrededores de Numancia, pero únicamente consigue encontrar siete puntos que pudieran acoger instalaciones para el asedio (1905: 67-68), por lo que rechaza el relato de Apiano e imagina una circunvalación formada únicamente por los 7 fuertes (pero llamándoles campamentos). Y los dos campamentos iniciales habrían sido ubicados en el centro de cada una de las dos secciones semicirculares en las que el Duero divide a la circunvalación para ser controladas por ellos (1905: 68), pero que no habrían formado parte de la circunvalación de 7 recintos, sino que habrían sido dos campamentos provisionales anteriores al asedio desde los que Escipión movió sus legiones para construir el cerco.

Esta errónea interpretación de Apiano será su norte y guía durante los años siguientes. Así, para sacar adelante sus conclusiones prefijadas no dudará en amoldar los resultados de sus excavaciones, prescindiendo de valiosos datos aportados por éstas que no se ajustaban o incluso contradecían aquellas.

Apiano diferencia claramente los términos griegos $\delta \dot{v} o$ $\sigma \tau \rho \alpha \tau o ́ \pi \varepsilon \delta \alpha=$ dos campamentos de $\varphi \rho o \dot{v} \rho \iota \alpha$ $\delta^{\prime} \varepsilon \pi \tau \alpha=$ siete castillos (a los que posteriormente se añadieron

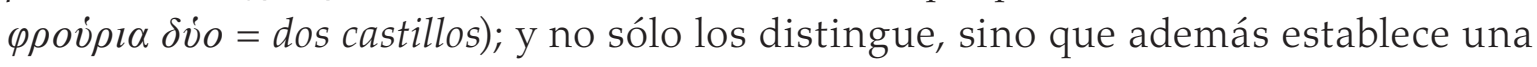
clara secuencia cronológica.

Por tanto, Schulten escribe: «Todos los lectores imparciales entenderán que los 7 castillos se añadieron a los 2 campamentos, y que entonces Numancia fue bloqueada primero por sólo dos grandes campamentos y luego por dos grandes y siete pequeños. Apiano diferencia estos dos conceptos también en el idioma, calificando a las dos primeras fortificaciones

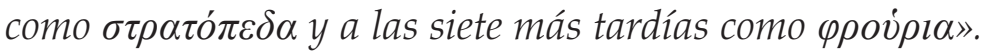


Así se expresaba Schulten $(1927,19)$ al comentar el texto de Apiano. Considera

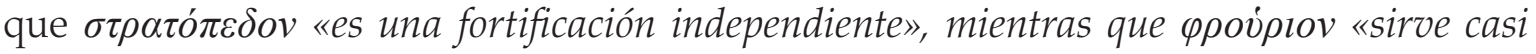
siempre de defensa de una fortificación, de una ciudad, de un campamento o, como aquí, de una circunvalación. Especialmente en este caso, donde los dos $\sigma \tau \rho \alpha \tau o ́ \pi \varepsilon \delta \alpha$ son completados

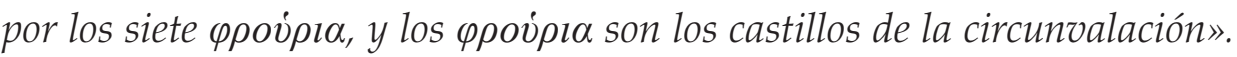

Tras un análisis minucioso de los términos griegos y sus equivalentes latinos (castra y su diminutivo castella) basado en su empleo más o menos semejante o diferenciado según los autores, Schulten opina que «desde el punto de vista de su significado lingüístico son conceptos relativos utilizados a menudo indistintamente, porque ¿dónde debe estar la frontera entre un campamento grande y uno pequeño?» Primer argumento para generar confusión y llegar a su propósito final de identificar campamento y fuerte.

No obstante, se detiene a citar una serie de pasajes en los que se hace una clara distinción entre «campamento» y «castillo»: en Agrigento Polibio diferencia 2 campamentos y entre ellos muchos castillos; Livio en Ambrakia habla de 2 campamentos y 1 castillo; César en Alesia instaló varios castra y 23 castella; en Corfinium, 2 campamentos y entre ellos castillos; en Dyrrachium, el campamento principal y 24 castella; etc.

«En todos los pasajes, dice Schulten, donde aparecen campamentos y castillos, unos junto a otros, son por supuesto, los campamentos las fortalezas más grandes, y los castillos más pequeños. Pero esta distinción cuantitativa no es la esencial. Los campamentos son ante todo las bases de la línea que constituye el cerco, colocados los primeros en los lugares más importantes, son primarios, y los castillos secundarios. "Castra" designa por lo general bien un campamento independiente y aislado, bien el campamento principal en caso de asedio, mientras que "castella" son allí fuertes instalados para proteger el campamento, y unidos a él por medio de trincheras» $(1927,20) »$.

Aunque aparentemente Schulten parece mantener el tamaño como el factor determinante de diferenciación, a continuación lo relativiza para concluir que donde realmente reside la diferencia, al margen del tamaño, es en el cometido, en la funcionalidad. Esto sin duda es cierto, pero la funcionalidad no excluye el tamaño; los dos conceptos van unidos. Segundo paso para sembrar dudas y conseguir su objetivo.

Tras esta detallada exposición, Schulten, como no puede ser de otra manera, concluye: «Entonces parece que Apiano designa con $\sigma \tau \rho \alpha \tau o ́ \pi \varepsilon \delta \alpha$ los dos primeros campamentos como campamentos principales, grandes e independientes, con $\varphi \rho$ ovpra los siete campamentos más tardíos como pequeñas instalaciones que constituían miembros de la cadena de bloqueo. De modo que sería correcto llamar a los dos primeros campamentos "Lager" (campamentos), y a los siete más tardíos "Kastelle" (castillos)».

A partir de aquí, y por la razón que luego veremos, Schulten realiza una impresionante pirueta interpretativa, olvida toda la correcta argumentación inicial y vuelve a considerar el tamaño como factor determinante de diferenciación: «Pero ya que 
entendemos por castillo un campamento pequeño, mientras los siete castillos alrededor de Numancia son en parte grandes (Dehesilla 11 Has), llamaré también "Lager" (campamentos)

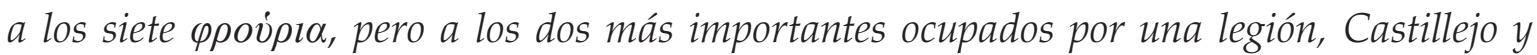
Peña Redonda, "Legionslager" (campamentos de legión), a los dos primeros campamentos "Feldlager" (campamentos provisionales), y a las dos pequeñas trincheras junto al Duero, "Uferkastelle" (castillos de ribera)».

Aquí Schulten ya ha conseguido su propósito de confundir los conceptos con el objetivo final de adecuar el texto de Apiano a sus resultados, llamando a los castillos «campamentos», cuando un castillo no tiene la función de «base» que tiene el campamento. El cometido del castillo, como parece haber dejado claro anteriormente, es otro.

La razón última por la que realiza estos quiebros conceptuales no es otra que ésta: «Según Apiano, se debería aceptar por tanto 2 campamentos grandes y 7 pequeños. Pero las excavaciones han mostrado sólo 7 campamentos, de los cuales 2, Castillejo y Peña Redonda, sobresalen como campamentos de legión. Y como no pueden haber desaparecido sin dejar rastro los otros dos campamentos especialmente grandes para los que además no existe ni espacio ni ocupantes (porque las 2 legiones se encuentran en Castillejo y Peña Redonda), quiero aceptar que Apiano no se ha expresado con exactitud, que los 7 castillos no se añadieron a los 2 primeros campamentos, sino que los sustituyeron, y que los dos campamentos principales, Castillejo y Peña Redonda, fueron al principio campamentos provisionales y luego transformados en campamentos fijos» $(1927,20)$.

Esta interpretación que hace Schulten de los textos de Apiano es muy cuestionable. Sin embargo, su propuesta ha sido aceptada unánimemente por la investigación (Taracena, 1941: 81; Bosch y Aguado, 1955: 168; García Bellido, 1969: cap. VII; Jimeno y Martín, 1995: 184; Sanmartí y Principal, 1997: 36; Blázquez, 1999: 71; Luik, 2005: 79; Cabrero y, 2017: 233) salvo excepciones (Simon, 1962: 195, nota 12; Capalbo, 1996: 189-190; Morales, 2000: 228-229; 2002: 284; 2004: 252; 2009b: 289-291; Dobson, 2008: 413; Morillo y Morales, 2015: 280; Jimeno y Chaín, 2017: 241-242).

\begin{abstract}
A continuación, designó un jefe para cada una de esas partes y ordenó rodear la ciudad de una zanja y una empalizada.

Una vez que tuvo adoptadas todas las medidas y podía ya rechazar eficazmente a los que trataban de impedirlo, cavó otro foso detrás, no lejos de aquél, lo fortificó con una empalizada y construyó un muro de ocho pies de ancho y diez de alto sin contar las almenas. Erigió torreones a lo largo de todo este muro, a intervalos de cien pies. Como no le fue posible prolongar el muro de circunvalación alrededor de una laguna adyacente, la rodeó de un terraplén de igual anchura y altura que las de la muralla para que sirviera a manera de muralla.
\end{abstract}

Una vez que Escipión hubo establecido los dos campamentos y los siete fuertes en torno a la ciudad, para completar un férreo e implacable cerco unió todos estos 
recintos con un foso (del que no especifica anchura ni profundidad) y un muro de 2,35 m de ancho y 2,95 m de alto sin contar las almenar, y a lo largo de él levantó torreones cada pletro $(30 \mathrm{~m})$.

Sin embargo, para poder realizar esta obra sin ser molestado por los numantinos, que como dice Apiano trataban de evitarlo con ataques selectivos y puntuales a diferentes puntos del trazado, con anterioridad había ordenado rodear la ciudad con una zanja (fossa fastigata) y una empalizada (vallum). La estructura del vallum consiste en un terraplén (agger) formado con los materiales extraídos de la zanja sobre el que va clavada la propia empalizada.

Apiano no ofrece ningún dato sobre donde se encontraban cada una de estas dos líneas defensivas. Únicamente menciona que primero rodeo la ciudad con zanja y foso, y que una vez hubo terminado de construir esta y podía rechazar eficazmente los ataques de los numantinos, construyó una segunda línea formada por foso y muro, y reforzada con torres, no lejos de aquélla, es decir detrás de la primera. Pero no aclara cuánto.

Jimeno y Chaín mencionan que se encontraba 100 m detrás de la primera (2017: 241). Pero no explican por qué esta cifra y no otra, lo que no deja de ser una mera conjetura, pues, como ya hemos dicho, ni Apiano ni otras fuentes mencionan ninguna distancia, tan solo que «no lejos de aquel».

En nuestra opinión la separación entre ambas líneas pudo ser de 70 m. Proponemos esta cifra basándonos en la anchura polibiana del intervallum en los campamentos romanos republicanos, que es de 240 pies, distancia de seguridad que evitaba en un ataque al campamento que los proyectiles enemigos llegaran a las tiendas. Sin embargo, también hemos de decir que esta distancia en los campamentos del cerco de Numancia es sólo teórica, ya que en el campamento romano de Peña Redonda, por ejemplo, el intervallum oscila entre 12 y 25 m (Dobson, 2008: 356). Aunque en este sentido debemos aclarar que la construcción de estos campamentos del cerco se adapta a la forma del terreno, muy reducido por lo general, quedando las instalaciones interiores muy constreñidas, por lo que las medidas y disposiciones polibianas difícilmente se cumplen.

Esta primera línea defensiva no debió ser una obra grande, ya que era provisional y únicamente tenía como objetivo proteger a los constructores del foso y el muro que se estaba levantando detrás. Y Schulten no menciona haberla encontrado en ningún lugar de la circunvalación.

A un tramo de este vallum puede corresponder el hallazgo producido en el año 2000 entre el fuerte de Alto Real y el Duero, de unos $75 \mathrm{~m}$ de longitud, y con dirección al fuerte de La Vega. Está formado por zanja y terraplén, muy suavizados en la actualidad hasta pasar casi desapercibidos entre la vegetación de monte bajo que 
cubre la zona, pero que se reconocen todavía en una ligera depresión de apenas $25 \mathrm{~cm}$ y de unos 3,50 m de anchura junto a una suave elevación de unos $30 \mathrm{~cm}$ y 2,50 m de anchura, y que podrían responder a la zanja y terraplén con empalizada descritas por Apiano (Morales, 2004: 255-256; 2007: 274; 2009b: 297).

El tramo de vallum de Alto del Real estaba atravesado por un camino que en su lado sur había dejado recortado el perfil del foso y el terraplén, y por tanto al descubierto parte de su estructura interior. Así, el agger, hoy muy aplanado, podría haber presentado sección trapezoidal y encontrarse formado por un relleno interior de tierra y piedras menudas, los mismos materiales que se extrajeron del foso (Luzón y Alonso, 2018, cap. V).

Creemos que estos restos se pueden identificar con esta primera línea defensiva ya que, como hemos apuntado, delatan a primera vista una obra de escasa entidad, levantada para cubrir una necesidad perentoria, es decir, provisional, y por tanto, una vez cumplida su función, llamada a ser desmantelada en favor de la obra principal que se estaba levantando detrás y que, como relata Apiano, consistía en un muro de ocho pies $(2,35 \mathrm{~m})$ de ancho y diez pies $(2,95 \mathrm{~m})$ de alto, sin contar las almenas, y un foso que, en este caso, hemos de suponer de unas dimensiones acordes con el muro. Restos del muro de este segundo vallum los halló Schulten en algunos lugares de la circunvalación (entre Castillejo y Travesadas; entre Dehesilla y Molino; entre Dehesilla y Peña del Judío, etc), y recientemente han aparecido trazas de su cimentación entre Alto Real y Peña del Judío (Arquetipo, S. C. L., 2013).

¿O quizá este tramo que describimos y cuyos posibles restos permanecían enterrados, por su posición retrasada respecto al fuerte, pudo pertenecer a este segundo vallum defensivo?

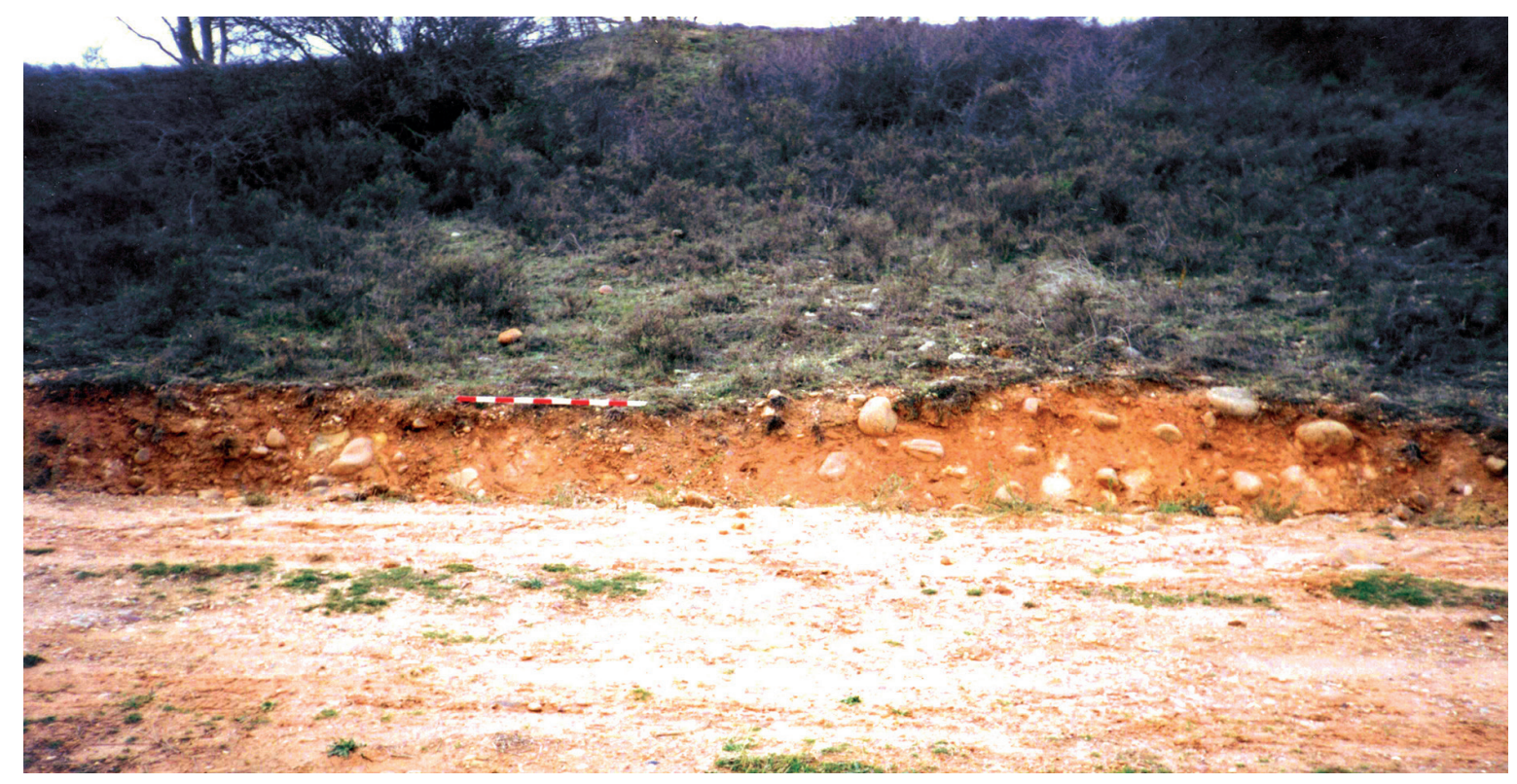

Figura 15

Fotografía con los restos del foso (izquierda) y el terraplén (derecha) 


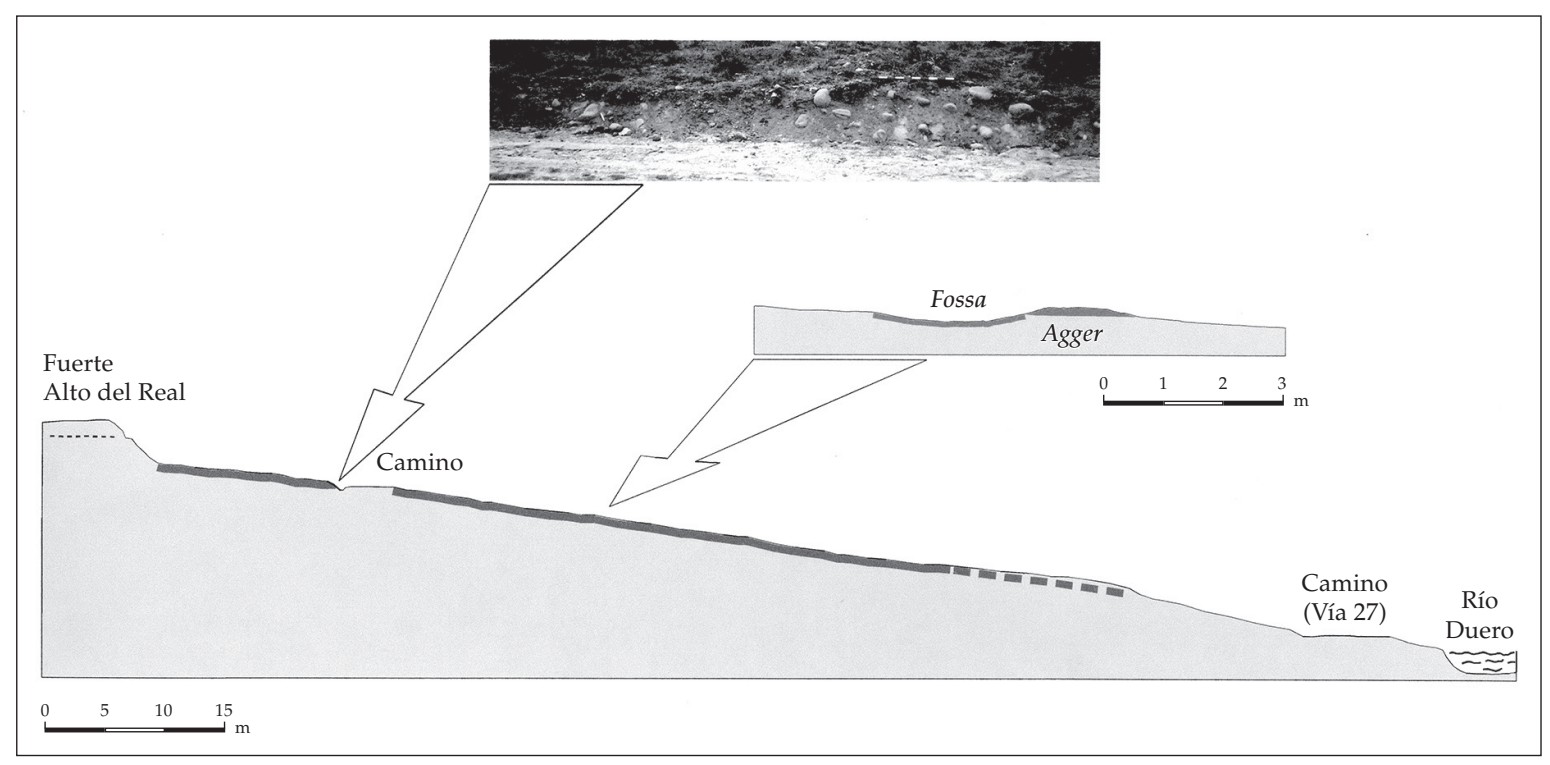

Figura 16

Corte del terreno entre el fuerte de Alto del Real y el río Duero con los vestigios de vallum hallados

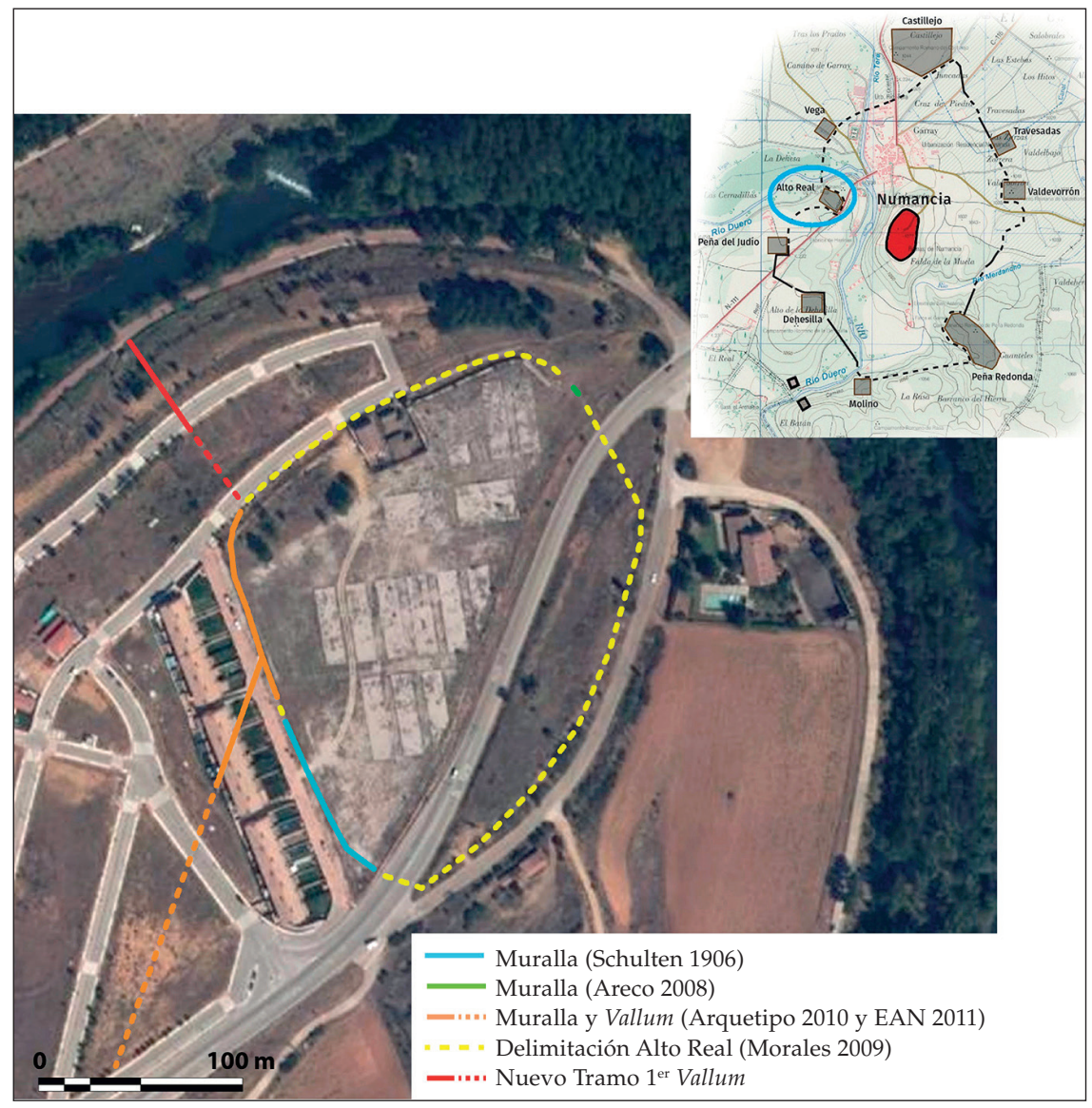

Figura 17

Mapa de situación del fuerte de Alto Real (https://www.numanciamultimedia.com/) y fotografía aérea del mismo con los restos de muralla aparecidos y la localización del posible vallum (dibujo C. Tabernero/Areco Arqueología) 
En cualquier caso, en el año 2003 el Equipo Arqueológico de Numancia realizó excavaciones arqueológicas en esta zona (EAN, 2006: 3, sondeo 8; Sanz et al., 2008: 11; Tabernero et al., 2010: 26), aunque los resultados de las mismas todavía no han sido publicados. Sin embargo, únicamente en una parte del sondeo programado se profundizaron apenas $20 \mathrm{~cm}$, siendo abandonada la excavación al considerar que aquellos restos no eran nada más que una separación de parcelas (Arquetipo, S. C. L., 2013: 8). Desgraciadamente, al poco tiempo de realizarse la «excavación» esta zona fue explanada por máquinas para la construcción de los viales de la urbanización «Balcón de Numancia», siendo totalmente destruida, así como los posibles restos que todavía pudiera haber, por lo que ahora resulta imposible re-excavar correctamente estos vestigios para comprobar (y en su caso demostrar o rechazar) su antigüedad.

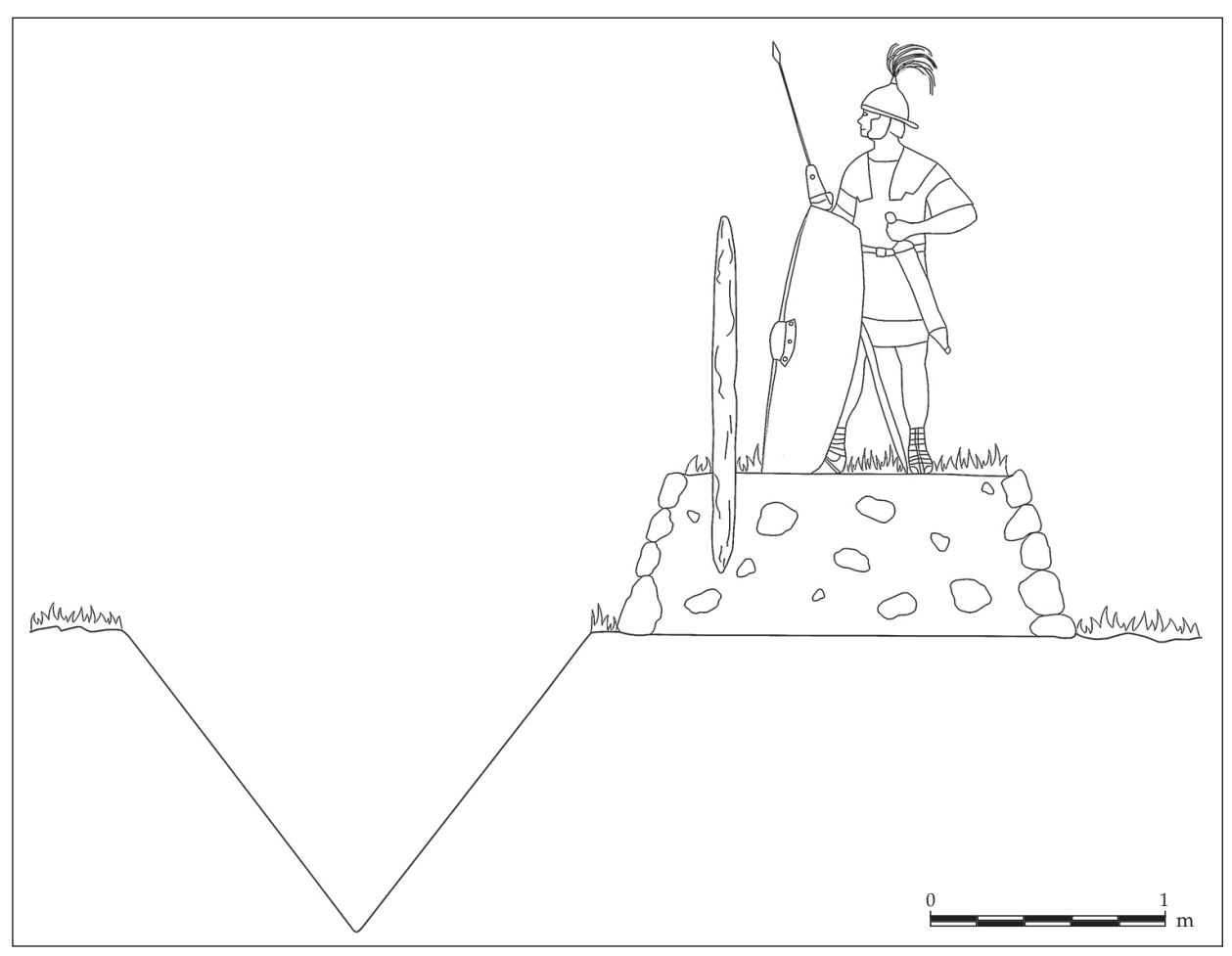

Figura 18

Hipotética reconstrucción del primer vallum en función de los restos hallados

AP. Iber. 91.- De este modo, Escipión fue el primero, según creo, que cercó con un muro a una ciudad que no rehuía el combate. El río Duero fluía a lo largo del cinturón de fortificaciones y resultaba de mucha utilidad a los numantinos para el transporte de víveres y para la entrada y salida de sus hombres.

Como no podía unir sus orillas por ser ancho y muy impetuoso, construyó dos torreones, en vez de un puente, uno en cada orilla y desde cada uno colgó, con cuerdas, grandes tablones de madera que dejó flotar a lo ancho del río, y que llevaban clavados numerosos dardos y espadas. Estos tablones, entrechocando continuamente, debido a la corriente que se precipitaba contra las espadas y los dardos, no permitían pasar a ocultas ni a quienes lo intentaban nadando, sumergidos o en botes. 
Sobre este tema del cierre del río Duero no vamos a insistir por haber sido ya estudiado en una monografía, a la cual remitimos (Morales, 2009a).

Vemos que poco a poco se van superando algunas de las conclusiones de Schulten que están siendo revisadas y parcialmente modificadas como resultado de nuevas investigaciones y la aplicación de nuevos enfoques metodológicos.

Muchos de sus planteamientos, fruto de su formación filológica y su egolatría científica, le llevaron a cometer importantes errores en sus interpretaciones como consecuencia de un uso excesivamente imaginativo de las fuentes clásicas, en su intento de hacer encajar sus ideas preconcebidas en los acontecimientos recogidos por los textos clásicos (García y Bellido, 1960; Wulff, 2004; 2016; Rodríguez-Tajuelo, 2008; Massó y Rodríguez-Tajuelo, 2011).

A esto hay que añadir que el peso de su autoridad científica hizo que sus errores hayan permanecido vigentes durante mucho tiempo. La renovación de planteamientos científicos ha motivado una revisión general de la obra de Schulten y de sus hipótesis, en la que es preciso delimitar de forma objetiva aquello que continúa siendo válido de aquello otro en lo que se equivocó.

Sin negar el valor del impresionante trabajo llevado a cabo por el investigador alemán en Numancia y los campamentos romanos de su entorno, sus interpretaciones y aportaciones plantean, como hemos visto, numerosos problemas, lo que no es óbice para que todavía hoy se le deba tratar con gran respeto.

A este respecto, nada mejor para concluir que las palabras de nuestro colega, paisano y amigo Enrique Baquedano (2016: 26), que suscribo en su totalidad:

«Es muy frecuente que a los arqueólogos sorianos interesados por estos asuntos se nos pregunte si somos pro o anti Schulten.

Quiero hacer, en este sentido, una declaración de principios diciendo que aunque Schulten como personaje no me emocione, ni me repugne, entre otros motivos porque intento analizarle con ojos de entomólogo, siento un gran respeto y hasta admiración por su trabajo.

No fue el descubridor de Nomantia, y quiso pasar por ello. Ni siquiera fue un arqueólogo de campo en el sentido estricto del término. Ni retornó los materiales arqueológicos exhumados en los campamentos. Pero destinó al menos siete años de su vida muy intensamente y mucho tiempo más de forma esporádica al estudio de los acontecimientos numantinos. Descubrió y excavó los campamentos de Renieblas y los del cerco de Escipión, y nos propuso una interpretación histórico-arqueológica que aún sigue siendo discutida, como prueba de su parcial vigencia». 


\section{REFERENCIAS BIBLIOGRÁFICAS}

ABARQUERO MORA, F. J.; PALOMINO LÁZARO, Á. L. (2006): «Vertavillo, primeras excavaciones arqueológicas en un oppidum vacceo del Cerrato palentino». PITTM, 77, Palencia, 31-116. https://www.academia.edu/1205937/Vertavillo_primeras_excavaciones_ arqueol\%C3\%B3gicas_en_un_oppidum_vacceo_del_Carrato_palentino

ABASOlO ÁlVAREZ, J. A.; GARCÍA ROZAS, R. (1980): Carta Arqueológica de Burgos. Vol. 4: Partido judicial de Salas de los Infantes. Universidad de Valladolid; Diputación Provincial de Burgos; Universidade de Santiago de Compostela.

ALCALDE CRESPO, G. (1997): El Cerrato Palentino. Palencia, Edit. Cálamo.

ALFARO GINER, C. (2001): «Vías pecuarias y romanización en la Península Ibérica». En: Gómez-Pantoja, J. (ed.): Los rebaños de Gerión. Pastores y trashumancia en Iberia antigua y medieval. Collection de la Casa de Velázquez, volume n. 73, Madrid, 215-231.

ARANEGUI, C. (2015): «Arqueología e Historia del Sucronensis Sinus en época ibérica», Saguntum extra 17, 9-25. https://www.academia.edu/15538174/Arqueolog\%C3\%ADa _e_Historia_del_Sucronensis_Sinus_en_\%C3\%A9poca_ib\%C3\%A9rica_Saguntum_ extra_17_2015

ARNAUD, P. (2005): Les routes de la navigation Antique. Itinéraires en Méditerranée. Edit. Errance, París.

ARQUETIPO, S. C. L. (2013): Informe del control arqueológico de la urbanización de viales del Sector 3, Garray (Soria). Informe inédito depositado en el Servicio Territorial de Cultura de Soria.

ARRIBAS ARRIBAS, S. (1994): Fuentepelayo. Segovia.

ASTIN, A. (1967): Scipio Aemilianus. Oxford, Clarendon.

BAQUEDANO, E. (2016): «De vanitas vanitatis, Saavedra, Schulten y el descubrimiento de Numantia». En, Baquedano, E. y Arlegui, M. (eds), Schulten y el descubrimiento de Numantia. Madrid, 18-27.

BLÁZQUEZ MARTÍNEZ, J. M. (1999): «Campamentos romanos en la meseta hispana en época romano republicana». En: Las guerras cántabras. Fundación Marcelino Botín, Santander, 67-118.

BOSCH GIMPERA, P.; AGUADO BLEYE, P. (1955): «Las guerras de lusitanos y celtíberos contra Roma: Segundo periodo: La guerra numantina (143 a 133 a. de J. C.)», cap. VI. En: Ramón Menéndez Pidal (Dir.), Historia de España, tomo II: España Romana (218 a. de

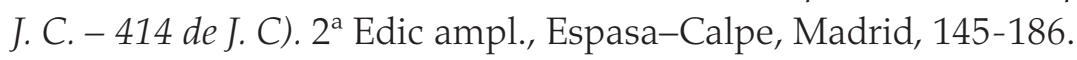

CABRÉ AGUILÓ, J. (1917): Catálogo Monumental de la Provincia de Soria. Madrid. http://simurg.bibliotecas.csic.es/viewer/image/CSIC001475816_V02TF/3/

CABRERO PIQUERO, J.; FERNÁNDEZ URIEL, P. (2016): «Publio Cornelio Escipión Emiliano». En, Baquedano, E. y Arlegui, M. (eds), Schulten y el descubrimiento de Numantia. Madrid, 174-201. 
CAPALBO, A. (1996): Celtiberia. Un estudio de Fuentes literarias antiguas. Institución «Fernando El Católico», Zaragoza. https://ifc.dpz.es/recursos/publicaciones/17/59/_ebook.pdf

CASTRO GARCÍA, L. de (1977): Palenzuela en la Historia y en el Arte. Palencia.

CHOFRE NAVARRETE, M. L. (2002): Las ciudades de «Sicana» y «Sucro»: su localización a partir de las Fuentes. Tesis Doctoral. Director: Mangas Manjarrés, J. Departamento de Historia Antigua. Facultad de Geografía e Historia. Universidad Complutense de Madrid. https://eprints.ucm.es/4574/1/T25960.pdf

CUNZT, O. (1902): Polybius und Sein Werk. Teubner, Leipzig. https://archive.org/stream/poly biusundseinw00cuntuoft/polybiusundseinw00cuntuoft_djvu.txt

DÍAZ TEJERA, A. (1972): Polibio. Historias, libro I, (caps. 1-31). CSIC, Madrid-Barcelona.

DÍAZ TEJERA, A. (2000): «Apiano». En: López Férez, J. A. (Ed.), Historia de la literatura griega. Madrid, 1066-1073. http://docshare04.docshare.tips/files/30639/306392573.pdf

DOBSON, M. (2008): The Army of the Roman Republic. The Second Century BC, Polybius and the Camps at Numantia, Spain. Oxbow Books, Oxford.

DOBSON, M.; MORALES, F. (2008): «Monedas inéditas de los campamentos romanos republicanos del cerco de Escipión y de la Gran Atalaya de Renieblas, y algunas consideraciones cronológicas sobre el campamentoV de Renieblas». Archivo Español de Arqueología, 81: 213-228.

EIROA GARCÍA, J. J. (1984-85): «Aportación a la cronología de los castro sorianos». Cuadernos de Prehistoria y Arqueología, n. 11-12.

EAN. EQUIPO ARQUEOLÓGICO DE NUMANCIA (2006): Numancia. Documentación aportada con motivo de la visita a Numancia y al cerco de Escipión del XX Congreso Internacional de Estudios sobre la Frontera Romana. León, España. 2-IX-2006.

FABRICIUS, E. (1911): «Über die Ausgrabungen in Numantia». Archäologischer Anzeiger. http://dlibra.bibliotekaelblaska.pl/publication/46196

GARCÍA BELLIDO, A. (1969): Numantia. Homenaje a los héroes numantinos en el XXI Centenario de su gesta. Zaragoza.

GARCÍA MARTÍN, P. (2001): «La principal sustancia destos reynos. De la trashumancia premesteña en la Península Ibérica». En: Gómez-Pantoja, J. (ed.): Los rebaños de Gerión. Pastores y trashumancia en Iberia antigua y medieval. Collection de la Casa de Velázquez, volume n. 73, Madrid, 1-20.

GARCÍA MERINO, C. (1973): «La evolución del poblamiento de Gormaz (Soria) desde la Edad del Hierro a la Edad Media». B.S.E.A.A., 39, Valladolid, 31-79.

GARCÍA MERINO, C. (1975): «Población y poblamiento en Hispania Romana. El Conventus Cluniensis». Estudia Romana I, Universidad de Valladolid.

GARCÍA MORENO, L. A. (2002): «Polibio y la creación del estereotipo de lo hispano en la etnología y la historiografía helenísticas». Polis, 14, 127-146. https://core.ac.uk/download/pdf/58906101.pdf

GIMÉNEZ SOLER, A. (1921): Crítica del libro «Numantia»: Die Keltiberer und ihre Kriege mit Rom', Discurso leído en la solemne apertura de los estudios. Universidad de Zaragoza, 31-32. 
GÓMEZ ESPELOSÍN, F. J. (1993): (Trad) Apiano: Sobre Iberia y Aníbal. Alianza Editorial, Madrid.

GÓMEZ ESPELOSÍN, F. J. (2009): «Contradicciones y conflictos de identidad en Apiano». Gerión, 27, n.o 1, 231-250. https://www.researchgate.net/publication/279483550_ Contradicciones_y_conflictos_de_identidad_en_Apiano

GÓMEZ-PANTOJA, J. L.; MORALES HERNÁNDEZ, F. (2008): «Los etolios en Numancia». Salduie n. 8, 37-58. https://www.academia.edu/406030/Los_etolios_en_Numancia

GONZÁLEZ-CONDE PUENTE, P. (1987): Romanidad e indigenismo en Carpetania. Alicante.

GONZÁlEZ GONZÁLEZ, J. (1990): Historia de Palencia. Vol. I: Edades Antigua y Media. Excma. Diputación Provincial de Palencia.

GONZÁLEZ MARRERO, J. A.; MEDINA HERNÁNDEZ, C. (2012): «Estrategias para navegar: de Plinio a Isidoro de Sevilla». Lingüistica y Literatura, n. . 62, 255-271.

https://dialnet.unirioja.es/servlet/articulo? codigo $=4235535$

GOUKOWSKY, P. (2003): (Trad) Appien. Histoire Romaine. Tome II, Livre VI, L'Ibérique. Les Belles Letres, París.

GOZALBES CRAVIOTO, E.; GONZÁLEZ BALLESTEROS, I. (2012): «Un factor de romanización: viajar en la Hispania romana». En: Bravo, G. y González Salinero, R. (eds.): Ver, viajar y hospedarse en el mundo romano. Signifer Libros, Madrid/Salamanca, 341-355. https://www.academia.edu/3319881/Un_factor_de_romanizaci\%C3\%B3n_viajar_en_ la_Hispania_romana

HILDEBRANDT, H, T. (1979): «Die Römerlager von Numantia. Datierung anhand der Münzfunde». Madrider Mitteilungen 20, 238-271.

JIMENO MARTÍNEZ, A. (1980): Epigrafía romana de la provincia de Soria. Publicaciones de la Diputación Provincial de Soria. Temas Sorianos, 2. Soria.

JIMENO MARTÍNEZ, A. (2002): «Numancia: campamentos romanos y cerco de Escipión». Archivo Español de Arqueología, 75, Madrid,159-176.

JIMENO MARTÍNEZ, A. (2004): «Numancia y los campamentos romanos: investigación y recuperación del pasado». En: Pérez-González, C. e Illarregui Gómez, E. (Coord), Arqueología Militar Romana en Europa, 237-249.

JIMENO MARTÍNEZ, A. (2006): "Conquest and Romanization in Celtiberia Ulterior: Numantia as paradigm». En: Abad Casals, L.; Keay, S. \& Ramallo Asensio, S. (Edit.), Early Roman Towns in Hispania Tarraconensis. Supplementary Series, 62, Portsmouht, Rhode Island, 173-183.

JIMENO MARTÍNEZ, A. (2011): «Las ciudades celtibéricas de la Meseta Oriental». En: Complutum, 22 (2), 223-276. https://www.academia.edu/4055181/Las_ciudades_celtib \%C3\%A9ricas_de_la_Meseta_Oriental

JIMENO MARTÍNEZ, A.; MARTÍN BRAVO, A. Ma . (1995): «Estratigrafía y Numismática: Numancia y los campamentos». En: García-Bellido, Ma. P. y Sobral Centeno, R. M. (Edit.), La moneda hispánica. Ciudad y Territorio. Anejos del A.E.A., XIV, 179-190. https://www.researchgate.net/publication/327468170_Estratigrafia_y_Numismatica_ Numancia_y_los_campamentos/link/5b910d6ca6fdcce8a4ca20ff/download 
JIMENO, A.; REVILLA, Ma. L.; DE LA TORRE, J. I.; BERZOSA, R. y MARTÍNEZ, J. P. (2002): Numancia. Guía Arqueológica del Yacimiento. Garray, Soria. Consejería de Educación y Cultura. Junta de Castilla y León y Asociación de Amigos del Museo Numantino. Soria.

JIMENO MARTÍNEZ, A.; CHAÍN GALÁN, A. (2017): «La guerra numantina: cerco y conquista de Numancia». En: Numancia Eterna. 2150 Aniversario: La memoria de un símbolo. Junta de Castilla y León, 237-250.

LACOMBE, H.; TCHERNIA, P. (1972): «Caractères Hydrologiques et Circulation des Eaux en Méditerranée». En: Stanley, D. J.; Kelling, G. and Weiler,Y (Edit.), The Mediterranean Sea: A Natural Sedimentation Laboratory. Dowden, Hutchinson \& Ross, Inc. Stroudsburg, Pennsylvania, 25-36.

LÓPEZ MERINO, L.; LÓPEZ SÁEZ, J. A.; ALBA SÁNCHEZ, F.; PÉREZ DÍAZ, S.; ABEL SCHAAD, D.; GUERRA DOCE, E. (2009): «Estudio polínico de una laguna endorreica en Almenara de Adaja (Valladolid, Meseta Norte): cambios ambientales y actividad humana durante los últimos 2.800 años». Revista Española de Micropaleontología, 41 (3), 333-347. https://digital.csic.es/bitstream/10261/93733/1/Estudio_polinico_laguna_endorreica.pdf

LUIK, M. (1997): Fibels von Typ Alesia aus den römischen Lagern um Numantia. Archäologisches Korrespondenzblattz, 27.

LUIK, M. (2002): Die Funde aus den römischen Lagern um Numantia im Römisch-Germanischen Zentralmuseum. Mainz, Römisch-Germanisches Zentralmuseum.

LUIK, M. (2005): Der schwierige Weg zur Weltmacht. Roms Eroberung der Iberischen Halbinsel 218-19 v. Chr. Verlag Philipp von Zabern, Mainz am Rhein.

LUZÓN, J. M.; ALONSO, M. C. (2018): Numancia: Arqueología e Historia. Libro multimedia con textos de Alfredo Jimeno Martínez. Numancia 2017, AC/E y RABASF. https://www.numanciamultimedia.com/

MARÍN MARTÍNEZ, A. P. (2012): «Los itinerarios de Polibio en Hispania y su visión de la actividad guerrera de los pueblos peninsulares». En: Bravo, G. y González Salinero, R. (eds.): Ver, viajar y hospedarse en el mundo romano. Signifer Libros, Madrid/Salamanca, 447-462. https://www.researchgate.net/publication/264711223_Los_itinerarios_de_ Polibio_en_Hispania_y_su_vision_de_la_actiividad_guerrera_de_los_pueblos_ peninsulares/link/53ec71c30cf202d087d02248/download

MASSÓ CARBALLIDO, J.; RODRÍGUEZ-TAJUELO AMANEDO, M. E. (2011): Adolf Schulten en Reus y Tarragona: El legado Salvador Vilaseca. Edic. La Ergástula, S. L., Madrid.

MILLOT, C. (1989): «La circulation générale en Méditerranée occidentale: Aperçu de nos connaisances et proyects d'études». Annales de Géographie, n.o 549, XCVIII année, Septembre-Octobre, 497-515.

https://www.persee.fr/doc/geo_0003-4010_1989_num_98_549_20925

MOLTO, L. (1992): «Tipos de aguas minero-medicinales en yacimientos arqueológicos de la Península Ibérica». Espacio, Tiempo y Forma, Serie II, Historia Antigua, t. V, 211-228. http://revistas.uned.es/index.php/ETFII/article/view/4191/4030 
MONTALBÁN CARMONA, J. A. (2017): «La ciutat romana de Sucro i la seua errònia relació amb Sueca». Clapir. Revista Digital d'Història Valenciana. Edició Especial (2013-2017), 20-23.https://www.academia.edu/9041070/La_ciutat_romana_de_Sucro_i_la_seua_e rrònia_relació_amb_Sueca

MORALES HERNÁNDEZ, F. (1995): Carta Arqueológica de Soria: La Altiplanicie Soriana. Publicaciones de la Excma. Diputación Provincial. Soria.

MORALES HERNÁNDEZ, F. (2000): «Una reinterpretación de la circunvalación escipiónica de Numancia». Revista d'Arqueologia de Ponent, n. 10, Lérida, 227-241.

MORALES HERNÁNDEZ, F. (2002): «La circunvalación escipiónica de Numancia: viejos y nuevos datos para una reinterpretación». Gladius, Anejos 5, 283-291.

MORALES HERNÁNDEZ, F. (2004): «Los campamentos y fuertes del asedio de Numancia». En: Pérez-González, C. e Illarregui Gómez, E. (Coord), Arqueología Militar Romana en Europa, 251-258.

MORALES HERNÁNDEZ, F. (2007): «Circunvallatio de Numancia». En: A. Morillo (ed): El ejército romano en Hispania, 263-276.

MORALES HERNÁNDEZ, F. (2009a): «El cerco de Numancia: el cierre del Duero». Gladius, XXIX, 71-92. http://gladius.revistas.csic.es/index.php/gladius/article/view/216

MORALES HERNÁNDEZ, F. (2009b): «El trazado de la circunvalación de Numancia: pasado y presente de la investigación». En, Morillo, A.; Hanel, N; Martín, E. (eds), Limes XX. XX Congreso Internacional de Estudios sobre la Frontera Romana, León, septiembre, 2006; Anejos de Gladius, 13, vol. 1, C.S.I.C. Madrid.

MORALES HERNÁNDEZ, F.; MORILLO CERDÁN, Á. (en prensa): «Nuevas aportaciones sobre el campamento III de Renieblas (Soria): ¿castra de Nobilior o castra de Escipión?». Cuadernos de Prehistoria y Arqueología de la Universidad Autónoma de Madrid, 46.

MORALES RODRÍGUEZ, C. G.; ORTEGA VILLAZÁN, M. T. (2000): «Riesgos climáticos en Castilla y León: Análisis de su peligrosidad». Boletín de la A. G. E., n.o 30, 155-179. http://age.ieg.csic.es/boletin/30/10.pdf

MORENO GALLO, I. (S/AÑO): Vías romanas en Castilla y León. Junta de Castilla y León. http://www.viasromanas.net/pdf/00_Vias_romanas_en_Castilla_y_Leon.pdf

MORENO GALLO, I. (2006): Vías romanas: Ingeniería y técnica constructiva. Ministerio de Fomento. Centro de Estudios Históricos de Obras Públicas (CEHOP), 2006. http://www.traianvs.net/viasromanas/viasromanas.pdf

MORENO GALLO, I. (2010a): «Vías romanas. Identificación por la técnica constructiva». Rev. Cimbra, 389, CITOP. http://www.traianvs.net/pdfs/2010_tecnica_constructiva_romana.pdf

MORENO GALLO, I. (2010b): «Vías romanas. Las huellas de la ingeniería perdida». Las técnicas y las construcciones en la ingeniería romana. Congreso de las Obras Públicas Romanas (5. 2010, Córdoba), 11-46.

MORILLO CERDÁN, Á.; MORALES HERNÁNDEZ, F. (2015): «Campamentos romanos de la Guerra de Numancia: la circunvalación escipiónica». En, Bendala, M. (ed.), Los Escipiones en Hispania, Alcalá de Henares, 275-297. 
MORILlO CERDÁN, Á.; MORALES HERNÁNDEZ, F.; DURÁN CABELLO, R. (2016): «Schulten y los campamentos romanos republicanos en Hispania: una mirada desde el siglo XXI». En, Baquedano, E. y Arlegui, M. (eds), Schulten y el descubrimiento de Numantia. Madrid,174-201.https://www.academia.edu/33190835/Schulten_y_los_campamentos_ romanos_republicanos_en_Hispania._Una_mirada_desde_el_siglo_XXI

NORDEN, E. (1920): Die Germanische Urgeschichte in Tacitus Germania. Teubner, LepzigBerlín. https://archive.org/details/diegermanischeur00norduoft/page/n15/mode/2up

ORTEGO Y FRÍAS, T. (1969): «Un poblado celtibérico en Fuentes Grandes de Gormaz (Soria)». Archivo Español de Arqueología, 119-120, Madrid, 46-55.

ORTEGOY FRÍAS, T. (1972): «Gormaz, su contorno arqueológico». Celtiberia, n. 4, C.E.S., Soria.

ORTEGOY FRÍAS, T. (1975): Numancia. Guía breve histórico-arqueológica. Ministerio de Educación y Ciencia. Dirección General del Patrimonio Artístico y Cultural.

ORTEGO Y FRÍAS, T. (1985): «Edad Antigua». En: Pérez-Rioja, J. A. (Dir), Historia de Soria. Tomo I. Centro de Estudios Sorianos (CSIC), Soria.

OSABA, B. (1964): «Catálogo Arqueológico de la Provincia de Burgos». Noticiario Arqueológico Hispánico, VI, Madrid.

PASCUAL DíEZ, A. C. (1991): Carta Arqueológica de Soria: Zona Centro. Publicaciones de la Excma. Diputación Provincial. Soria.

PASQUINUCCI, M.; DEL RIO, A.; MENCHELLI, S. (2002): «I porti dell’Etruria settentrionale costiera (ager Pisanus e Volaterranus) e le dinamiche commerciali mediterranee (III secolo a. C.-VI d. C.)». En: Mustapha, K.; Ruggeri, P.;Vismara, C. (a cura di), L'Africa Romana. Lo spazio marittimo del Mediterraneo occidentale: geografía storica ed economía. Atti del XIV convegnodi studio. Sassari, 7-10 dicembre 2000.Vol. Secondo, Roma, 767-778.

PASQUINUCCI, M.; MENCHELLI, S. (2017): «Rural, Urban and Suburban Communities and Their Economic Interconnectivity in Coastal North Etruria $\left(2^{\text {nd }}\right.$ Century BC- $2^{\text {nd }}$ Century AD)». En: de Haas, T.C.A. and Tol, G.W. (Edit), The Economic Integration of Roman Italy. Rural Communities in a Globalizing World. Leiden | Boston, 322-341. https://arpi.unipi.it/ retrieve/handle/11568/889444/335834/Pasquinucci_Menchelli_accepted.pdf

PASTOR MUÑOZ, M.; PASTOR ANDRÉS, H. F. (2012): «Vehículos y medios de transporte en el mundo romano». En: Bravo, G. y González Salinero, R. (eds.): Ver, viajar y hospedarse en el mundo romano. Signifer Libros, Madrid/Salamanca, 67-92.

PÉDECH, P. (1964): La méthode historique de Polybe. Les Belles Lettres, Paris.

PÉREZ BALLESTER, J.; CARMONA GONZÁLEZ, P.; RIBERA, A.; PASCUAL BERLANGA, G. (2010): «Puertos y fondeaderos en la costa valenciana: interacciones económicas y culturales (S.VII a.E - s. I d.E.)», en Meetings between Cultures in the Ancient Mediterranean, XVII International Congress of Classical Archaeology (Sesion: Infrastrutture della navigazione e dei commerci nel Mediterraneo (etá arcaica - I sec.d.C.): topografía dei litorali e dinamiche storico-economiche), Roma, 2008, Bolletino di Archaologia On Line, I, 14-35. https:// www.academia.edu/16451044/Puertos_y_fondeaderos_en_la_costa_valenciana_ din \%C3\%A1mica_costera_tipolog\%C3\%ADa_de_asentamientos_e_interacciones_ econ\%C3\%B3micas_y_culturales 
PÉREZ VILATELA, L. (2000): Lusitania: Historia y Etnología. Real Academia de la Historia, Madrid. https://books.google.es/books?id=rwFnYh9zkgAC\&pg=PA117\&hl=es\&sour

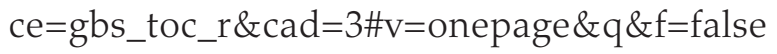

REVILlA ANDÍA, Ma. L. (1985): Carta Arqueológica de Soria: Tierra de Almazán. Publicaciones de la Excma. Diputación Provincial. Soria.

RAFFELINI, Ch. (2002): «Archaeologia e paleogeografía del Portus Lunae». En: Mustapha, K.; Ruggeri, P.; Vismara, C. (a cura di), L'Africa Romana. Lo spazio marittimo del Mediterraneo occidentale: geografía storica ed economía. Atti del XIV convegnodi studio. Sassari, 7-10 dicembre 2000. Vol. Secondo, Roma, 731-751.

REMACLE, Ph. (Trad): Appien. Ibérique. http://remacle.org/bloodwolf/historiens/appien/iberiquegr.htm

RICHARDSON. J. S. (2000): (Trad) Wars of the Romans in Iberia. Iberike. Ars \& Phillips LTD, Warminster.

ROMERO CARNICERO, F. (1991): Los castros de la Edad del Hierro en el norte de la provincia de Soria. Studia Archaeologica n. 80, Universidad de Valladolid.

ROMERO CARNICERO, M. V. (1990): «Lucernas republicanas de Numancia y sus campamentos». En Boletín del Seminario de Estudios de Arte y Arqueología, vol. LVI, 257-296.

ROSA, M. C. de la; MOSSO, M. A. (2004): «Historia de las aguas mineromedicinales en España». Observatorio medioambiental, n. 7, 117-137.

ROSSIGNANI, M. P.; BRUNO, B.; LOCATELLI, D. (2002): «Insediamenti ed economía nell'area del Portus Lunae nella prima metà del II secolo a. C.». En: Mustapha, K.; Ruggeri, P.; Vismara, C. (a cura di), L'Africa Romana. Lo spazio marittimo del Mediterraneo occidentale: geografía storica ed economía. Atti del XIV convegnodi studio. Sassari, 7-10 dicembre 2000. Vol. Secondo, Roma, 752-765.

SAAVEDRA, E. (1879): Descripción de la vía romana entre Uxama y Augustobriga. Madrid.

SACRISTÁN DE LAMA, J. D. (1998): «La Edad de Hierro en la Provincia de Burgos». Congreso de Arqueología de Burgos.

SACRISTAN DE LAMA, J. D.; RUIZVELEZ, I. (1985): «La Edad del Hierro». Historia de Burgos I, Edad Antigua. Caja de Ahorros Municipal de Burgos.

SACRISTÁN DE LAMA, J. D.; SAN MIGUEL MATÉ, L. C.; BARRIO MARTÍN, J.; CELIS SÁNCHEZ, J. (1995): «El poblamiento de época celtibérica en la cuenca media del Duero». En: Burillo Mozota, F. (coord.): Poblamiento Celtibérico. III Simposio sobre los celtíberos. Institución «Fernando El Católico», Zaragoza.

SALINAS DE FRÍAS, M. (1986): Conquista y Romanización de Celtiberia. Ediciones Universidad de Salamanca y Museo Numantino de Soria. Salamanca.

SALINAS DE FRÍAS, M. (1989): «Quintus Fulvius Q. F. Flaccus». En Studia historica. Historia antigua, n. $7,67-84$.

SALVATORE, J. P. (1996): Roman Republican Castrametation. A reappraisal of historical and archaeological sources. BAR International Series 630. Oxford. 
SÁNCHEZVERDÚ, A. (2016): «La puesta en valor de las calzadas romanas. Estudio, excavación y recuperación social del patrimonio arqueológico inmueble». Cuadernos de Arqueología de la Universidad de Navarra, 24, 138-155. https://www.academia.edu/298294 19/La_puesta_en_valor_de_las_calzadas_romanas._Estudio_excavaci\%C3\%B3n_y_ recuperaci\%C3\%B3n_social_del_patrimonio_arqueol\%C3\%B3gico_inmueble

SÁNCHEZ-LÓPEZ, G.; HERNÁNDEZ, A; PLA RABES, S.; TRIGO, R. M.; TORO, M.; GRANADOS, I.; SÁEZ, A.; MASQUÉ, P.; PUEYO, J. J.; RUBIO-INGLÉS, M. J.; GIRALT, S. (2016): «Climate reconstruction for the last two millennia in central Iberia: The role of East Atlantic (EA), North Atlantic Oscillation (NAO) and their interplay over the Iberian Peninsula». Quaternary Science Reviews, 149, 135-150.

SÁNCHEZ-MORENO, E. (2010): «Los vacceos a través de las fuentes: una perspectiva actual». En, Romero Carnicero, F. y Sanz Mínguez, C. (eds): De la Región Vaccea a la Arqueología Vaccea. (Vaccea Monografías, 4. Centro de Estudios Vacceos «Federico Wattenberg». Universidad de Valladolid, 65-103. https://www.academia.edu/620816/_ Los_vacceos_a_trav\%C3\%A9s_de_las_fuentes_una_perspectiva_actual_._In_ Romero_Carnicero_F._and_Sanz_M\%C3\%ADnguez_C._eds._De_la_Regi\%C3\%B3n_ Vaccea_a_la_Arqueolog\%C3\%ADa_vaccea._Vaccea_Monograf\%C3\%ADas_4._ Centro_de_Estudios_Vacceos_Federico_Watteneberg___Universidad_de_Valladolid_._ Valladolid_2010_pp.65-103

SANCHO ROYO, A. (1973): «En torno al“Bellum Numantinum” de Apiano». Habis, 4, Sevilla, 23-40.

SANCHO ROYO, A. (1976): «En torno al Tratado del Ebro entre Roma y Asdrubal». Habis, 7, Sevilla, 75-109.

SANCHO ROYO, A. (1980): (Trad) Apiano. Historia Romana. Madrid, Alianza.

SANMARTÍ, E. (1985): «Las ánforas romanas del campamento numantino de Peña Redonda (Garray, Soria)». Empúries, vol. 47, 130-161.

SANMARTÍ, E. (1992): «Nouvelles donées sur la chronologie du camp de Renieblas V à Numance». Documents d'Archéologie Méridionale, vol. 12, 417-430.

SANMARTÍ, E.; PRINCIPAL, J. (1997): «Las cerámicas de importación, itálicas e ibéricas, procedentes de los campamentos numantinos». Revista d'Arqueología de Ponent, vol. 7, 35-75.

SANZ ARAGONÉS, A.; BENITO BATANERO, J. P.; TABERNERO GALÁN, C. (2008): Informe de la intervención arqueológica en el yacimiento de Alto Real, dentro de las obras de la Ruta Verde en la Cañada Real Soriana Oriental, Tramo Soria-Garray (Soria). Informe inédito depositado en el Servicio Territorial de Cultura de Soria.

SCHULTEN, A. (1905): Numantia. Eine topographisch-historische Untersuchung. Berlin.

SCHULTEN, A. (1914): Numantia. Die Ergebnisse der Ausgrabungen 1905-1912. I, Die Keltiberer und Ihre Kriege mit Rom. Munich.

SCHULTEN, A. (1922): «Feldzüge in Nordspanien bis zum Falle von Numantia 133 v. Chr.» En: Kromayer-Veith (Edit): Schlachten-Atlas zur Antiken Kriegsgeschichte, mit Begleitenden Text, Römischen Abteilung II, Blatt. 12, Leipzig, 57-62.

https://www.numanciamultimedia.com/pdf/kromayer1922.pdf 
SCHULTEN, A. (1937): Fontes Hispaniae Antiquae, 4. Las guerras de 154-72 a. C. Barcelona.

SCHULTEN, A. (1945): Historia de Numancia. Barcelona.

SCHWEIGWESER, J. (1852): Las Guerras ibéricas de Appiano Alejandrino. Traducción del Texto greco-latino al castellano, con notas históricas y geográficas de D. Miguel Cortés y López, Valencia.

SIERRAVIGIL, J. M.; SAN MIGUEL MATÉ, L. C. (1995): «Las cañadas como medios de comunicación entre los asentamientos vacceos». En: Burillo Mozota, F. (coord.): Poblamiento Celtibérico. III Simposio sobre los celtíberos. Institución «Fernando El Católico», Zaragoza.

SIMON, H. (1962): Roms Kriege in Spanien. 154 - 133 v. Chr. Frankfurt am Main.

SOPEÑA GENZOR, G. (2013): «El periodo de la Guerra Numantina (154-133 a. C.)». En: Sopeña Genzor, G. (ed.); Marco Simón, F., Sopeña Genzor, G. y Pina Polo, F. (coords.): Aragón Antiguo. Fuentes para su estudio. Zaragoza.

SOPEÑA GENZOR, G. (2016): «Emiliano en el Ebro: el camino hacia Numancia». En: Baquedano, E. y Arlegui, M. (Edit), Schulten y el descubrimiento de Numancia. Alcalá de Henares, $164-172$.

STRATO (2011): Estudio arqueológico integrado en la revisión de las Normas Subsidiarias de Ayllón (Segovia). (Catálogo y Normativa). Informe depositado en el Servicio Territorial de Cultura de Segovia.

TABERNERO GALÁN, C.; SANZ ARAGONÉS, A. BENITO BATANERO, J. P. (2010): Informe de la intervención arqueológica en las obras de construcción de la EDAR de Garray (Soria). Informe inédito depositado en el Servicio Territorial de Cultura de Soria.

TARACENA AGUIRRE, B. (1929): «Excavaciones en las provincias de Soria y Logroño». Memoria de la JSEA, n. 103, Madrid.

TARACENA AGUIRRE, B. (1932): «Excavaciones en la provincia de Soria». Memoria de la JSEA, n. 119 , Madrid.

TARACENA AGUIRRE, B. (1934-35): «Vías romanas del Alto Duero». Separata del Anuario del Cuerpo Facultativo de Archiveros, Bibliotecarios y Arqueólogos. https://bibliotecadigital.jcyl.es/i18n/catalogo_imagenes/grupo.cmd?path=10066002

TARACENA AGUIRRE, B. (1941): Carta Arqueológica de España. Soria. Madrid.

VIERECK, P.; ROSS, A. G. (1939): Appiani. Historia Romana. Prooemium. Iberica. Annibalica. Libyca. Illyrica. Syriaca. Mithridatica. Fragmenta. Vol. I. (Edic. 1962).

WALBANK, F. W. (2002): «The geography of Polybius». In Polybius, Roma and the Hellenistic World. Essays and Reflections. Cambridge University Press, 31-52. https://www.cambri dge.org/core/books/polybius-rome-and-the-hellenistic-world/6FD28843B4B93CD058 72322D411AF0D1

WERNER, H. M. (1878): De Polybii Vita et Itineribus Quaestiones Chornologicae. Dissertatio Inauguralis Philologica, Lipsiae.

WHITE, H. (1979): (Trad) Appian's Roman History. Loeb. 
WILSDORF, D. (1878): Fasti Hispaniarum Provinciarum. Lipsiae.

WULFF ALONSO, F. (2004): «Adolf Schulten. Historia de Numancia. Arqueología y racismo en medio siglo de historia europea». En, Introducción a la reedición de A. Schulten, Historia de Numancia, Editoria Urgoiti, Pamplona, XI-CCXLI.

WULFF ALONSO, F. (2016): «Ascendía por la colina un joven investigador alemán. A propósito de Schulten». En: Baquedano, E. y Arlegui, M. (Edit), Schulten y el descubrimiento de Numancia. Alcalá de Henares, 104-119.

ZAMORA CANELLADA, A. (1993): «El castillo de Ayllón (Segovia). Estudio arqueológico e histórico». Estudios Segovianos, 90.

ZOZAYA STABEL-HANSEN, J. (1989): «Gormaz, síntesis de arqueología soriana». En: Argente Oliver, J. L., (Coord.): Diez años de Arqueología Soriana (1978-1988). Museo Numantino, Junta de Castilla y León, Soria, 107-112. 